\title{
GuSTAVO FERNANDES
}

Avaliação do metabolismo glicêmico e perfil entero-hormonal no pós-operatório precoce em pacientes obesos graves diabéticos submetidos à gastroplastia em $\mathrm{Y}$ de Roux. Comparação da oferta alimentar por via oral e por gastrostomia

Dissertação apresentada à Faculdade de Medicina da Universidade de São Paulo para obtenção do título de Mestre em Ciências

Programa de Ciências em Gastroenterologia

Orientador: Prof. Dr. Marco Aurelio Santo

São Paulo 
Dados Internacionais de Catalogação na Publicação (CIP)

Preparada pela Biblioteca da

Faculdade de Medicina da Universidade de São Paulo

Creprodução autorizada pelo autor

\section{Fernandes, Gustavo}

Avaliação do metabolismo glicêmico e perfil entero-hormonal no pós-operatório precoce em pacientes obesos graves diabéticos submetidos à gastroplastia com derivação intestinal em Y de Roux. Comparação da oferta alimentar por via oral e por gastrostomia / Gustavo Fernandes. -- São Paulo, 2017.

Dissertação(mestrado)--Faculdade de Medicina da Universidade de São Paulo. Programa de Ciências em Gastroenterologia.

Orientador: Marco Aurelio Santo.

Descritores: 1.Derivação Gástrica 2.Diabetes mellitus 3.Gastrostomia 4.Homeostase 5.Incretinas 6.Indução de remissão

USP/FM/DBD-312/17 


\section{DEDICATÓRIA}

A minha esposa Fernanda e meu filho João Pedro, meus amores.

Meu pai, minha mãe e meu irmão.

Meu sogro e minha sogra. 


\section{AGRADECIMENTOS}

A Deus pai todo poderoso.

Aos pacientes.

Ao Prof. Dr. Marco Aurélio Santo, pela oportunidade, dedicação e ensinamentos.

Aos amigos Dra. Andréa de Fátima Cristina Bastos Crespo e Dr. Gabriel Barbosa Biancardi, pela grande ajuda e empenho na confecção dessa dissertação.

Ao Dr. Ailton Ferreira Souza Filho, meu fiel amigo.

À equipe de Cirurgia Geral do Hospital Santa Marcelina, em especial, o Dr. Laércio Robles, pelo apoio, conselhos e orientações, sem o qual esta tese não seria possível.

À equipe de Gastrocirurgia do Hospital Santa Marcelina - Dr. Erton Rivo Bancher, Dr. Leonardo Christian Laia e Dr. Raoni Salomão Santana, pelos ensinamentos e dias de trabalho.

Às irmãs Marcelinas, por acreditarem em meu trabalho.

À equipe de Cirurgia Geral da Santa Casa de Misericórdia de São José dos Campos - Dr. Othon Ferreira da Silva Maldos, Dr. Lázaro Vitor Vilela dos Reis, Dr. Renato Sebbe, Dr. Artur Chagas Vilela dos Reis, Dr. Walter Rodrigo Miyamoto, Dr. Renato Poli Veneziani Sebbe, pela paciência, compreensão e apoio incondicional. 
A toda equipe da Unidade de Cirurgia Bariátrica e Metabólica do Hospital das Clínicas, pela recepção, acolhimento e respeito.

A toda equipe de enfermagem do serviço de Cirurgia Bariátrica e Metabólica do HCFMUSP, em especial, Sra. Tatiana, Sonia e Graziele.

À Sra. Myrtes, Sra. Priscila e Sra. Vilma.

A meus cunhados, sobrinhos e afilhados pelo carinho dispensado à minha família.

A todos meus familiares presentes nesta jornada.

Aos amigos de longa data Dr. Phillipe Heckler Salgado, Dra. Luana Padilha e Dr. Marcelo de Melo Viveiros.

À Sra. Caroline do Laboratório de Investigações Médicas, pela dedicação e rapidez com os resultados dos exames.

Ao Sr. Leandro, do Laboratório de Epidemiologia e Estatística da Faculdade de Medicina USP.

A todos que direta ou indiretamente contribuíram para este estudo e minha formação profissional. 


\section{Normatização Adotada}

Esta dissertação está de acordo com as seguintes normas, em vigor no momento desta publicação:

Referências: adaptado de International Committee of Medical Journals Editors (Vancouver).

Universidade de São Paulo. Faculdade de Medicina. Divisão de Biblioteca e Documentação. Guia de apresentação de dissertações, teses e monografias. Elaborado por Anneliese Carneiro da Cunha, Maria Julia de A. L. Freddi, Maria F. Crestana, Marinalva de Souza Aragão, Suely Campos Cardoso, Valéria Vilhena. 3a ed. São Paulo: Divisão de Biblioteca e Documentação; 2011.

Abreviaturas dos títulos dos periódicos de acordo com List of Journals Indexed in Index Medicus. 


\section{SUMÁRIO}

LISTA DE SIGLAS

LISTA DE TABELAS

LISTA DE FIGURAS

LISTA DE GRÁFICOS

RESUMO

ABSTRACT

1 INTRODUÇÃO

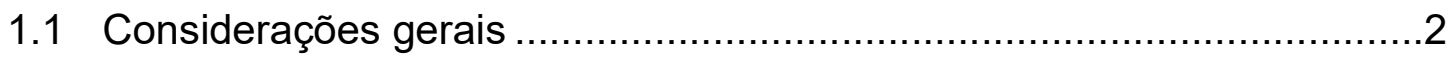

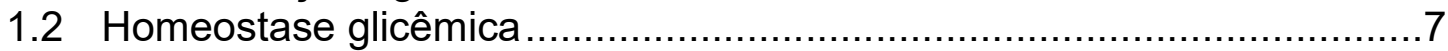

1.3 GDYR e os mecanismos de controle glicêmico pós-operatório ..............13

1.4 Formas de avaliação do controle glicêmico .........................................19

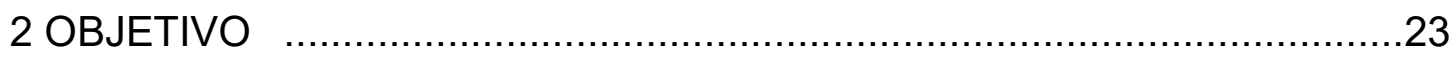

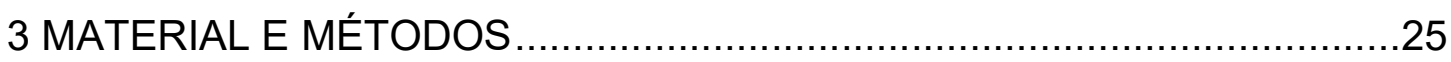

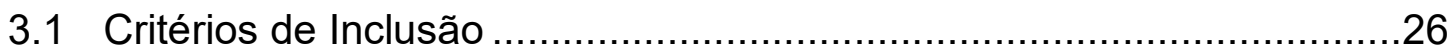

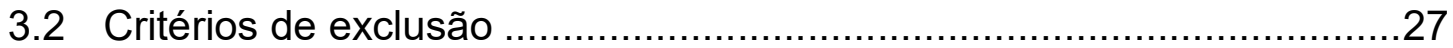

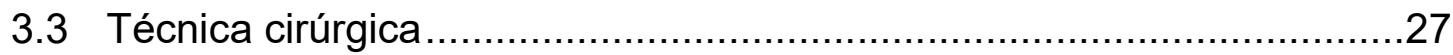

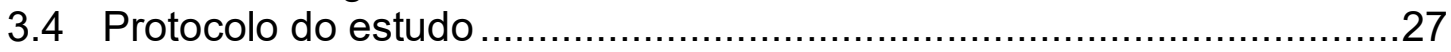

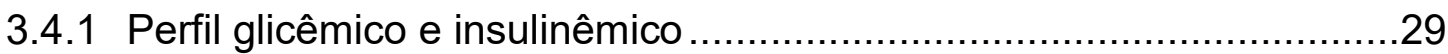

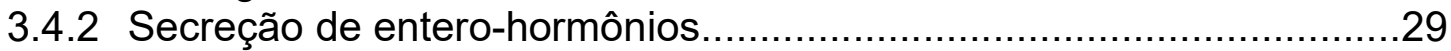

3.4.3 Teste de tolerância oral à glicose ………......................................30

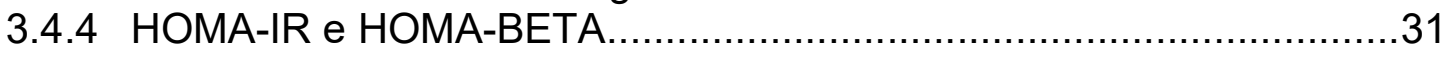

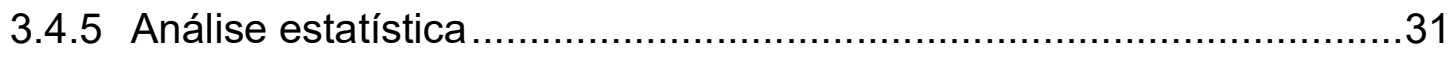

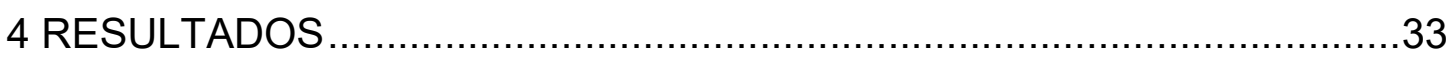

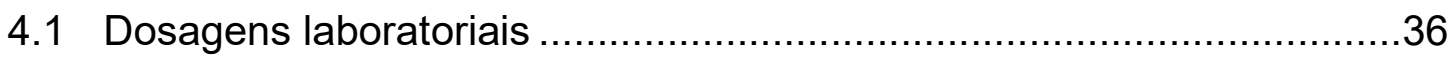

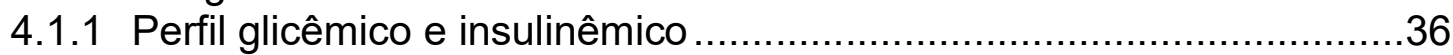

4.1.2 Secreção de entero-hormônios.....................................................42

4.1.3 Teste de tolerância oral à glicose - TTOG ….................................51

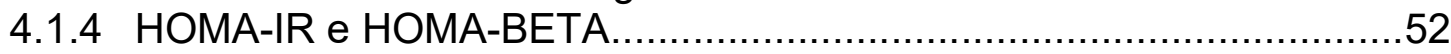

4.1.5 Comparações do perfil glicêmico e insulinêmico, secreção de enterohormônios e TTOG entre os três tempos de avaliação. .......................53

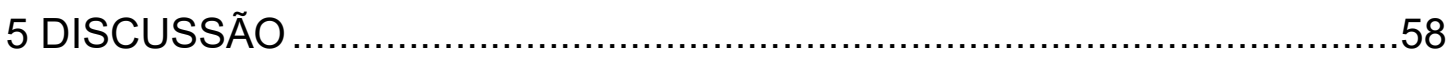

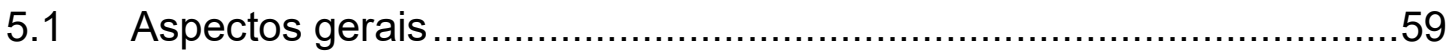

5.2 Remissão do DM2 e melhora da resistência insulínica ......................59 


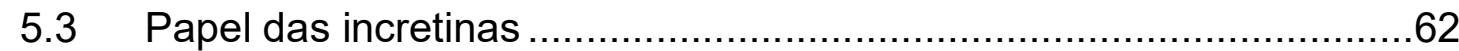

5.4 Correlação entre a melhora da glicemia e as teorias do intestino proximal e intestino distal .........................................................64

5.5 Outros mecanismos de controle glicêmico precoce .........................65

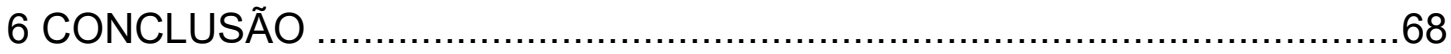

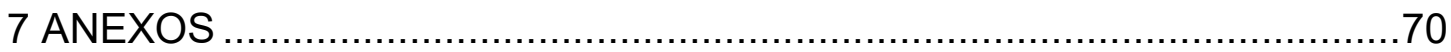

TERMO DE CONSENTIMENTO LIVRE E ESCLARECIDO $\ldots \ldots \ldots \ldots \ldots \ldots \ldots \ldots . . . \ldots \ldots$

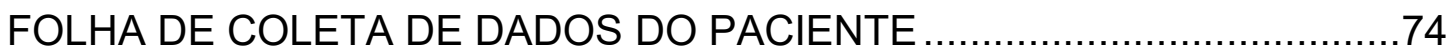

FOLHA DE ANOTAÇÃO DE CONTROLES DIÁRIOS DO PACIENTE ............75

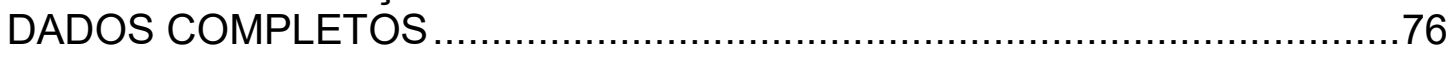

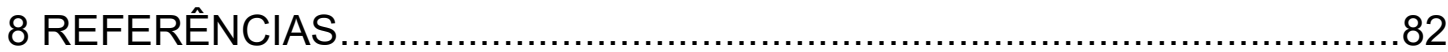




\section{LISTAS}

\section{SIGLAS}

A1c Hemoglobina Glicosilada

AUC Área Under de Curve

CDC Centers for Disease Control and Prevention

DM Diabetes Mellitus

DM2 Diabetes Mellitus tipo 2

DP Desvio-Padrão

EUA Estados Unidos da América

FXR Receptor Farsenoid $X$

GIP Gastric Inibitory Peptide (hormônio inibitório gástrico)

GLP1 Glucagon like Peptide-1 (peptídeo similiar ao glucagon 1)

GDYR Gastroplastia com derivação intestinal em Y de Roux

HOMA Homeostasis Model Assessment

HOMA-BETA Homeostasis Model Assessment-Beta Cells

HOMA-IR Homeostasis Model Assessment-Insulin Resistence

NIH National Institutes of Health

PC1 Prohormônio convertase 1

PDPG Peptídeos derivados do Proglucagon

SM Síndrome Metabólica

TTOG Teste de tolerância oral à Glicose

VG pós-op Via Gastrostomia pós-operatório

VO pré-op Via Oral pré-operatório

VO pós-op Via Oral pós-operatório

VLCD Very Low Calory Diet 
TABELAS

Tabela 1 - Valores de glicose plasmática (em $\mathrm{mg} / \mathrm{dl}$ ) e hemoglobina glicada para diagnóstico de diabetes mellitus e seus estágios pré-clínicos ………................................................... 3

Tabela 2 - Definição de remissão do DM2, conforme ADA ........................ 7

Tabela 3 - Resumo das ações do GLP1 e GIP no controle da glicose e tratamento do DM2 .......................................................... 11

Tabela 4 - Perfil demográfico dos pacientes avaliados na internação ..... 34

Tabela 5 - Perfil laboratorial dos pacientes avaliados na internação ........ 35

Tabela 6 - Tabela das médias \pm DP dos valores das dosagens de glicemia, insulina, GLP1, GIP, grelina e TTOG, conforme o tempo de coleta

Tabela 7 - Comparação da glicemia entre administração da soluçãopadrão via oral pré-operatória e por via gastrostomia pósoperatória, por tempo de coleta

Tabela 8 - Comparação da glicemia entre a administração da soluçãopadrão via oral pré-operatória e por via oral pós-operatória, por tempo de coleta

Tabela 9 - Comparação da glicemia entre administração da soluçãopadrão por via gastrostomia e via oral pós-operatória, por tempo de coleta

Tabela 10 - Comparação da insulinemia entre administração da solução via oral pré-operatória e por via gastrostomia pósoperatória, por tempo de coleta

Tabela 11- Comparação da insulinemia entre administração da solução via oral pré-operatório e via oral pós-operatório, por tempo da coleta

Tabela 12 - Comparação da insulinemia entre administração da solução por via oral pós-operatória e por via gastrostomia pós-operatória, por tempo de coleta

Tabela 13 - Comparação do GLP1 na administração da solução via oral pré-operatório e via gastrostomia no pós-operatório, por tempo de coleta 
Tabela 14 - Comparação do GLP1 na administração da solução via oral pré-operatório e via oral pós-operatório, por tempo de coleta

Tabela 15 - Comparação do GLP1 na administração da solução por via oral e via gastrostomia no pós-operatório, por tempo de coleta

Tabela 16 - Comparação do GIP na administração da solução via oral pré-operatória e via gastrostomia pós-operatória, por tempo de coleta

Tabela 17 - Comparação do GIP na administração da solução no pré e por via oral pós-operatória, por tempo de coleta

Tabela 18 - Comparação do GIP na administração da solução via oral e via gastrostomia no pós-operatório, por tempo de coleta

Tabela 19 - Comparação da grelina na administração da solução via oral pré-operatória e via gastrostomia no pós-operatório, por tempo de coleta

Tabela 20 - Comparação da grelina na administração da solução via oral pré-operatória e via oral pós-operatória, por tempo de coleta

Tabela 21 - Comparação da grelina na administração da solução por via oral e via gastrostomia no pós-operatório, por tempo de coleta

Tabela 22 - Comparação da glicemia por TTOG na administração da solução por via oral pré-operatória e via oral pósoperatório, por tempo de coleta

Tabela 23 - Comparação entre HOMA-IR e HOMA-BETA no préoperatório, via gastrostomia pós-operatória e via oral pósoperatória 
FIGURAS

Figura 1 - Curvas do efeito incretínico estudado por Nauck et al..............8

Figura 2 - $\quad$ Mecanismos de ação do GIP e GLP1 ....................................10

Figura 3 - Curva de GIP e GLP-1 …………............................13

Figura 4 - Resumo dos mecanismos de controle glicêmico no pósoperatório da GDYR .....................................................17

Figura 5 - Comparação entre estímulo via oral e gastrostomia ................18

Figura 6 - Via de administração do Nutren e TTOG ....................................30

Figura 7 - Esquema do protocolo do estudo ..........................................30 


\section{GRÁFICOS}

Gráfico 1 - Curva da glicemia vo pré-op e vg pós-op.................................36

Gráfico 2 - Comparação entre as curvas glicêmicas vo pré-op e vo pósop

Gráfico 3 - Curva glicêmica entre administração da solução vo pós-op e vg pós-op

Gráfico 4 - Comparação entre as curvas de insulinemia vo pré-op e vg pós-op....

Gráfico 5 - Comparação da curva de insulina vo pré-op e vo pós-op. 40

Gráfico 6 - Comparação entre as curvas de insulinemia vg pós-op e vo pós-op

Gráfico 7 - Comparação das curvas de GLP1 vo pré-op e vo pós-op 42

Gráfico 8 - Comparação das curvas do GLP1 na administração da solução no pré-operatório e por via oral pós-operatório

Gráfico 9 - Comparação das curvas de GLP1 na administração da solução por via oral e via gastrostomia no pós-operatório .........44

Gráfico 10 - Comparação das curvas de GIP vo pré-op e vg pós-op ............45

Gráfico 11 - Comparação das curvas do GIP vo pré-op e vo pós-op ...........46

Gráfico 12 - Comparação das curvas de GIP na administração da solução por via oral e via gastrostomia no pós-operatório .........47

Gráfico 13 - Comparação das curvas de grelina vo pré-op e vg pós-op.......48

Gráfico 14 - Comparação das curvas de grelina vo pré-op e vo pós-op.......49

Gráfico 15 - Comparação das curvas de grelina vg pós-op e vo pós-op ......50

Gráfico 16 - Comparação entre curvas de glicemia do TTOG vo pré-op e vo pós-op

Gráfico 17 - Comparação entre HOMA-IR e HOMA-BETA no vo pré-op, vg pós-op e vo pós-op.

Gráfico 18 - Curvas da glicose, insulina, GLP1, GIP e grelina na comparação vo pré-op e vg pós-op 
Gráfico 19 - Curvas da glicose, insulina, GLP1, GIP, grelina e TTOG na comparação vo pré-op e vo pós-op

Gráfico 20 - Curvas da glicose, insulina, GLP1, GIP e grelina na comparação vg pós-op e vo pós-op..........................................55

Gráfico 21 - Curvas da glicose, insulina, TTOG, GLP1, GIP e grelina na comparação vo pré-op, vg pós-op e vo pós-op. 


\section{RESUMO}

Fernandes G. Avaliação do metabolismo glicêmico e perfil entero-hormonal no pós-operatório precoce em pacientes obesos graves diabéticos submetidos à gastroplastia com derivação intestinal em $Y$ de Roux. Comparação da oferta alimentar por via oral e por gastrostomia [dissertação]. São Paulo: Faculdade de Medicina, Universidade de São Paulo; 2017.

INTRODUÇÃO: O diabetes mellitus tipo 2 (DM2) é uma doença correlacionada com a obesidade mórbida. O paciente obeso apresenta efeito incretínico suprimido e consequente desbalanço da homeostase glicêmica. Diversos estudos evidenciam a melhora do DM2 após a confecção da Gastroplastia com derivação intestinal em $\mathrm{Y}$ de Roux (GDYR). Os mecanismos de controle da glicemia podem ser de longo e curto prazo. Os mecanismos de ação precoce estão ligados à restrição calorica, melhora da resistência insulínica, da função da célula beta pancreática e retorno do efeito incretínico pelo aumento do GLP1 e GIP, porém os dados são conflitantes. MÉTODOS: Onze pacientes obesos graves diabéticos foram submetidos à GDYR com confecção de gastrostomia no remanescente gástrico após perda de peso inicial de $10 \%$. Os pacientes foram submetidos à coleta de entero-hormônios, perfil glicêmico e Teste de Tolerância Oral à glicose (TTOG) no pré-operatório em curva temporal que foi comparado ao pós-operatório por Via Oral e por Via da Gastrostomia em até 7 dias após o procedimento. RESULTADOS: A média da idade foi $46,09 \pm 7,08$ anos. No pré-operatorio, o peso médio foi $120,97 \pm 17,02$ quilogramas, altura $1,67 \pm 0,11$ metros, IMC médio 44,06 $\pm 6,59 \mathrm{~kg} / \mathrm{m}^{2}$, glicemia de jejum média 194,55 $\pm 62,45$ $\mathrm{mg} / \mathrm{dl}$ e hemoglobina glicada $8,74 \pm 1,64 \%$. Em $77,7 \%$ dos pacientes, houve remissão precoce do DM2 no pós-operatório avaliado pelo TTOG. Também foi observada queda significante da glicemia, insulinemia e do HOMA-IR independente da via administrada. Ocorreu aumento significativo do GLP1 e redução do GIP pela Via Oral pós-operatória. A Grelina não apresentou alterações. CONCLUSÃO: Evidenciou-se redução da glicemia e da resistência periférica nos primeiros dias de pós-operatório da GDYR, independente da via de passagem do alimento. A alteração no efeito incretínico (aumento do GLP1 e redução do GIP) só foi observada na Via Oral pós-operatória.

Descritores: derivação gástrica; diabetes mellitus; gastrostomia; homeostase; incretinas; indução de remissão. 


\section{ABSTRACT}

Fernandes G. Glycemic metabolism and enterohormonal evaluation in early postoperative Roux-en-Y gastric bypass in morbidly diabetic obese patients. Comparison the oral and gastrostomy route [dissertation]. São Paulo: "Faculdade de Medicina, Universidade de São Paulo"; 2017.

INTRODUCTION: Type 2 diabetes mellitus (DM2) is a disease correlated with morbidly obesity. The obese patient has a suppressed incretin effect and consequent inbalance of glycemic homeostasis. Several studies have shown an improvement in DM2 after Gastroplasty with Roux-en-Y gastric bypass (RYGB). The mechanisms of glycemic control may be long-term and shortterm. The mechanisms of early action are linked to caloric restriction, improvement of insulin resistance, pancreatic beta cell function and return of the incretin effect through the increase of GLP1 and GIP, but the data are conflicting. METHODS: Eleven diabetic obese patients underwent RYGB with gastrostomy in gastric remnant after initial 10\% weight loss. Patients were submitted to assessment of enterohormones, glycemic profile and Oral Glucose Tolerance Test (OGTT) in the preoperative period in a time curve that was compared to the postoperative period by Oral Via and Gastrostomy Via up to 7 days after the procedure .RESULTS: The mean age of the group was $46.09 \pm 7.08$ years. In the preoperative the mean weight was $120.97 \pm$ 17.02 kilograms, height of $1.67 \pm 0.11$ meters, mean BMl of $44.06 \pm 6,59$ $\mathrm{kg} / \mathrm{m} 2$, mean fasting blood glucose of $194.55 \pm 62.45 \mathrm{mg} / \mathrm{dl}$ and glycated hemoglobin $8.74 \pm 1.64 \%$. In $77.7 \%$ of the patients there was remission of DM2 in postoperative evaluated by the OGTT. Significant decrease in glycemia, insulinemia and HOMA-IR was also observed, regardless of the route of administration. There was a significant increase in GLP1 and reduction of GIP by the postoperative oral route. Ghrelin did not change. CONCLUSION: A reduction in glycemia and peripheral insulinal resistance was observed in early postoperative days of RYGB, independent of the food route. The change in incretin effect (increase of GLP1 and reduction of GIP) was only observed in the postoperative oral route.

Descriptors: gastric bypass; diabetes mellitus; gastrostomy; homeostasis; incretins; induction of remission. 
1 INTRODUÇÃO 


\section{INTRODUÇÃO}

\subsection{Considerações gerais}

O diabetes mellitus tipo 2 (DM2) é uma síndrome de etiologia múltipla, decorrente da deficiência de insulina e/ou da incapacidade de exercer adequadamente suas funções, determinando uma hiperglicemia crônica com consequências em múltiplos órgãos e suas funções, comumente associada à disfunção endotelial e alterações micro e macrovasculares, com risco maior de doença vascular aterosclerótica. Nos dias de hoje, corresponde cerca de $90 \%$ dos casos de diabetes ${ }^{(1)}$.

A incidência de DM2 vem aumentando significativamente nas últimas décadas. Dados do CDC (Centers for Disease Control and Prevention) e do $\mathrm{NIH}$ (National Institutes of Health), apontam uma prevalência de cerca de 7,2 milhões de diabéticos em tratamento, e aproximadamente 25 milhões não diagnosticados nos Estados Unidos da América (EUA). É um problema de saúde pública mundial com estimativas de, aproximadamente, 280 milhões de diabéticos no mundo, e expectativa de mais de 500 milhões até $2030{ }^{(2)}$.

Atualmente, os dados epidemiológicos apontam o DM2 como a terceira causa de morte no mundo com tendência de aumento progressivo dessa mortalidade. Estima-se sua prevalência em torno de $7 \%$ da população adulta $^{(3)}$.

Os custos diretos com DM2 nos EUA foram estimados em 116 milhões de dólares em 2007, porém elevando-se para 170 bilhões, quando incluídos nos cálculos também as implicações da doença, como o risco aumentado, de duas a quatro vezes, do desenvolvimento de doenças cardiovasculares. Este custo subiu de 170 bilhões, em 2007, para 245 bilhões de dólares em $2012^{(4)}$. O NIH relata um custo de 11,7 bilhões de libras esterlinas no Reino Unido em $2012^{(2)}$.

No Brasil a prevalência do diabetes na década de 1980 era presumida em $7,6 \%$ da população, porém estudos isolados mais recentes 
mostram que essa proporção deva chegar entre $13 \%-15 \%$, sendo a taxa de mortalidade de 213,4/100.000 habitantes (dados subestimados), com custo direto estimado em 3,9 bilhões de dólares ${ }^{(5)}$.

O diagnóstico do DM2 ocorre pela medida da glicemia e da hemoglobina glicada (A1c), conforme os parâmetros abaixo ${ }^{(5,6)}$ (Tabela1) (Sociedade Brasileira de Diabetes (SBD) e American Diabetes Association (ADA):

Tabela 1 - Valores de glicose plasmática (em mg/dl) e hemoglobina glicada para diagnóstico de diabetes mellitus e seus estágios préclínicos

\begin{tabular}{|c|c|c|c|}
\hline CATEGORIA & JEJUM* & $\begin{array}{c}2 \mathrm{H} \text { após } 75 \mathrm{~g} \text { de } \\
\text { Glicose - } \\
\text { TTGO }\end{array}$ & CASUAL** \\
\hline $\begin{array}{l}\text { Glicemia } \\
\text { normal }\end{array}$ & $\begin{array}{c}<100 \text { ou } \\
\text { A1c }<6,5 \%\end{array}$ & $<140$ & \\
\hline $\begin{array}{l}\text { Tolerância à } \\
\text { glicose } \\
\text { diminuída }\end{array}$ & $>100 a<126$ & $\geq 140 a<200$ & \\
\hline $\begin{array}{l}\text { Diabetes } \\
\text { mellitus }\end{array}$ & $\begin{array}{c}\geq 126 \\
A 1 c \geq 6,5 \% \text { ou } \\
\geq 5,7 \text { e }<6,4^{* * *}\end{array}$ & $\geq 200$ & $\begin{array}{l}\geq 200 \text { com sintomas } \\
\text { clássicos }^{\star \star \star *}\end{array}$ \\
\hline
\end{tabular}

FONTE: American Diabetes Association. Standards of medical care in diabetes 2016. Diabetes Care. 2014;37(Suppl.1):14-80.

* - Jejum é difinido como a falta de ingestão calorica por, no mínimo, 8 horas

** - Glicemia plasmática casual é aquela realizada a qualquer hora do dia, sem se observar o intervalo desde a última refeição

*** - Para pacientes com alto risco de desenvolver diabetes (sedentarismo, parente de primeiro grau com diagnóstico de DM2, obesidade severa, acantose nigrans, raça/etnia, $\mathrm{HDL}<35 \mathrm{mg} / \mathrm{dl}$, Trigliceridemia $>250 \mathrm{mg} / \mathrm{dl}$, hipertensão)

**** - Poliúria, polidipsia e perda de peso não explicada

***** - TTGO - Teste de Tolerância Oral à Glicose

Essa doença está sob um amplo campo de pesquisa e desenvolvimento de novas terapias, sendo um dos principais focos das políticas de saúde pública. Como a doença apresenta evolução crônica, deve-se considerar o processo de envelhecimento, a prática de atividades de vida diária, atividades instrumentais e mobilidade; que são medidas, 
frequentemente, utilizadas para avaliar a capacidade funcional e estão comumente diminuídas nos indivíduos portadores do DM2 ${ }^{(7)}$.

O DM2 tem como tratamento o uso de medicamentos, mudança de estilo de vida e hábitos associados a uma maior prática de atividade física. No que se refere aos aspectos comportamentais do tratamento do DM, um dos princípios básicos é o manejo nutricional, porém com baixa adesão por parte dos pacientes. Estratégias convencionais para o tratamento da DM2 incluindo o mudança de estilo de vida e farmacoterapia vêm apresentando sucesso e, com isso, atrasando o surgimento de doenças cardiovasculares e complicações tardias por meio do controle glicêmico, hipertensão e dislipidemia. Estas, porém, requerem uma boa aderência ao tratamento, check-ups regulares e, eventualmente, medicação de uso crônico ${ }^{(8)}$.

Uma condição intimamente relacionada ao DM é a síndrome metabólica, que é caracterizada por um conjunto de fatores, como dislipidemia, obesidade visceral, hipertensão arterial e resistência insulínica ${ }^{(9)}$ e está relacionada com hipersensibilidade aos glicocorticoides, elevados níveis plasmáticos de glicose, secreção aumentada de angiotensina o que aumenta o risco de hipertensão arterial, aumento da secreção de interleucina-6, dos triglicérides e redução do colesterol HDL. O aumento da hipersensibilidade do tecido adiposo aos glicocorticoides está associada à maior capacidade de vasoconstrição arterial e, consequentemente, à hipertensão arterial. O excesso de glicocorticoides estimula a glicose-6-fosfatase, promovendo maior liberação de glicose das células pancreáticas (e outros tecidos como fígado e músculos), levando a estados de hiperglicemia e de resistência dos tecidos à ação da insulina. Durante vários anos, esta hiperglicemia crônica estimula o aumento da secreção de insulina, induzindo uma hiperinsulinemia, que, aliada à hipersecreção de glicocorticoides do tecido adiposo visceral exercem um feedback negativo sobre o pâncreas, inibindo a secreção de insulina e contribuindo à resistência a este hormônio e desenvolvimento do DM2 ${ }^{(10)}$.

No obeso, a base fisiopatológica do DM2 ocorre por meio da resistência insulínica $(\mathrm{RI})$. O paciente encontra-se em um estado crônico de 
hiperglicemia e dislipidemia (ácidos graxos livres) pela ingesta constante de alimentos ricos em açúcar e gordura, levando ao aumento de diversos mediadores pró-inflamatórios, como IL-Beta, IL-6, entre outras. A isso, dá-se o nome de estresse oxidativo, que recruta os macrófagos no tecido adiposo. Estes liberam uma série de citocinas, levando a uma síndrome autoinflamatória no tecido periférico ocasionando disfunção da própria célula beta do pâncreas, um aumento da resistência insulínica periférica e diminuição da secreção de insulina deixando o paciente em um estado hiperglicêmico, novamente, entrando, assim, em um ciclo ${ }^{(11)}$.

O DM2 cresce em paralelo com a obesidade, sendo ambas doenças diretamente relacionadas ao sedentarismo e à dieta rica em carboidratos e gorduras. Ao associar estes fatores aos comportamentais, explica-se o aumento da incidência destas duas doenças em crianças, adolescentes e adultos. A obesidade é um fator de risco significativo para o desenvolvimento do DM2, já que cerca de $80 \%$ dos pacientes diabéticos estão acima do peso. Assim como o tempo de duração da obesidade está diretamente relacionado ao risco de DM2 ${ }^{(8,12)}$.

Atualmente, a cirurgia bariátrica é o melhor tratamento para o DM2 em pacientes obesos graves. A cirurgia ganhou tamanha importância que a Associação Americana do Diabetes (ADA) e a Federação Internacional do Diabetes (IDF) recomendam a cirurgia em seus "guidelines" ao paciente obeso diabético ${ }^{(13,14)}$. Diversos estudos apontam para o controle ou remissão da doença de forma importante. As técnicas apresentam resultados diferentes entre si, mas todas elas possuem um melhor controle glicêmico quando comparadas ao tratamento clínico ${ }^{(15)}$. Uma metanálise com 621 artigos mostra que a remissão da DM2 pode chegar a $80 \%$ em pacientes submetidos à cirurgia bariátrica ${ }^{(16)}$. Nas cirurgias em que há predominância de má absorção, como na derivação biliopancreática ou "duodenal switch", a remissão do diabetes gira em torno de 95\%. Na gastroplastia com derivação intestinal em Y de Roux (GDYR), a taxa é cerca de $85 \%$. Já nas técnicas puramente restritivas, como é o caso da banda gástrica é, aproximadamente, $50 \%{ }^{(16)}$. 
Um dos primeiros grandes estudos sobre cirurgia em diabéticos foi o de Greenville (EUA). Neste estudo, 165 pacientes obesos graves foram submetidos ao bypass gástrico e $83 \%$ dos pacientes permaneceram em remissão do diabete após 14 anos ${ }^{(17)}$. Outro grande estudo, o SOS (Swedish Obesity Subjects) comparou um grupo de pacientes operados a um grupo não operado, após 2 anos de seguimento mostrou prevalência de diabetes tipo 2 de $8 \%$ no grupo controle e $1 \%$ no grupo operado, e após 10 anos, $24 \%$ no grupo controle e apenas $7 \%$ no grupo operado ${ }^{(18)}$. O estudo denominado STAMPEDE, de 2017, comparou um grupo submetido a GDYR, um grupo submetido à gastrectomia vertical e outro controlado somente com medicações quanto ao controle do DM2 durante 5 anos. Dosagens de hemoglobina glicada abaixo de $6 \%$ após 12 meses foram $5 \%$ no grupo de tratamento medicamentoso, $23 \%$ no grupo da gastrectomia vertical e $29 \%$ no grupo da GDYR, mostrando a importante influência da cirurgia na homeostase glicêmica ${ }^{(19)}$.

O mecanismo de controle da DM2 pela GDYR e suas relações com a anatomia gastrointestinal e homeostase da glicose foram revisados por Rubino, em 2006. Evidenciou-se que a GDYR e o desvio biliopancreático foram métodos efetivos no controle do diabetes em cerca de $80 \%$ a $100 \%$ dos casos, resultando em concentrações persistentemente normais da glicose, insulina e hemoglobina glicada ${ }^{(20)}$.

O controle do diabetes é um tema polêmico, porém já bem definido por consenso. Ficou estabelecido que não existe definição para cura, apenas controle do DM2. Os parâmetros estão abaixo, conforme consenso da American Diabetes Association (ADA)(Tabela2) ${ }^{(13)}$ : 
Tabela 2 - Definição de remissão do DM2, conforme a ADA

\begin{tabular}{ll}
\hline \multicolumn{1}{c}{ DEFINIÇÃo } & \multicolumn{1}{c}{ PARÂMETRO } \\
\hline Remissão Parcial & Glicemia de Jejum 100-125mg/dl \\
& HbA1 $<6,5 \%$ \\
& Pelo menos, 1 ano de duração \\
& Sem terapêutica associada \\
& Glicemia de Jejum <100mg/dl \\
& HbA1 $<6,0 \%$ \\
Remissão Completa & Pelo menos, 1 ano de duração \\
& Sem terapêutica associada \\
\hline Remissão Prolongada & Remissão completa por, pelo menos, 5 \\
& anos de duração \\
\hline
\end{tabular}

FONTE: National Diabetes Education Initiative. 2016 American Diabetes Association (ADA) diabetes guidelines summary recommendation from NDEI. 2016;1-46.

Estudo de Everheart et al. ${ }^{(12)}$ (1992) mostra que a taxa de remissão pode ser menor dependendo da gravidade do diabetes do indivíduo. Esta severidade e sua provável remissão após cirurgia bariátrica foi estudada por Lee et al. (2013). Neste estudo foram avaliados o peso de variáveis, como IMC, idade, gênero, peptídeo-C, HDL-colesterol, entre outros. Dentre todas elas, somente idade, IMC, tempo de diagnóstico de DM2 e peptídeo-C tiveram significância. Com isso, os autores apresentaram um escore chamado de "Diabetes Surgery Score" ou também conhecido por escore ABCD (de maneira mnemônica A-Age, B-BMI, C- Peptídeo C, D- Time of Disease). Este escore avalia a probabilidade de remissão do paciente no pós operatório tardio (1 ano após o procedimento) ${ }^{(21)}$.

\subsection{Homeostase glicêmica}

O trato gastrointestinal tem função crucial no controle da homeostase energética por meio de seu papel na digestão, absorção e assimilação de 
nutrientes ingeridos. Sinais do trato gastrointestinal são importantes reguladores da motilidade intestinal e saciedade, que têm implicação para o controle de peso a longo termo. Dentre os tipos de células especializadas da mucosa gastrointestinal, células enteroendócrinas têm papel importante, regulando a entrada de energia e a homeostase da glicose por meio de suas ações em órgãos periféricos específicos, incluindo o pâncreas endócrino. Depois da ingestão dos alimentos, a digestão e a absorção dos nutrientes são associadas ao aumento da secreção de múltiplos peptídeos intestinais que agem a distância, promovendo a utilização e armazenagem de energia. Os entero-hormônios ativam um circuito neural que se comunica com órgãos periféricos, incluindo o fígado, tecido muscular, tecido adiposo e as ilhotas de Langerhans no pâncreas para coordenar essa utilização e armazenagem de energia. No papel principal dessa coordenação, temos as incretinas que atuam de maneira central na homeostase da glicose. Aos hormônios do trato gastrointestinal, que possuem ação sobre a insulina e o controle glicêmico, dá-se o nome de incretinas.

O efeito incretínico foi estudado por Nauck et al. ${ }^{(22)}$ em 1986, em que foi evidenciada resposta insulínica maior após a ingestão oral de glicose comparada à infusão endovenosa de glicose (Figura 1). Mostrou-se, assim, que a passagem do alimento pelo trato gastrointestinal estimula o controle glicêmico, e a isso deu-se o nome de efeito incretínico. A partir daí, uma série de entero-hormônios relacionados a esse efeito vêm sendo estudados, sendo os principais o GLP1 e o GIP.
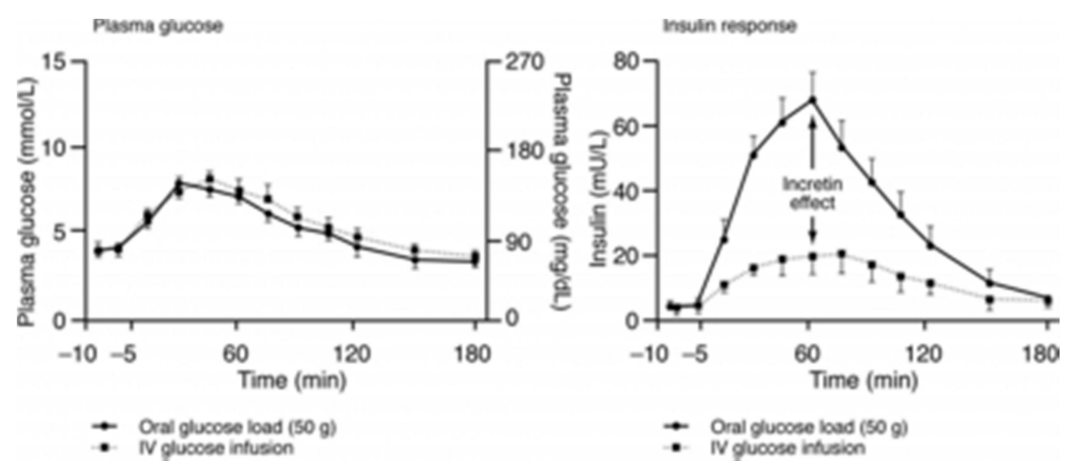

Figura 1- Curvas do efeito incretínico estudado por Nauck et al. ${ }^{\text {(22) }}$ 
O polipeptídeo insulinotrópico dependente da glicose ou também conhecido como hormônio inibitório gástrico (GIP) é um peptídeo de 42 aminoácidos que tem a expressão de seus receptores em quase todos os órgãos periféricos, sobretudo pâncreas, estômago, intestino delgado, tecido adiposo, córtex da adrenal, pulmão, glândula pituitária, coração, testículo, endotélio vascular, ossos e cérebro ${ }^{(23,24)}$. Ele é expressado, predominantemente, no estômago e duodeno, e é estimulado pela ingestão de carboidratos e gorduras. Tem como uma de suas principais funções a regulação da homeostase glicêmica. Esta função foi evidenciada após o bloqueio dos receptores de GIP em ratos, mostrando prejuízo na secreção insulínica após administração via oral de glicose ${ }^{(25)}$. Ele age nas células beta, aumentando a biossíntese e secreção da insulina além de fornecer um fator protetor a essas células ${ }^{(26)}$. Tem também efeito na biologia do adipócito. Ratos que não expressavam seus receptores tiveram menor ganho de peso, além do uso preferencial da gordura como energia e resistência à obesidade induzida por dieta hipercalórica ${ }^{(27)}$.

Outros peptídeos relacionados à homeostase glicêmica são os Peptídeos Derivados do Proglucagon (PDPG). Eles são gerados por um processo traducional do RNAm de seu precursor proglucagon no pâncreas, intestino e cérebro. O principal produto dos PDPG é o glucagon, produzido nas células alfa das ilhotas de Langerhans. $O$ pró-hormônio convertase 1 (PC1), enzima presente nas células $L$ enteroendócrinas, gera a glicentina, GLP1 e GLP2 a partir dos PDPG. Estes peptídeos são estimulados por via neuronal, GIP e alguns nutrientes como proteína hidrolisada, ácidos graxos de cadeia curta e dieta rica em fibra ${ }^{(28)}$.

O glucagon-like-peptide 1 ou GLP1 é um peptídeo composto de 36 ou 37 aminoácidos, sendo a forma mais comum no homem a de 36 aminoácidos ${ }^{(29)}$. Ele também apresenta receptores em órgãos periféricos muito semelhante aos receptores do GIP, como coração, cérebro, pâncreas, tecido adiposo, intestino e estômago (Figura 2, Tabela 3). É responsável por aumentar a transcrição do gene, aumentar a estabilidade do RNAm de codificação da insulina, como também sua biossíntese por diversos 
mecanismos. Estes mecanismos são dependentes do AMPc, da proteína kinase $\mathrm{A}$ e de vias que aumentam a concentração intracelular de cálcio ${ }^{(30)}$. O GLP1 tem múltiplas ações fisiológicas levando ao controle da utilização e assimilação da energia. É o principal entero hormônio a estimular a secreção insulínica, aumentando a função das células beta da ilhota de Langerhans (aumenta sua sensibilidade e estímulo da célula à glicose), e por meio do efeito "glucagonestático" diminui o efeito do glucagon, promovendo a proliferação e o aumento da população de células beta e ainda evita a apoptose das mesmas ${ }^{\left({ }^{31}\right)}$. O glucagon é produzido nas células alfa do pâncreas e tem como função ação contrarregulatória da insulina e promove a elevação da glicemia por meio sobretudo da gliconeogênese e glicogenólise hepáticas ${ }^{(32)}$.

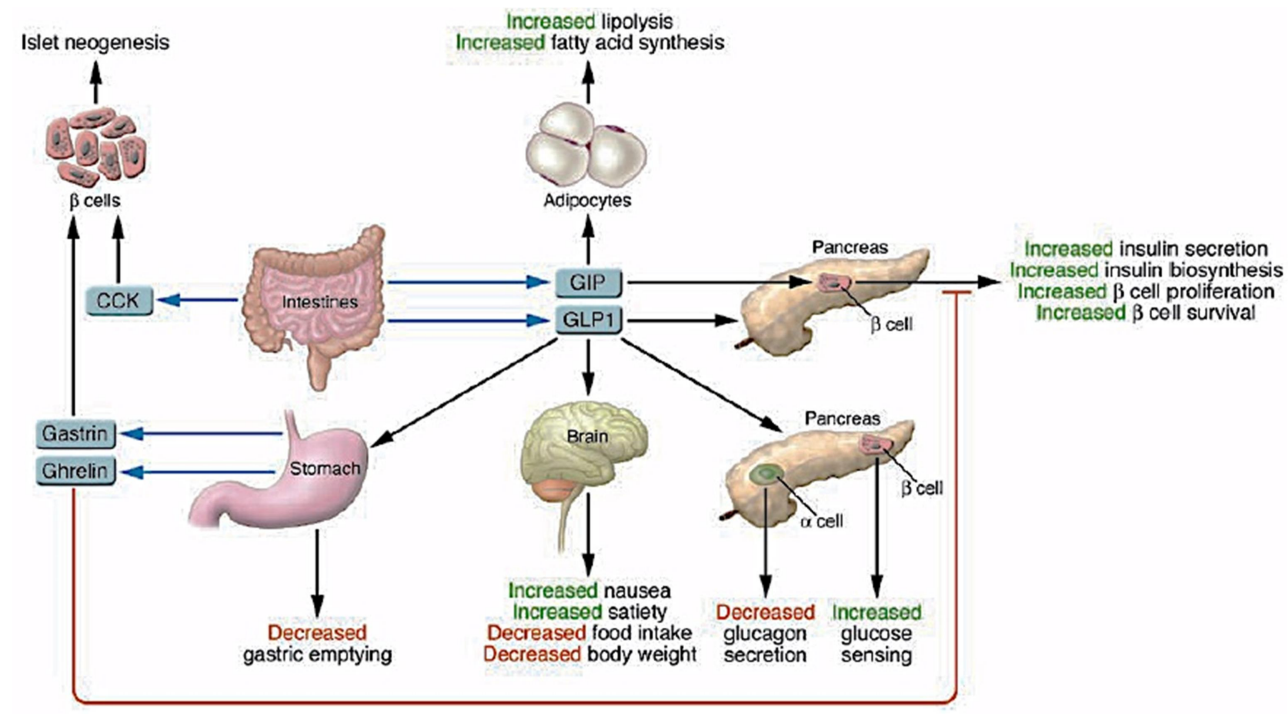

Figura 2 - Mecanismos de ação do GIP e GLP1 ${ }^{(31)}$ 
Tabela 3 - Resumo das ações do GLP1 e GIP no controle da glicose e tratamento do DM2

\begin{tabular}{|c|c|c|}
\hline & GLP1 & GIP \\
\hline \multicolumn{3}{|l|}{ PÂNCREAS } \\
\hline $\begin{array}{l}\text { Estimula a secreção de insulina dependente da } \\
\text { glicose }\end{array}$ & + & + \\
\hline Aumenta transcrição do gene da insulina & + & + \\
\hline Inibe secreção do glucagon & + & - \\
\hline Estimula secreção de somatostatina & + & - \\
\hline Aumenta resposta da célula Beta à glicose & + & + \\
\hline Induz proliferação da célula Beta & + & - \\
\hline Inibe apoptose da célula Beta & + & + \\
\hline Aumenta diferenciação e função da célula Beta & + & + \\
\hline \multicolumn{3}{|l|}{ TRATO GASTRO INTESTINAL } \\
\hline Inibe esvaziamento gástrico & + & - \\
\hline Inibe secreção gástrica & + & + \\
\hline \multicolumn{3}{|l|}{ SISTEMA NERVOSO CENTRAL } \\
\hline Inibe ingesta de comida e água & + & - \\
\hline Promove saciedade e perda de peso & + & - \\
\hline Melhora memória e vida neuronal & + & - \\
\hline Náuseas/Vômitos & + & - \\
\hline \multicolumn{3}{|l|}{ SISTEMA CARDIOVASCULAR } \\
\hline Aumenta função cardiovascular após isquemia & + & - \\
\hline Reduz a extensão da morte celular por isquemia & + & - \\
\hline \multicolumn{3}{|l|}{ TECIDO ADIPOSO } \\
\hline Ações lipogênicas & - & + \\
\hline Armazenamento lipídico & - & + \\
\hline
\end{tabular}

(+) efeito estimulador / (-) efeito inibitório. Drucker DJ. Review series The role of gut hormones in glucose homeostasis. ${ }^{(31)}$

Atualmente, é bem estabelecido que o DM2 caracteriza-se não somente pela resistência periférica insulínica, mas também por um defeito das células beta de Langerhan que as tornam incapazes de responder adequadamente à essa resistência. Estudos de Nauck et al. ${ }^{(33)}$ indicaram que o efeito incretínico é severamente reduzido ou ausente em pacientes 
magros com diabetes mellitus (1986). Em estudo semelhante realizado por Knop et al. em 2008 realizado com pacientes obesos diabéticos tipo 2 ficou confirmada a perda do efeito incretínico, sendo essa perda mais intensa até em paciente magros. Observou-se que a quantidade de glicose intravenosa necessária para mimetizar a resposta da ingestão oral da glicose foi idêntica. Dessa forma, a via de administração não mostrou diferença do comportamento da glicose e do efeito incretínico. Com isso, não há dúvida que o prejuízo no efeito incretínico contribui para a intolerância à glicose nos indivíduos obesos diabéticos ${ }^{(34)}$.

Dado que o GLP1 e o GIP são as incretinas mais importantes, vários estudos foram realizados a fim de aprofundar sua contribuição nesse efeito em pacientes diabéticos. Tais contribuições podem ser devido à secreção, ação ou metabolismo desses entero-hormônios. Estudos detalhados sobre secreção do GIP e GLP1 em resposta à refeição-padrão em pacientes com DM2 mostraram uma diminuição na secreção de ambos. A maior alteração ocorreu na secreção do GLP1, com queda de $50 \%$ de seu efeito em comparação a pacientes saudáveis ${ }^{(35,36)}$.

O metabolismo desses hormônios foi comparado por Vilsboll et al. (2003) em pacientes diabéticos e controles, mas ambos foram metabolizados de maneira semelhante, então, alterações em sua eliminação não ajudam a explicar o prejuízo do efeito incretínico ${ }^{(37,38)}$. Quanto à ação dos hormônios incretínicos, descobriu-se que infusões suprafisiológicas de GLP1 eram capazes de restaurar a sensibilidade à glicose da célula beta para valores normais, mas nos pacientes diabéticos essa sensibilidade estava muito diminuída. Em outros estudos com pacientes DM2, foram administrados GIP e GLP1 a ponto de estimular de maneira fisiológica o efeito incretínico. No entanto, não houve efeito sobre a secreção insulínica, apesar das mesmas taxas de infusão aumentarem a secreção insulínica em pacientes saudáveis ${ }^{(39)}$. Esses achados ilustram a dramática perda de ação do GLP1 e do GIP em pacientes diabéticos tipo 2. Outra suposição é que exista uma falha primária dos entero-hormônios. Alguns estudos apontam para uma redução da secreção do GLP1 secundário ao DM2. Na avaliação 
de gêmeos idênticos discordantes para DM2 mostrou-se que a secreção de GLP1 estava diminuida somente no irmão diabético ${ }^{(40)}$. Outro estudo de Vilsboll et al. ${ }^{(41)}$ (2003) avaliou a resposta insulínica ao GIP em pacientes diabéticos de diferentes etiologias, incluindo diabetes secundária à pancreatite crônica. Nesses indivíduos, houve diminuição do efeito insulinotrópico do GIP, assim como nos pacientes com DM2, ajudando a corroborar essa hipótese.

\subsection{GDYR e os mecanismos de controle glicêmico pós-operatório}

Como discutido anteriormente, diversos estudos mostram a ação da cirurgia bariátrica na homeostase da glicose e, sobretudo, no efeito incretínico. Em 2009, Laferrere et al. avaliaram o controle glicêmico, analisando grupos de pacientes com DM2 e obesidade mórbida. Um grupo foi submetido à GDYR e o outro grupo à dieta para redução de peso. Observou-se melhor homeostase da glicose nos pacientes submetidos à intervenção cirúrgica. $O$ estudo também mostrou a significativa redução das concentrações de glicose durante o teste de tolerância à glicose no grupo GDYR ${ }^{(42)}$. No entanto, o mais relevante foi que, após cerca de 1 mês do procedimento, as curvas de GLP1 e GIP já mostravam uma melhora significativa do efeito incretínico e do aumento desses hormônios (Figura 3):

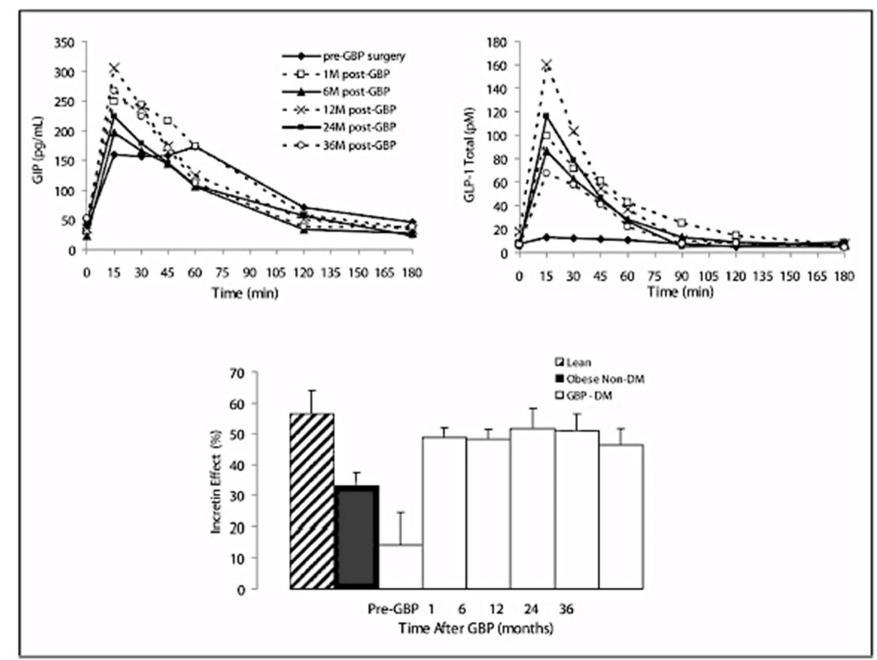

Figura 3 - Curva de GIP e GLP-1 Laferrere et al. ${ }^{(42)}$ 
O mecanismo para essa melhora tão importante ainda não é completamente entendido. Existem duas teorias: a do intestino proximal e a do intestino distal. A teoria do intestino proximal sugere que a exclusão do duodeno do trânsito diminui a secreção de algum hormônio anti-incretínico o que permitiria a ação das incretinas. Sugere-se que esse efeito antiincretínico venha das células $\mathrm{K}$ (que existem em maior concentração no duodeno) por algum tipo de hormônio ainda não identificado ${ }^{(20,43)}$. As células $\mathrm{K}$ também produzem o GIP ${ }^{(44)}$. Estudos com ratos não obesos e diabéticos submetidos à cirurgia com desvio duodenal sem manipulação gástrica somados a outros estudos com manga duodenal (Endobarrier ${ }^{\circledR}$ ) mostraram uma melhora significativa na glicemia de jejum e da $A 1 c{ }^{(45)}$ quando o alimento não passava pelo duodeno, e as taxas de glicemia aumentavam quando o alimento percorria novamente o duodeno. Isso mostra algum fator diabetogênico ou anti-incretínico nessa região ${ }^{(46)}$. Vários estudos sobre o efeito anti-incretínico foram feitos, como jejunectomia de ratos e proteínas extraídas de extrato de duodeno destes, mostrando efeitos diabetogênicos, provando, assim, que existe algum mecanismo contrarregulatório ao efeito incretínico ${ }^{(47)}$. Já a teoria do intestino distal se dá pelo maior aporte de nutrientes no intestino delgado mais distalmente, que possui maior concentração de células L. Isso aumentaria a secreção de GLP1 e do peptídeo YY (PYY), o que ajudaria a estabilizar a taxa de glicose. O PYY diminui a peristalse ileal e promove a gastroparesia o que aumenta a saciedade, facilita a entrada da glicose nas células musculares e adipócitos mas não tem ação direta sobre a insulina ${ }^{(20,44)}$.

Outros mecanismos, de curto e longo prazos, podem estar relacionados ao controle glicêmico pós-operatório da GDYR. O primeiro e mais rápido é a diminuição abrupta da ingesta de calorias pelo mecanismo de restrição da cirurgia, esta diminuição já leva a menores índices glicêmicos. Outro hormônio que diminui consideravelmente, de maneira paradoxal, pois este, normalmente, está aumentado nos períodos de fome ou jejum, nas primeiras 24 horas após cirurgia é a Grelina ${ }^{(48)}$. A Grelina é um hormônio produzido no estômago (fundo gástrico) e duodeno e tem um 
papel orexígeno, mas também estimula os hormônios contrarregulatórios da insulina, suprime a adiponectina (hormônio produzido nos adipócitos e que tem função de aumentar a sensibilidade à insulina) e bloqueia a sinalização hepática da insulina ao nível da phosphatidylinositol-3-kinase o que inibe a secreção da insulina. Outros hormônios anorexígenos também aumentam consideravelmente no pós-operatório de maneira precoce da GDYR, como o PYY e o GLP1, esse mecanismo causa inapetência o que diminui a ingesta calórica e ajuda a manter a homeostase da glicose ${ }^{(49)}$. Vários estudos também demonstraram que existe uma melhora na secreção do GLP1 no pós-operatório precoce. Isso pode acontecer com poucos dias e se prolongar por anos mas esse não é o principal fator de melhora nesse período do pós-operatório ${ }^{(50-52)}$.

Em 2008, Wang et al. ${ }^{(53)}$ mostraram em ratos que a infusão de mínima quantidade de lipídios intraduodenal ativa um neurocircuito intestinocérebro-fígado que aumenta a sensibilidade hepática à insulina. Esse caminho envolve a sensibilidade instestinal a moléculas de acyl-coenzima $A$ das gorduras, gerando sinais que são transmitidos pelo nervo vago aferente para o cerebelo e, então, retorna pelo nervo vago eferente para o fígado, aumentando a sensibilidade hepática à insulina reduzindo, com isso, a produção hepática de glicose. Esse mecanismo seria contraditório na GDYR, uma vez que o duodeno é excluído do trânsito, mas poderia ser explicado se esse mecanismo fosse presente ou até aumentado quando o alimento chega mais rápido ao intestino delgado (jejuno). Outra hipótese seria que a gordura chega livre ao intestino sem ter sido conjugada pelos ácidos biliares o que estimularia mais esse eixo, ou até, se o estímulo fosse realmente duodenal, esses ácidos biliares estariam "puros" no duodeno, ou seja, sem se ligarem a gorduras o que também poderia aumentar o estímulo a esse eixo.

Por fim, o aumento dos ácidos biliares está ligado a uma redução da ingesta de alimentos, da gliconeogênese e da resistência insulínica ${ }^{(54)}$. $O$ aumento da reabsorção dos ácidos biliares mostrou-se um potente mecanismo na melhora da sensibilidade à insulina depois da GDYR. Em 
estudos de animais sugere-se que os ácidos biliares aumentem o gasto energético pela ativação da proteína-G ligada ao receptor TGR5. Concentrações séricas de ácidos biliares são duas vezes maiores em pósoperatório de GDYR e foram inversamente correlatas a níveis de glicose pós-prandial (2 horas após a ingesta da glicose) e trigliceridemia de jejum. $E$ foram positivamente correlatas com a adiponectina e os picos de GLP1 ${ }^{(55)}$. Os ácidos biliares também agem sobre um receptor chamado farnesoid $X$ estimulador da secreção do fator de crescimento de fibroblasto (FGF) 19 aumentando sua secreção, o que inibe a gliconeogênese hepática. Em estudos prospectivos humanos e animais de 2012, Pournaras et al. concluíram que a GDYR leva a um aumento de ácidos biliares no íleo terminal o que aumenta a concentração sérica de ácidos biliares no plasma e de GLP1, PYY e FGF $19{ }^{(56)}$.

Outro mecanismo descrito onde o intestino regula a sensibilidade à insulina envolve o metabolismo intestinal de carboidratos. Estudos de Mithieux et al. (2004) mostraram que enzimas-chave para a gliconeogênese são expressadas por genes no intestino delgado, que são induzidas em condições de déficit de energia (jejum prolongado). Estas enzimas são também responsáveis por $30 \%$ da produção endógena da glicose no paciente diabético. Então, a GDYR promove a gliconeogênese intestinal pelo aumento da expressão desses genes no intestino delgado por meio do receptor hepatoportal de glutamina (GLUT-2). Isso modifica a gliconeogênese e sensibilidade hepática à insulina e diminui a ingesta de alimentos ${ }^{(57-59)}$.

A longo prazo a perda de peso tem seu papel mais importante, pois diminui a gordura visceral o que leva a uma diminuição da resistência periférica, aumento da sensibilidade hepática da insulina e melhora da captação e uso da glicose pela musculatura por meio da diminuição de uma resposta inflamatória crônico-sistêmica do indivíduo. Também ocorre o aumento em quantidade e a melhora da função das células beta do pâncreas pelo aumento do GLP1 e GIP, melhorando muito o efeito incretínico $^{(44)}$ (Figura 4). 


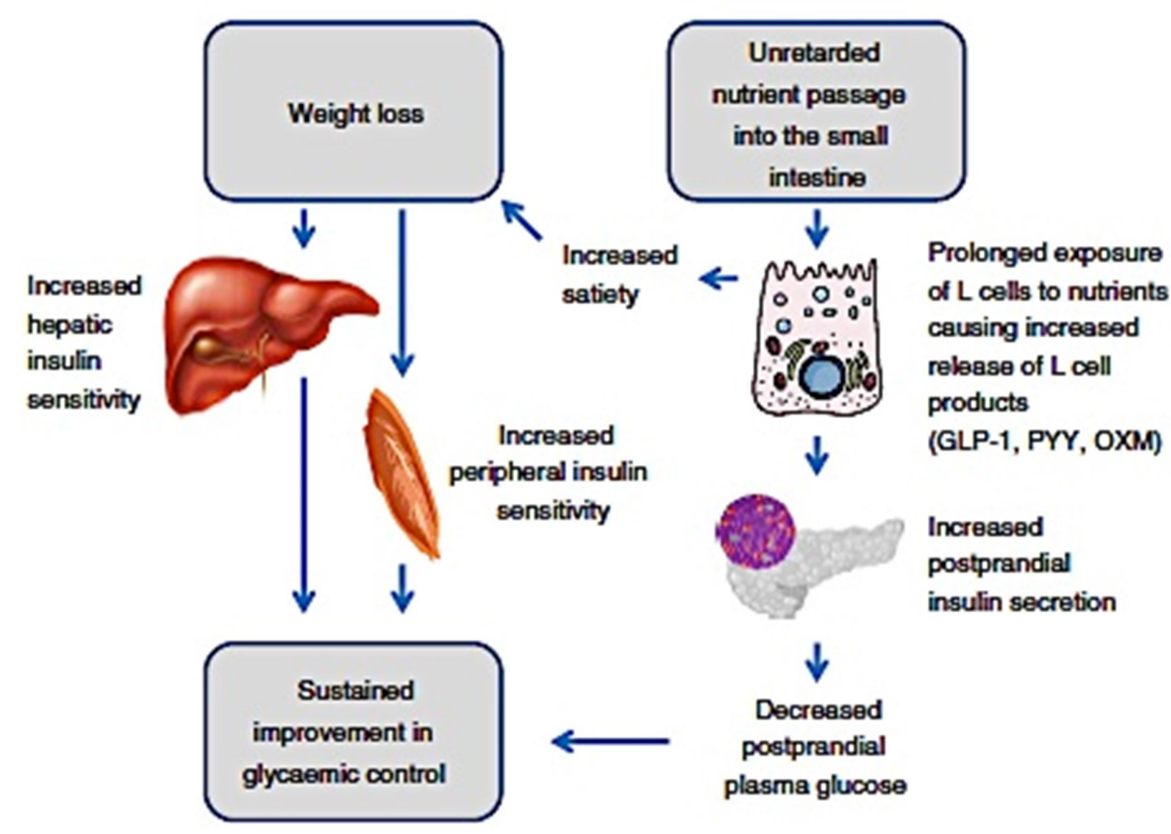

Figura 4 - Resumo dos mecanismos de controle glicêmico no pósoperatório da GDYR. Dirksen et al. ${ }^{(44)}$

A cirurgia apresenta o melhor controle do diabetes ${ }^{(18,20,60,61)}$ e da homeostase da glicose, porém ainda não se entende completamente os mecanismos de saciedade, estimulação, melhora da resistência periférica, sobretudo no pós-operatório precoce.

Em estudo realizado na Dinamarca por Dirksen et al. (2010), um paciente no segundo dia de pós-operatório de gastroplastia redutora foi submetido a uma gastrostomia, como procedimento de segurança em razão de uma suspeita de complicação cirúrgica que não se confirmou na laparoscopia. Quatro semanas após a realização dessa gastrostomia comparou-se a administração de solução-padrão (balanceada com carboidrato, proteína e gordura) por via oral e por via da gastrostomia e notou-se aumento de 2,5 vezes o estímulo das células beta pancreáticas e cinco vezes do GLP1 na via oral em comparação com a via da gastrostomia. Dessa maneira, concluiu-se que antes de existir um emagrecimento expressivo já havia melhora dos níveis de diabetes e também do efeito incretínico ${ }^{(61)}$. Um estudo muito importante de Hansen et al. (2011) realizado 
em pacientes que foram submetidos à GDYR e colocação de gastrostomia no estômago excluso, comparou a administração de solução padronizada por via oral e por via da gastrostomia nos tempos pré operatório, 7 dias e 6 semanas do pós-operatório (Figura 5). Ele verificou que o aumento de GLP1 e o efeito incretínico são potencializados pela cirurgia, de forma gradual sendo seu pico em 6 semanas. A curto prazo não foi evidenciado aumento expressivo de GLP1 ou alguma outra mudança significativa de GIP ou glucagon, concluindo que existam outros mecanismos de controle glicêmico nesse período pós-operatório precoce ${ }^{(62)}$.
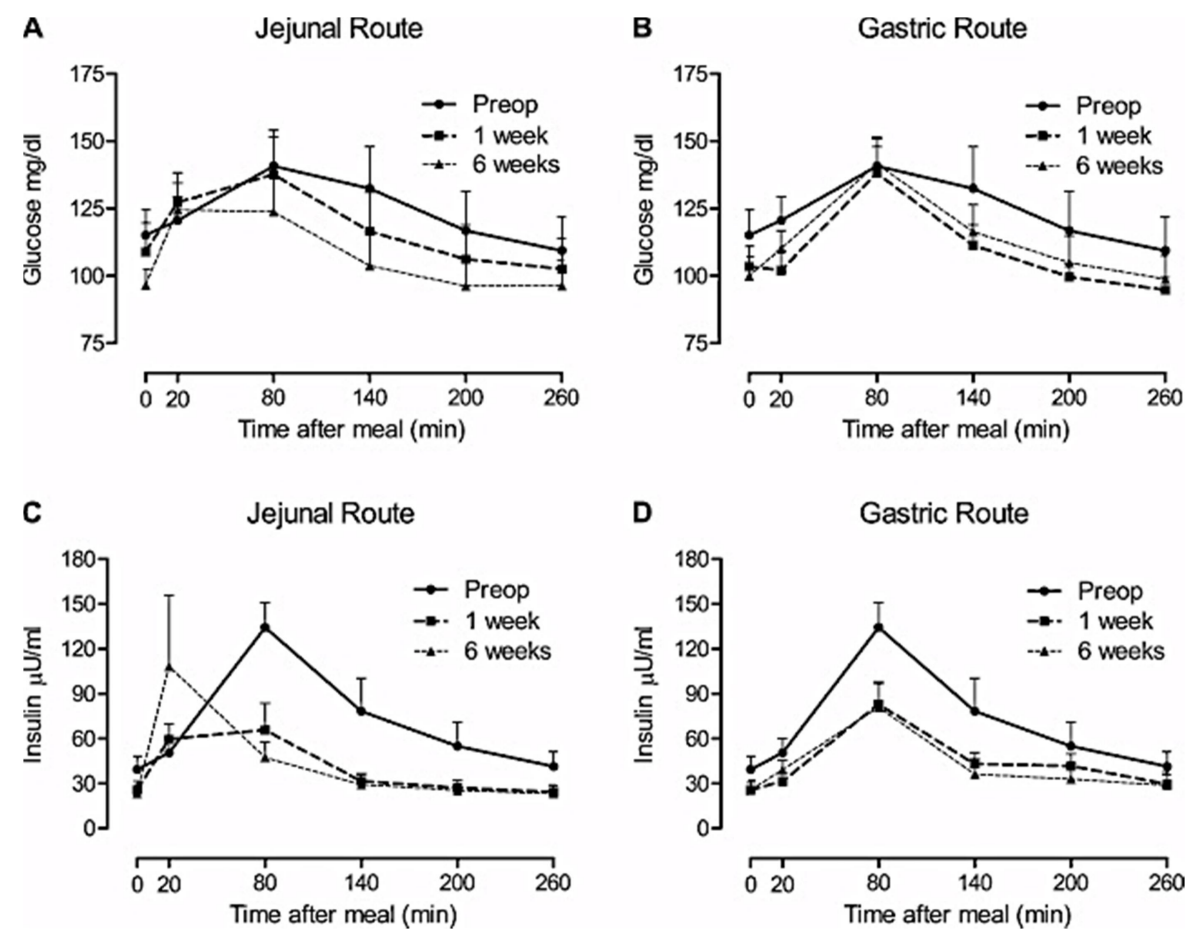

Figura 5 - Comparação entre estímulo via oral e gastrostomia ${ }^{(62)}$

Outros estudos sobre o efeito incretínico a curto prazo são discrepantes e escassos. Em 2010, Isbell et al. estudaram pacientes obesos diabéticos em pós-operatório precoce (até 7 dias) e os compararam com pacientes obesos diabéticos que foram submetidos à dieta liquida exclusiva e restrição calórica de 200-300 kcal por dia. As curvas de GLP1 e GIP tiveram melhora entre os pré e pós-operatórios, mas não houve diferença no 
perfil glicêmico entre os dois grupos, o que mostra que somente a dieta restrita também apresenta melhora da taxa de glicose e resposta das incretinas nos primeiros dias. $O$ fator incretínico não é o responsável pela melhora precoce do DM2 no pós-operatório precoce da GDYR ${ }^{(51)}$. Estudo de Umeda et al. (2011) analisou pacientes obesos e diabéticos submetidos à GDYR no pré-operatório, 7, 30 e 90 dias após o procedimento cirúrgico. Nas dosagens dos entero-hormônios do sétimo dia de pós-operatório, não foram evidenciadas diferenças estatísticas em comparação ao pré-operatório, porém os pacientes já apresentaram melhora dos níveis de insulina, glicose e resistência insulínica. Já nas dosagens de 30 dias, foi evidente o aumento do GIP e GLP1, sobretudo, configurando somente nesse período a melhora do efeito incretínico. Esse estudo corrobora mais uma vez que o efeito incretínico não está relacionado à melhora dos níveis glicêmicos nos

primeiros dias de pós-operatório dos pacientes submetidos à GDYR ${ }^{(63)}$. Por isso, ainda restam dúvidas sobre o comportamento do DM2, da glicose e dos entero-hormônios nos primeiros dias do pós-operatório da GDYR.

\subsection{Formas de avaliação do controle glicêmico}

A dosagem da insulina de jejum vem sendo apontada como um método simples para a avaliação da sensibilidade à insulina no organismo. Em indivíduos resistentes à insulina, as concentrações plasmáticas de jejum estão elevadas e correlacionam-se com a intensidade da resistência à insulina determinada pelo clamp euglicêmico hiperinsulinêmico. $O$ padrãoouro para se avaliar a resistência insulínica é a infusão de insulina, até se atingir uma determinada concentração de insulina circulante (em geral, 100 $\mathrm{mU} / \mathrm{ml})$. Uma vez atingida esta concentração, a quantidade de glicose exógena necessária para manter normoglicemia $(80-90 \mathrm{mg} / \mathrm{dl})$ durante um período mínimo de 2 horas de hiperinsulinemia corresponde à medida da sensibilidade à insulina. Nestas condições, a insulina endógena é suprimida, o estado de equilíbrio dinâmico da glicemia plasmática e os níveis de insulina são mantidos e a quantidade de glicose infundida reflete 
diretamente a quantidade de glicose utilizada de modo dependente de insulina. Esta técnica é conhecida como "clamp euglicêmico hiperinsulinêmico" ${ }^{(64)}$. No entanto, a insulinemia é alvo de várias críticas quanto à sua interpretação, uma vez que ela é um método indireto de avaliação da sensibilidade tecidual, e apresentaria correlações fracas com a ação insulínica in vivo. Além disso, pode haver reação cruzada com a próinsulina, havendo distorções nos valores obtidos, uma vez que a pró-insulina está tanto mais elevada como mais resistente à insulina. Outra crítica referese ao fato que a dosagem da insulina em jejum não refletiria a ação insulínica nos tecidos insulino-dependentes, como o músculo, embora pudesse fornecer uma avaliação da sensibilidade hepática a essa ação.

Outro método de aferição da resistência insulínica, que contempla as mesmas críticas da dosagem da insulina em jejum, é o modelo matemático proposto por Matthews em 1985, que permite acessar a função das células beta e a sensibilidade à insulina pela simples medida combinada da glicemia e insulina de jejum. Este método foi chamado de HOMA (Homeostasis Model Assessment) e dele se extraem dois índices: HOMA-IR e HOMAbeta, que visam a traduzir a sensibilidade à insulina e a capacidade secretória das células beta. $O$ valor de referência para o HOMA-IR para diagnóstico da resistência à insulina e adotado no estudo nomeado BRAMS (Brazilian Metabolic Syndrome Study) é quando for maior que 2,71 ${ }^{\text {(65). }}$.

Para aferição do grau de controle glicêmico no paciente diabético vem se utilizando comumente as medidas da glicemia de jejum, glicemia após sobrecarga oral de glicose de $75 \mathrm{~g}$ (também conhecido como teste de tolerância oral à glicose - TTOG) e/ou glicemia pós-prandial e através da determinação da hemoglobina glicada (A1c).

O TTOG é utilizado sobretudo para o diagnóstico e screening populacional de DM2 em pacientes de alto risco ou em gestantes. Este teste pode ser realizado de várias maneiras, sendo colhida amostra de glicemia de jejum imediatamente antes da administração por via oral de solução de 75 gramas de glicose a ser tomada em 5 minutos. Após essa administração, colhe-se nova dosagem de glicemia em 2 horas ou pode-se colher em curva 
de zero, 30, 60, 90 e 120 minutos, sendo o diagnóstico de diabetes ou resistência insulínica afirmado, conforme parâmetros já discutidos previamente ${ }^{(6)}$.

A hemoglobina glicada, também denominada hemoglobina glicosilada ou glico-hemoglobina, é conhecida ainda como HbA1c e, mais recentemente, apenas como A1c. Embora seja utilizada, desde 1958, como uma ferramenta de diagnóstico na avaliação do controle glicêmico em pacientes diabéticos, a dosagem da A1c passou a ser cada vez mais empregada e aceita pela comunidade científica após 1993, depois de ter sido validada pelos dois estudos clínicos mais importantes sobre a avaliação do impacto do controle glicêmico sobre as complicações crônicas do diabetes: os estudos DCCT - Diabetes Control and Complications Trial (1993) e o UKPDS - United Kingdom Prospective Diabetes Study (1998). A A1c é um índice amplamente empregado que dá uma estimativa da glicemia nos 2 a 3 meses prévios à sua determinação. É de grande utilidade clínica e em pesquisas. Em um indivíduo não diabético, cerca de $4 \%$ a $6 \%$ do total de hemoglobina apresenta-se glicada, e no diabético com descontrole acentuado esta porcentagem pode atingir níveis duas a três vezes acima do normal. Níveis de A1c acima de $7 \%$ estão associados a um risco progressivamente maior de complicações crônicas. Por isso, o conceito atual de tratamento do diabetes por objetivos define $7 \%$ como o limite superior acima do qual está indicada a revisão do esquema terapêutico em vigor ${ }^{(66)}$.

Estes três parâmetros - glicemia em jejum, glicemia pós-estímulo e A1c - correlacionam-se entre si, embora sejam independentes, cada qual com seu valor próprio. Na prática clínica devem ser utilizados isoladamente e trazem informações complementares. Não cabe indicar qual dos exames seria o melhor, uma vez que os três são pertinentes, medindo condições fisiopatológicas diferentes no paciente que devem ser consideradas em conjunto.

Ainda na aferição do grau do controle glicêmico, podemos utilizar a glicemia capilar e o CGMS (Sistema de Monitorização Contínua da Glicose). A glicemia capilar obtém-se pela punção periférica e é medida por aparelho 
próprio. Ela reproduz a concentração de glicose sérica no momento da punção, porém pode apresentar variações dependendo da condição clínica do paciente, como níveis elevados de colesterolemia, variação na oferta de oxigênio, hipotensão severa, infusão de medicamentos ou substâncias redutoras, entre outras ${ }^{(66,67)}$.

Já o CGMS apresenta monitorização contínua e realiza médias das medidas a cada 5 minutos, o que dá um total de 288 medidas em 24 horas. Esse método vem sendo relatado como o melhor método para avaliar a curva glicêmica durante $\mathrm{o}$ dia e o diagnóstico de hipoglicemias ou hiperglicemias severas em intervalos que, normalmente, não são monitorizados. Está relacionada também a um melhor controle da $\mathrm{A} 1 \mathrm{c}$ e, consequentemente, das complicações do diabetes mellitus ${ }^{(67,68)}$.

O controle do diabetes é motivo de estudos e guidelines tamanha sua importância nos resultados a longo prazo. Utilizamos alguns métodos de monitorização da homeostase da glicose descritos acima para a coleta de dados deste estudo. 
2 OBJETIVO 


\section{OBJETIVO}

Avaliar o metabolismo glicêmico e o perfil entero-hormonal no pósoperatório precoce em pacientes obesos graves, submetidos à gastroplastia redutora com derivação em $\mathrm{Y}$ de Roux com gastrostomia, comparando a oferta alimentar pré-operatória e pós-operatória pela via oral e pela via da gastrostomia. 
3 MATERIAL E MÉTODOS 


\section{MATERIAL E MÉTODOS}

O estudo foi desenvolvido na Unidade de Cirurgia Bariátrica e Metabólica da Disciplina de Cirurgia do Aparelho Digestivo do Hospital das Clínicas da Faculdade de Medicina da Universidade de São Paulo no período entre junho de 2015 e março de 2017.

Trata-se de um estudo prospectivo, que foi submetido ao Comitê de Ética e Pesquisa do Hospital das Clínicas da Faculdade de Medicina da Universidade de São Paulo. Todos os pacientes foram submetidos ao Termo de Consentimento Livre e Esclarecido (Anexo 1).

\subsection{Critérios de inclusão}

- Pacientes obesos com IMC maior de $35 \mathrm{~kg} / \mathrm{m}^{2}$, diabéticos, em programação de tratamento cirúrgico, com tempo de diabetes menor que 10 anos e peptídeo $\mathrm{C}$ maior que $2 \mathrm{ng} / \mathrm{ml}$.

- Idade entre 18 e 65 anos.

- Pacientes que realizaram a Gastroplastia Redutora em Y de Roux e, durante o procedimento, foi necessária a realização de gastrostomia no Remanescente Gástrico. A gastrostomia foi realizada como procedimento de segurança. Em nosso serviço, tal procedimento é realizado em pacientes com idade maior que 60 anos, índice de massa corpórea maior que $50 \mathrm{~kg} / \mathrm{m}^{2}$, dificuldade técnica intra-operatória ou condição que aumente o risco de complicação pós-operatória. 


\subsection{Critérios de exclusão}

- Tratamento clínico com uso crônico de insulina e análogos do GLP-1.

- Uso de corticoide via oral ou injetável por mais de 14 dias consecutivos nos últimos 3 meses.

- Portadores de hepatites B e C ou HIV.

\subsection{Técnica Cirúrgica}

A técnica utilizada foi a Gastroplastia em $Y$ de Roux que consiste na confecção de uma bolsa gástrica com volume entre 30 e $50 \mathrm{ml}$ seguido de desvio intestinal (Bypass intestinal), medindo 70 a $80 \mathrm{~cm}$ de alça biliopancreática e $120 \mathrm{~cm}$ de alça alimentar com anastomose, configurando a técnica de $Y$ de Roux. No estômago excluso, foi realizada a Gastrostomia com técnica à Stamm ou Witzel e utilizada sonda apropriada de Gastrostomia de $20 \mathrm{Fr}$.

\subsection{Protocolo do estudo}

Dentro dos critérios descritos acima, 11 pacientes foram avaliados em dois tempos: pré-operatório e pós-operatório. Estes mesmos indivíduos ficaram internados no período pré-operatório para perda de $10 \%$ do seu peso de entrada com o intuito de controle glicêmico prévio ao estudo, para que não houvesse discrepância metabólica entre os indivíduos. Como os pacientes foram submetidos a GDYR com confecção de gastrostomia, o controle pós-operatório foi dividido em duas partes para comparação: administração de solução padrão de 1 frasco de Nutren $1.5^{\circledR}$, constituído de $200 \mathrm{ml}$ de solução com cerca de 300 Kcal e com distribuição energética proveniente de proteína (14\%), carboidrato (58\%) e gordura (28\%) semelhante à dieta normal de um adulto por via gastrostomia e com 
administração da mesma solução por via oral, conforme descrição do protocolo abaixo (Figura 6 e 7).

Foram realizados os seguimentos clínico (com mensuração de peso diário, controle de diurese, pressão arterial, frequência cardíaca, temperatura corporal e presença de intercorrências) e glicêmico (por meio de glicemia capilar de 6 em 6 horas desde a data da internação, conforme as folhas de acompanhamento (Anexo 2)), a fim de descartar qualquer complicação clínica ou cirúrgica que impossibilitasse ou interferisse na realização dos exames.

No pré-operatório após a perda de $10 \%$ do peso de entrada, o paciente foi submetido à coleta de entero-hormônios em curva de tempo de zero, 30, 60, 90 e 120 minutos. Após a coleta da amostra do tempo zero, foi administrada por via oral uma solução-padrão de 1 frasco de Nutren $1.5^{\circledR} \mathrm{e}$, então, foram realizadas as coletas dos tempos subsequentes. No dia seguinte, os pacientes foram submetidos ao TTOG-padrão. Para a realização do TTOG, permaneceram em jejum por 12 horas na noite anterior e, no período da manhã, foi coletada a primeira amostra no tempo zero e depois ofertada $150 \mathrm{ml}$ de solução de glicose a 50\% (75 g de glicose), seguida de coleta em 30, 60, 90 e 120 minutos.

Na sequência, os pacientes foram submetidos à GDYR, conforme a técnica descrita acima. O paciente foi acompanhado normalmente na rotina da enfermaria e observada a boa aceitação da dieta líquida do segundo dia pós-operatório. Quando era observada a boa aceitação da dieta, e o paciente evoluindo sem intercorrências, era programada a coleta das amostras imediatamente após o início da mesma. Em média no terceiro ao quinto dia pós-operatório, era realizada a coleta de sangue no tempo zero e depois os pacientes eram submetidos a administração da solução-padrão (Nutren $1.5^{\circledR}$ ) via gastrostomia no remanescente gástrico. Esta solução foi infundida em cerca de 15 minutos por recipiente apropriado sob responsabilidade da equipe de nutrição. A partir dai, foram colhidos os exames de perfil glicêmico e perfil entero-hormonal em curva de 30, 60, 90 e 120 minutos. 
De 1 a 3 dias após a infusão da solução-padrão por Gastrostomia (do quarto ao sexto dia pós-operatório), foi administrada a mesma solução por via oral. O paciente deveria ingerir o conteúdo dentro de 25 minutos após a coleta do tempo zero, seguido da coleta em curva de 30, 60, 90 e 120 minutos. Durante esse período, o paciente não poderia apresentar emese, para não invalidar o exame.

Um dia após a administração via oral do Nutren foi realizado o TTOG, via oral, administrado dentro de 25 minutos após a coleta de tempo zero e o mesmo também não podia apresentar emese nesse período porque também invalidaria o exame.

Dessa maneira, nos mesmos pacientes, foram comparados os perfis metabólicos nos pré e pós-operatórios precoces ( $\left.\begin{array}{llll}1 & \text { a } & 7 & \text { dias }\end{array}\right)$ da administração de alimento com passagem diretamente pela alça alimentar da GDYR (Grupo Via Oral) e pelo duodeno (Grupo da Gastrostomia).

Os seguintes exames em forma de curva foram realizados:

\subsubsection{Perfil glicêmico e insulinêmico}

Procedeu-se à análise laboratorial da glicemia e da insulinemia, em jejum e pós-prandial, com refeição-padrão em configuração de curva temporal zero, $30,60,90$, e 120 minutos.

\subsubsection{Secreção de entero-hormônios}

Foram dosados conforme descrito abaixo:

Concentração plasmática em jejum e pós-prandial com refeiçãopadrão (com configuração de curva temporal zero, 30, 60, 90, e 120 minutos) dos seguintes entero-hormônios: GLP-1, GIP e Grelina. 


\subsubsection{Teste de Tolerância Oral à Glicose}

O teste foi realizado da maneira padrão do laboratório, sendo utilizada uma solução de Glicose $50 \%$ em $150 \mathrm{ml}$ com $75 \mathrm{~g}$ de maltodextrose em curva temporal de zero, 30, 60, 90 e 120 minutos.

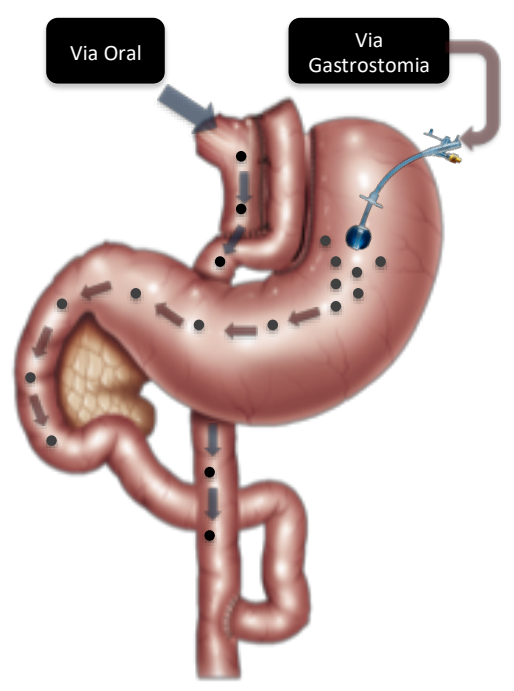

Figura 6 - Via de administração do Nutren e TTOG

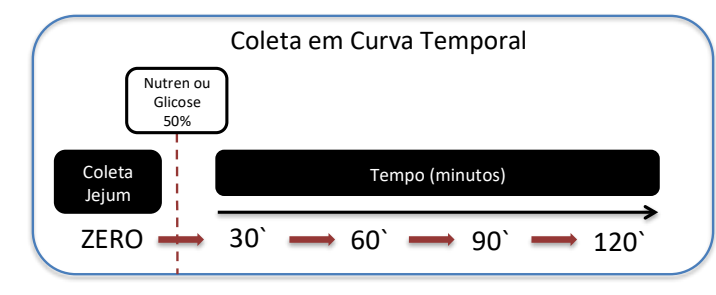

\section{GDYR}

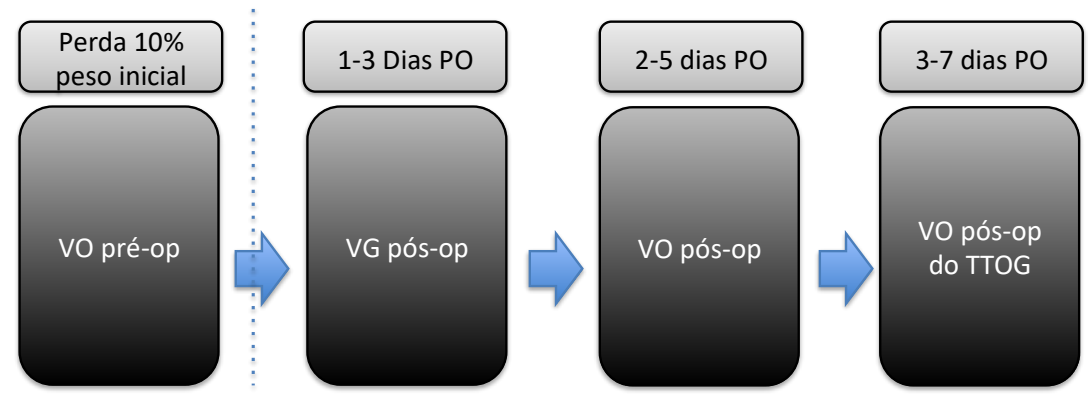

Legenda: GDYR: Gastroplastia com derivação intestinal em Y de Roux, PO: Pós-Operatório, VO pré-op: Via Oral pré-operatória, VG pós-op: Via Gastrostomia pós-operatória, VO pós-op: Via Oral pós-operatória, TTOG: Teste de Tolerância Oral à Glicose

Figura 7- Esquema do Protocolo do Estudo 
Os exames foram realizados pelo equipamento Bio-plex $200 \mathrm{com}$ o software Bio-plex Manager Software (Bio-rad Laboratories ${ }^{\circledR}$ ). O sangue foi coletado em tubo de ensaio roxo K3EDTA em gel separador. As amostras foram coletadas por meio de punção venosa na fossa antecubital do membro superior após aquecimento do mesmo em tubo descrito acima. Elas foram centrifugadas a $1.000 \mathrm{~g}$ a $4^{\circ} \mathrm{C}$ por 15 minutos, separadas do soro e centrifugadas novamente a $10.000 \mathrm{~g}$ a $4^{\circ} \mathrm{C}$ por 10 minutos. Imediatamente, as amostras foram congeladas a $-70^{\circ} \mathrm{C}$ para sua posterior análise.

Os exames de sangue de controle e de perfil entero-hormonal foram realizados no Laboratório Central do Instituto Central do Hospital das Clínicas de São Paulo.

\subsubsection{HOMA-IR e HOMA-BETA}

O HOMA-IR e o HOMA-BETA são fórmulas matemáticas que utilizam como variáveis a glicemia e insulinemia de jejum a fim de estimar a resistência insulínica e a função da célula betapancreática.

Abaixo a fórmula do cálculo do HOMA-IR e HOMA-beta:

HOMA IR - (Insulinajejum [ $\mu \mathrm{IU} / \mathrm{ml}]$ X Glicosejejum [mmol/l]) / 22.5

HOMA $\beta$ - 20 x Insulinajejum ( $\mu \mathrm{Ul} / \mathrm{mL})$ / Glicosejejum (mmol/L) - 3,5

(Glicose em mmol/L - Glicose em mg/dL dividido por 18)

\subsubsection{Análise Estatística}

Os dados são mostrados como MÉDIA \pm DP (desvio padrão). Nas tabelas, a Glicose e TTOG são mostrados em $\mathrm{mg} / \mathrm{dl}$ e os demais enterohormônios e insulina em $\mathrm{pg} / \mathrm{ml}$. A análise estatística entre os tempos (tempo tempo) foi feita pelo Mann-Whitney. A comparação entre os grupos (grupo:grupo e grupo:tempo) foi feita pelo teste ANOVA. A Area Under the 
Curve (AUC) foi comparada pelo Mann-Whitney e tem como unidade $\mathrm{mg} / \mathrm{dl} \mathrm{x}$ min (Glicose e TTOG) e pg/ml x min (nas demais dosagens). Tais métodos foram escolhidos em razão da pequena amostra e dos dados serem lineares. 
4 RESULTADOS 


\section{RESULTADOS}

O período de coleta foi entre junho de 2015 e março de 2017 configurando a coleta de 11 pacientes com o perfil descrito na tabela abaixo (Tabela 4). Não houve perda de paciente no seguimento nem complicações pós-operatórias ou óbitos durante a internação dos mesmos, apenas em dois pacientes houve problemas de coleta do TTOG e, por isso, esses dados não foram contabilizados, sendo utilizados nove dos 11 pacientes para o cálculo dessa variável.

A amostra teve sete indivíduos do sexo feminino e quatro do sexo masculino, idade média $46,09 \pm 7,08$ anos, peso médio $120,97 \pm 17,02$ quilogramas e altura $1,67 \pm 0,11$ metros sendo o índice de massa corpórea (IMC) médio $44,06 \pm 6,59 \mathrm{~kg} / \mathrm{m}^{2}$. O tempo do diagnóstico do diabetes variou entre 5,91 $\pm 2,95$ anos (Tabela 4).

A glicemia de jejum do pré-operatório no momento da internação foi $194,55 \pm 62,45 \mathrm{mg} / \mathrm{dl}$, a hemoglobina glicada $8,74 \pm 1,64 \%$ e o peptídeo C de $5,36 \pm 2,04 \mathrm{ng} / \mathrm{ml}$ (Tabela 5).

Tabela 4 - Perfil demográfico dos pacientes avaliados na internação

\begin{tabular}{|c|c|}
\hline GÊNERO & $\begin{array}{l}4 \text { Masculino } \\
7 \text { Femininos }\end{array}$ \\
\hline IDADE & $46,09 \pm 7,08$ anos \\
\hline PESO & $120,97 \pm 17,02 \mathrm{Kg}$ \\
\hline ALTURA & $1,67 \pm 0,11$ metros \\
\hline IMC & $44,06 \pm 6,59 \mathrm{~kg} / \mathrm{m}^{2}$ \\
\hline TEMPO DE DIABETES & $5,91 \pm 2,95$ anos \\
\hline
\end{tabular}


Tabela 5 - Perfil laboratorial dos pacientes avaliados na internação

\begin{tabular}{lc}
\hline GLICEMIA DE JEJUM & $194,55 \pm 62,45 \mathrm{mg} / \mathrm{dl}$ \\
A1C & $8,74 \pm 1,64 \%$ \\
PEPTÍDEO-C & $5,36 \pm 2,04 \mathrm{ng} / \mathrm{ml}$ \\
\hline
\end{tabular}

Os dados obtidos das incretinas, glicose, insulina e TTOG em curva estão identificados na tabela abaixo (Tabela 6).

Tabela 6 - Tabela das médias \pm DP dos valores das dosagens de Glicemia, Insulina, GLP1, GIP, Grelina e TTOG, conforme o tempo de coleta

\begin{tabular}{|c|c|c|c|c|c|c|}
\hline & Variável & 0 & 30 & 60 & 90 & 120 \\
\hline \multirow{6}{*}{$\begin{array}{c}\text { Vo } \\
\text { pré- } \\
\text { operatório }\end{array}$} & GLICOSE & $125,18 \pm 18,85$ & $164 \pm 22,19$ & $192,45 \pm 30,93$ & $198,73 \pm 36,46$ & $190,09 \pm 44,54$ \\
\hline & INSULINA & $738,77 \pm 351,63$ & $1650,67 \pm 868,39$ & $1678,69 \pm 1083,3$ & $1506,49 \pm 1030,83$ & $1172,4 \pm 563,54$ \\
\hline & GLP1 & $164,88 \pm 98,25$ & $164,26 \pm 104,68$ & $162,33 \pm 97,89$ & $175,99 \pm 102,16$ & $174,98 \pm 95,32$ \\
\hline & GIP & $177,97 \pm 100,82$ & $559,29 \pm 272,49$ & $578,42 \pm 249,53$ & $509,7 \pm 260,36$ & $474,99 \pm 285,98$ \\
\hline & GRELINA & $834 \pm 417,62$ & $880,72 \pm 491,36$ & $864,76 \pm 455,56$ & $852,62 \pm 487,73$ & $892,35 \pm 397,64$ \\
\hline & TTOG & $126,11 \pm 24,84$ & $187,67 \pm 32,09$ & $227 \pm 34,92$ & $240,89 \pm 42,19$ & $242,33 \pm 67,84$ \\
\hline \multirow{5}{*}{$\begin{array}{c}\text { VG } \\
\text { pós- } \\
\text { operatório }\end{array}$} & GLICOSE & $103,64 \pm 35,92$ & $117,91 \pm 43,68$ & $133,73 \pm 56,67$ & $142 \pm 63,61$ & $140,82 \pm 64,4$ \\
\hline & INSULINA & $480,12 \pm 324,6$ & $659,01 \pm 406,93$ & $731,81 \pm 517,38$ & $681,61 \pm 514,23$ & $700,67 \pm 672,08$ \\
\hline & GLP1 & $147,84 \pm 94,2$ & $227,72 \pm 170,1$ & $263,23 \pm 196,88$ & $193,49 \pm 116,61$ & $171,82 \pm 86,94$ \\
\hline & GIP & $115,85 \pm 61,42$ & $305,65 \pm 206,1$ & $472,59 \pm 206,69$ & $448,34 \pm 244,72$ & $365,08 \pm 225,67$ \\
\hline & GRELINA & $734,31 \pm 289,95$ & $738,59 \pm 289,75$ & $733,8 \pm 275,35$ & $734,17 \pm 291,37$ & $682,2 \pm 340,75$ \\
\hline \multirow{6}{*}{$\begin{array}{c}\text { Vo } \\
\text { pós- } \\
\text { operatório }\end{array}$} & GLICOSE & $94,36 \pm 31,46$ & $147 \pm 36,14$ & $169,18 \pm 43,46$ & $152,82 \pm 43,28$ & $139,55 \pm 40,05$ \\
\hline & INSULINA & $531,39 \pm 528,79$ & $988,83 \pm 775,7$ & $1121,27 \pm 463,04$ & $941,29 \pm 844,74$ & $684,68 \pm 364,58$ \\
\hline & GLP1 & $158,47 \pm 85,42$ & $375,61 \pm 276,8$ & $38,41 \pm 234,06$ & $229,09 \pm 119,7$ & $219,46 \pm 99,21$ \\
\hline & GIP & $135,86 \pm 93,05$ & $482,21 \pm 317,62$ & $432,98 \pm 171,02$ & $326,86 \pm 94,83$ & $270,78 \pm 119,77$ \\
\hline & GRELINA & $745,53 \pm 251,47$ & $796,49 \pm 285,95$ & $778,94 \pm 309,39$ & $773,74 \pm 299,53$ & $754,56 \pm 251,56$ \\
\hline & TTOG & $89,22 \pm 19,56$ & $141,44 \pm 20,43$ & $194,22 \pm 53,54$ & $196,89 \pm 59,57$ & $181,78 \pm 56,04$ \\
\hline
\end{tabular}




\subsection{Dosagens laboratoriais}

\subsubsection{Perfil glicêmico e insulinêmico}

\section{Glicemia}

Ao comparar a dosagem de glicemia Via Oral pré-operatória (VO préop) e Via Gastrostomia pós-operatória (VG pós-op) observou-se diferença estatística dos níveis de glicose $(p=0,006)$ com uma evidente queda desses níveis pela VG pós-op (Tabela 7, Gráfico 1).

Tabela 7 - Comparação da glicemia entre administração da solução padrão Via Oral pré-operatória e por Via Gastrostomia pós-operatória, por tempo da coleta

\begin{tabular}{cccccc}
\hline & Tempo & VO pré-op & VG pós-op & $\begin{array}{c}\text { p valor } \\
(\mathrm{M}-\mathrm{W})\end{array}$ & $\begin{array}{c}\text { p valor } \\
\text { (ANOVA) }\end{array}$ \\
\hline \multirow{4}{*}{ GLICOSE } & 0 & $125,18 \pm 18,85$ & $103,64 \pm 35,92$ & 0,224 & \\
& 30 & $164 \pm 22,19$ & $117,91 \pm 43,68$ & 0,007 & \\
& 60 & $192,45 \pm 30,93$ & $133,73 \pm 56,67$ & 0,007 & 0,006 \\
& 90 & $198,73 \pm 36,46$ & $142 \pm 63,61$ & 0,018 & \\
& 120 & $190,09 \pm 44,54$ & $140,82 \pm 64,4$ & 0,116 & \\
\hline
\end{tabular}

M-W: Mann-Whitney

Gráfico 1 - Curva da glicemia VO pré-op e VG pós-op

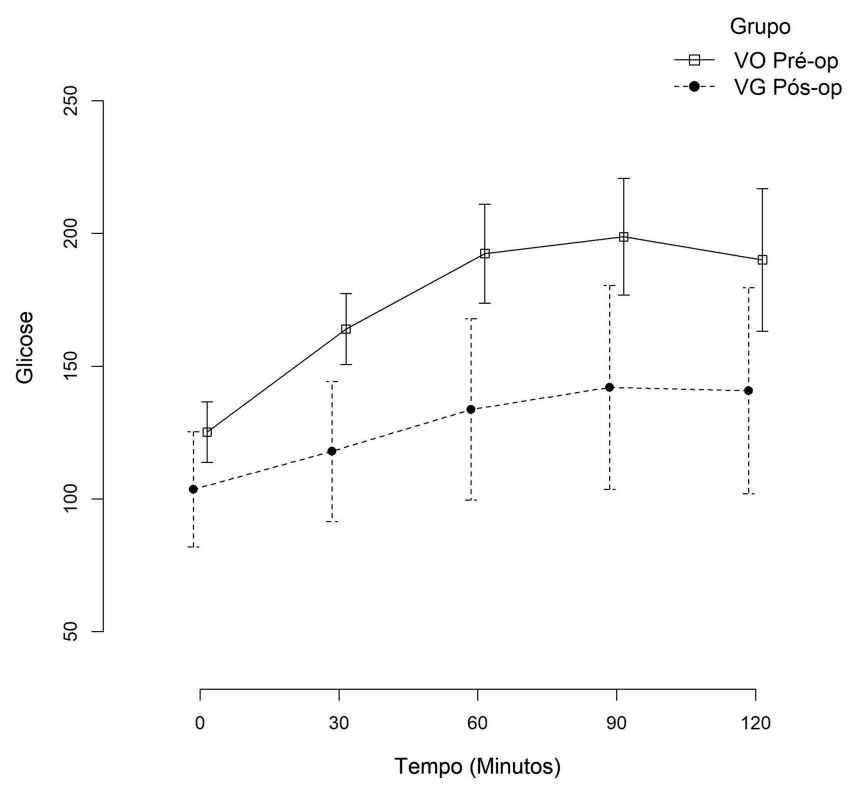


Já na comparação VO pré-op e Via Oral pós-operatória (VO pós-op) evidenciou-se diferença em quase todos os tempos, menos nos tempos de 60 e 90 minutos ( $p>0,05)$. No entanto, na avaliação da curva como um todo e na AUC, observou-se melhora importante na glicemia no pós-operatório pela mesma via de administração $(p<0,05)$ (Tabela 8 , Gráfico 2).

Tabela 8 - Comparação da glicemia entre a administração da soluçãopadrão Via Oral pré-operatória e por Via Oral pós-operatória, por tempo da coleta

\begin{tabular}{cccccc}
\hline & Tempo & VO pré-op & VO pós-op & $\begin{array}{c}\text { p valor } \\
(\mathrm{M}-W)\end{array}$ & $\begin{array}{c}\text { p valor } \\
(\text { ANOVA) }\end{array}$ \\
\hline \multirow{6}{*}{ GLICOSE } & 0 & $125,18 \pm 18,85$ & $94,36 \pm 31,46$ & 0,030 & \\
& 30 & $164 \pm 22,19$ & $147 \pm 36,14$ & 0,199 & \\
& 60 & $192,45 \pm 30,93$ & $169,18 \pm 43,46$ & 0,163 & 0,019 \\
& 90 & $198,73 \pm 36,46$ & $152,82 \pm 43,28$ & 0,014 & \\
& 120 & $190,09 \pm 44,54$ & $139,55 \pm 40,05$ & 0,011 & \\
\hline
\end{tabular}

M-W: Mann-Whitney

Gráfico 2 - Comparação entre as curvas glicêmicas VO pré-op e VO pós-op
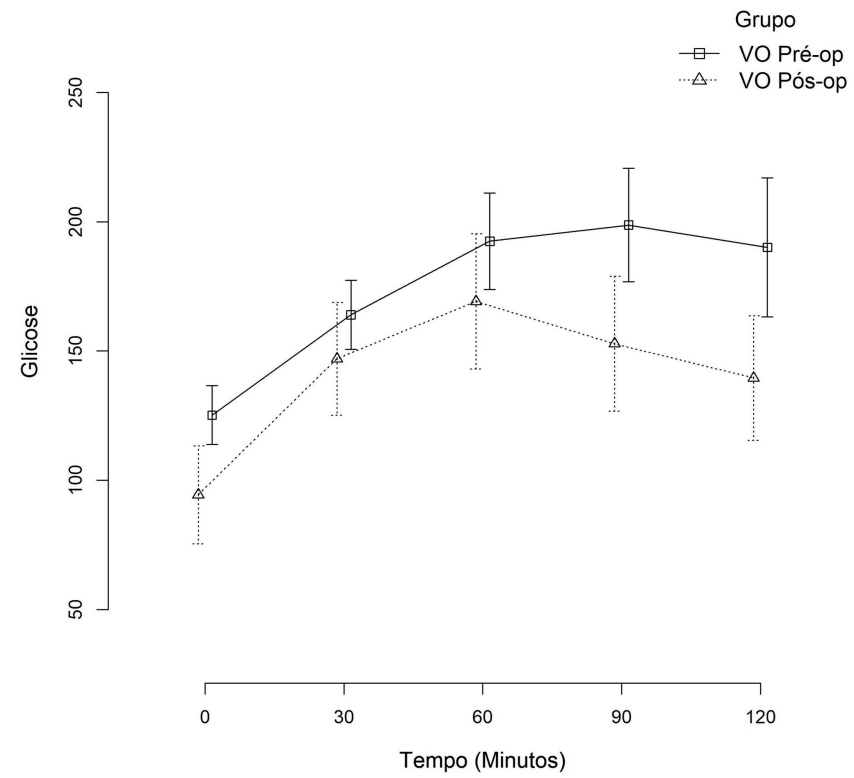
Na comparação da VO pós-op e a VG pós-op, houve diferença estatística na análise grupo:tempo encontrou-se um $p=0,001$, mostrando que, como curva temporal, existe diferença. A curva VO pós-op apresenta um pico maior que a VG pós-op no gráfico (Tabela 9, Gráfico 3).

Tabela 9 - Comparação da glicemia entre administração da solução-padrão por Via Gastrostomia e Via Oral pós-operatória, por tempo de coleta

\begin{tabular}{cccccc}
\hline & Tempo & VG pós-op & VO pós-op & $\begin{array}{c}\text { p valor } \\
(\mathrm{M}-\mathrm{W})\end{array}$ & $\begin{array}{c}\text { p valor } \\
\text { (ANOVA) } \\
\text { grupo:tempo }\end{array}$ \\
\hline \multirow{6}{*}{ GLICOSE } & 0 & $103,64 \pm 35,92$ & $94,36 \pm 31,46$ & 0,646 & \\
& 30 & $117,91 \pm 43,68$ & $147 \pm 36,14$ & 0,104 & \\
& 60 & $133,73 \pm 56,67$ & $169,18 \pm 43,46$ & 0,115 & 0,001 \\
& 90 & $142 \pm 63,61$ & $152,82 \pm 43,28$ & 0,646 & \\
\hline & 120 & $140,82 \pm 64,4$ & $139,55 \pm 40,05$ & 0,767 & \\
\hline
\end{tabular}

M-W: Mann-Whitney

Gráfico 3 - Curva glicêmica entre administração da solução VO pós-op e VG pós-op

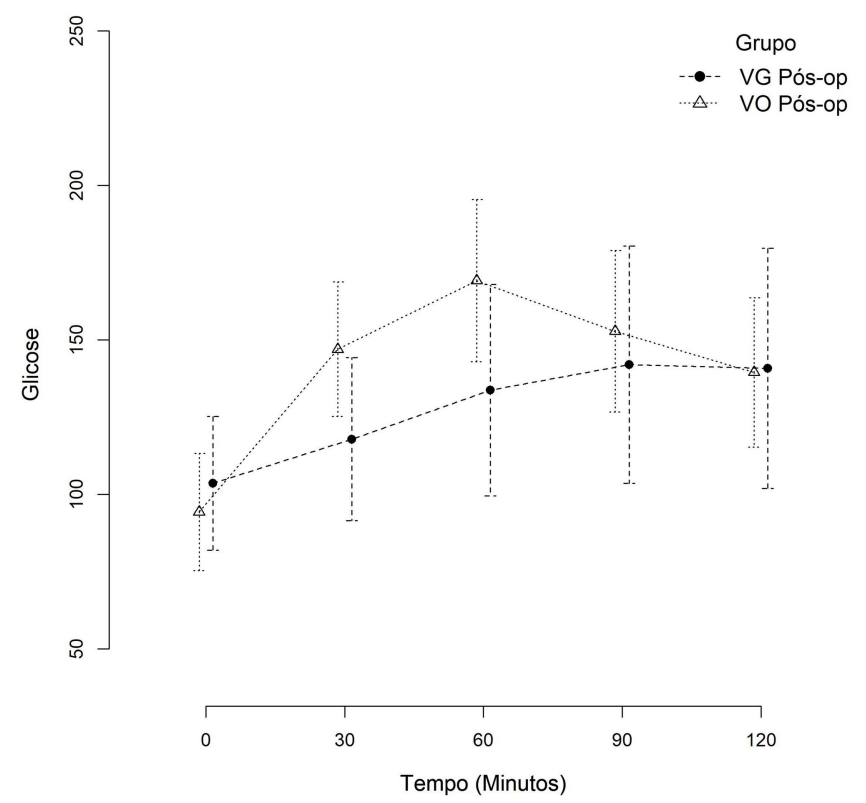




\section{Insulinemia}

$\mathrm{Na}$ comparação da insulinemia durante a administração da soluçãopadrão pela VO pré-op e VG pós-op, encontrou-se diferença entre quase todos os tempos da curva e na AUC ( $p<0,001)$. Percebeu-se que o estímulo da insulina foi muito menor pela VG pós-op (Tabela 10, Gráfico 4).

Tabela 10 - Comparação da insulinemia entre administração da solução Via Oral pré-operatória e por Via Gastrostomia pós-operatória, por tempo de coleta

\begin{tabular}{cccccc}
\hline & Tempo & VO pré-op & VG pós-op & $\begin{array}{c}\text { p valor } \\
(\mathrm{M}-W)\end{array}$ & $\begin{array}{c}\text { p valor } \\
\text { (ANOVA) }\end{array}$ \\
\hline \multirow{4}{*}{ INSULINA } & 0 & $738,77 \pm 351,63$ & $480,12 \pm 324,6$ & 0,088 & \\
& 30 & $1650,67 \pm 868,39$ & $659,01 \pm 406,93$ & 0,004 & \\
& 60 & $1678,69 \pm 1083,3$ & $731,81 \pm 517,38$ & 0,02 & 0,001 \\
& 90 & $1506,49 \pm 1030,83$ & $681,61 \pm 514,23$ & 0,032 & \\
& 120 & $1172,4 \pm 563,54$ & $700,67 \pm 672,08$ & 0,017 & \\
\hline
\end{tabular}

M-W: Mann-Whitney

Gráfico 4 - Comparação entre as curvas de insulinemia VO pré-op e VG pós-op

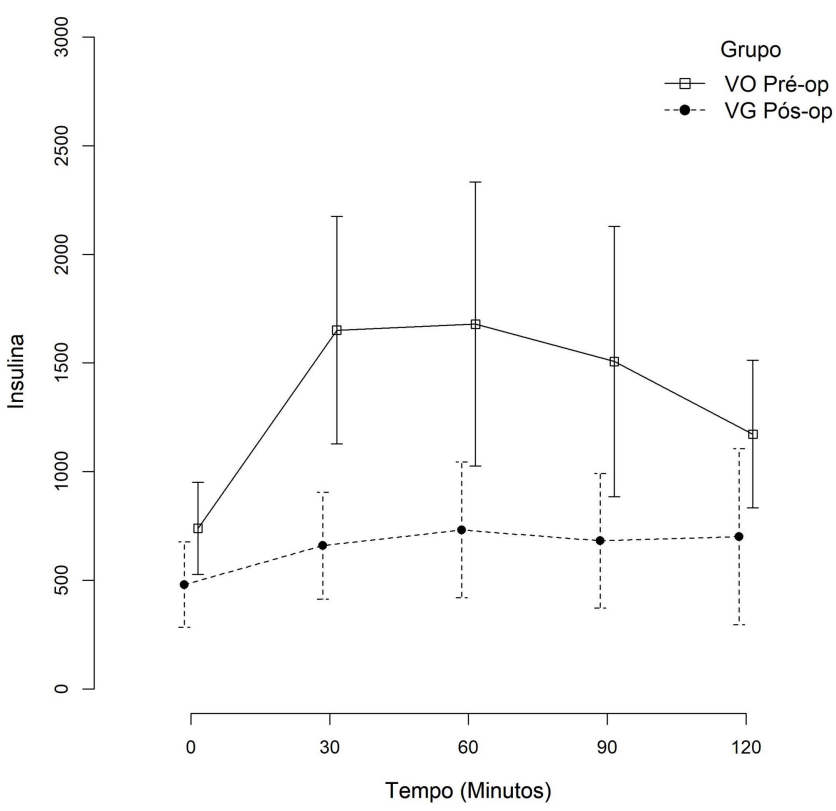


Nas dosagens da insulina VO pré-op e VO pós-op evidenciou-se diferença estatística entre os grupos e AUC $(p=0,042$ e $p=0,001$, respectivamente). As curvas eram distintas, apresentando menor secreção insulinêmica no pós operatório (Tabela 11, Gráfico 5).

Tabela 11 - Comparação da insulinemia entre administração da solução Via Oral pré-operatório e Via Oral pós-operatório, por tempo de coleta

\begin{tabular}{cccccc}
\hline & Tempo & VO pré-op & VO pós-op & $\begin{array}{c}\text { p valor } \\
(\mathrm{M}-\mathrm{W})\end{array}$ & $\begin{array}{c}\text { p valor } \\
\text { (ANOVA) }\end{array}$ \\
\hline \multirow{4}{*}{ INSULINA } & 0 & $738,77 \pm 351,63$ & $531,39 \pm 528,79$ & 0,04 & \\
& 30 & $1650,67 \pm 868,39$ & $988,83 \pm 775,7$ & 0,101 & \\
& 60 & $1678,69 \pm 1083,3$ & $1121,27 \pm 463,04$ & 0,14 & 0,042 \\
& 90 & $1506,49 \pm 1030,83$ & $941,29 \pm 844,74$ & 0,27 & \\
& 120 & $1172,4 \pm 563,54$ & $684,68 \pm 364,58$ & 0,026 & \\
\hline
\end{tabular}

M-W: Mann-Whitney

Gráfico 5 - Comparação da curva de insulina VO pré-op e VO pós-op

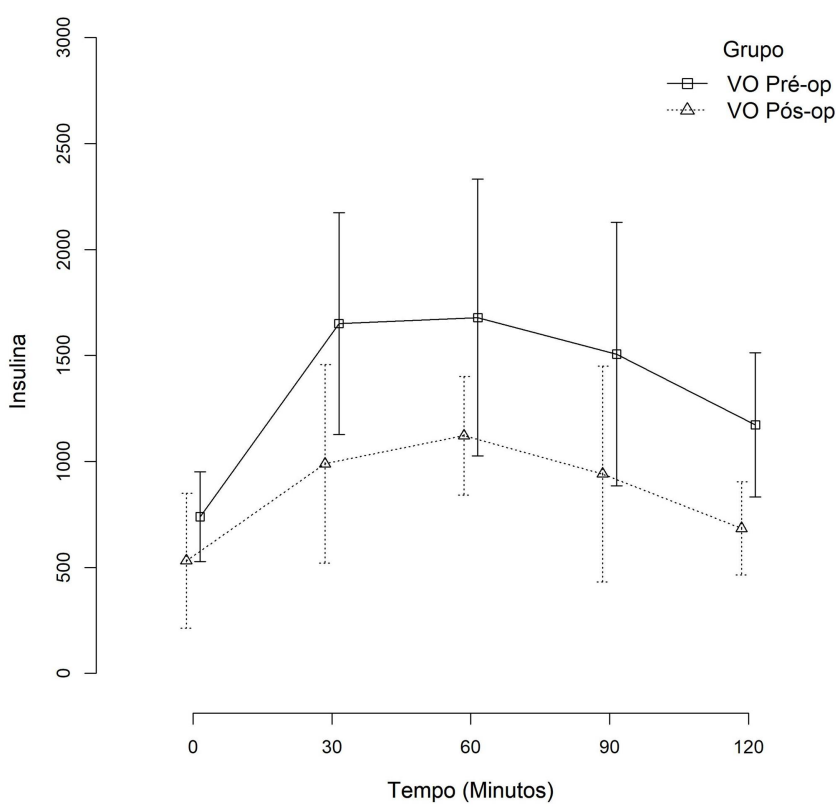


Na comparação do VO pós-op e VG pós-op, não se evidenciou diferença entre os tempos da insulinemia. No entanto, há uma tendência de curva de insulina maior quando administrada por via oral, observada no gráfico (Tabela 12, Gráfico 6).

Tabela 12 - Comparação da insulinemia entre administração da solução por Via Oral pós-operatória e por Via Gastrostomia pós-operatória, por tempo de coleta

\begin{tabular}{cccccc}
\hline & Tempo & VG pós-op & VO pós-op & $\begin{array}{c}\text { p valor } \\
(\mathrm{M}-\mathrm{W})\end{array}$ & $\begin{array}{c}\text { p valor } \\
(\text { ANOVA) }\end{array}$ \\
\hline \multirow{4}{*}{ INSULINA } & 0 & $480,12 \pm 324,6$ & $531,39 \pm 528,79$ & 0,748 & \\
& 30 & $659,01 \pm 406,93$ & $988,83 \pm 775,7$ & 0,3 & \\
& 60 & $731,81 \pm 517,38$ & $1121,27 \pm 463,04$ & 0,078 & 0,252 \\
& 90 & $681,61 \pm 514,23$ & $941,29 \pm 844,74$ & 0,365 & \\
& 120 & $700,67 \pm 672,08$ & $684,68 \pm 364,58$ & 0,438 & \\
\hline
\end{tabular}

M-W: Mann-Whitney

Gráfico 6 - Comparação entre as curvas de insulinemia VG pós-op e VO pós-op

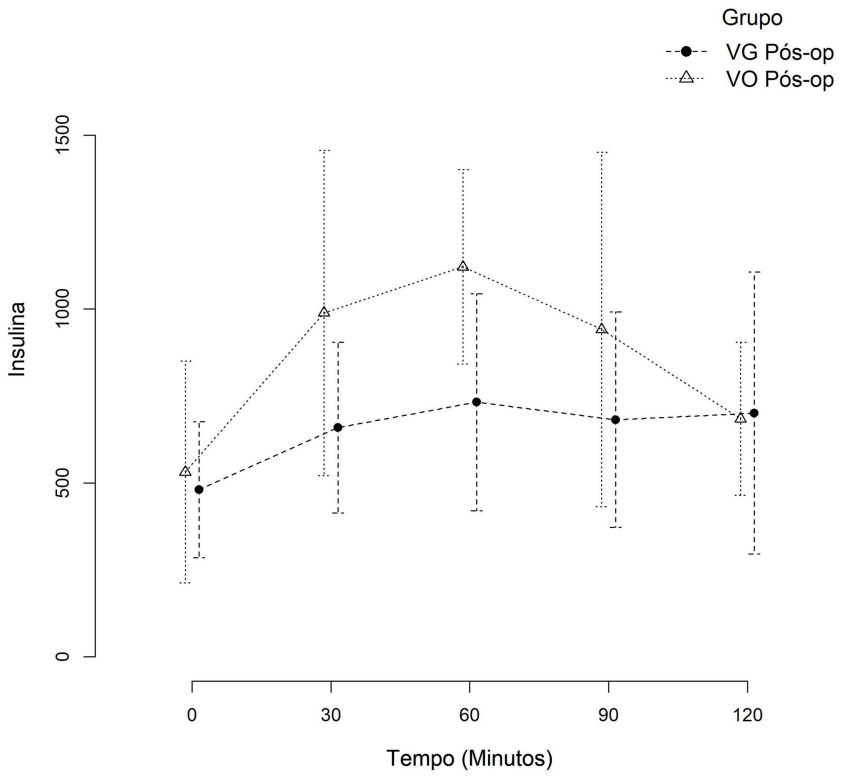




\subsubsection{Secreção de entero-hormônios}

\section{GLP1}

Evidenciou-se que a administração da solução VO pré-op e VG pósop não apresentou diferença na concentração sérica do GLP1 em nenhum dos tempos da curva, mas teve uma leve tendência de aumento na curva na VG pós-op observada no gráfico (Tabela 13, Gráfico 7).

Tabela 13 - Comparação do GLP1 na administração da solução Via Oral pré-operatória e Via Gastrostomia pós-operatória, por tempo de coleta

\begin{tabular}{cccccc}
\hline & Tempo & VO pré-op & VG pós-op & $\begin{array}{c}\text { p valor } \\
\text { (M-W) }\end{array}$ & $\begin{array}{c}\text { p valor } \\
\text { (ANOVA) }\end{array}$ \\
\hline \multirow{4}{*}{ GLP1 } & 0 & $164,88 \pm 98,25$ & $147,84 \pm 94,2$ & 0,682 & \\
& 30 & $164,26 \pm 104,68$ & $227,72 \pm 170,1$ & 0,305 & \\
& 60 & $162,33 \pm 97,89$ & $263,23 \pm 196,88$ & 0,149 & 0,7482 \\
& 90 & $175,99 \pm 102,16$ & $193,49 \pm 116,61$ & 0,712 & \\
& 120 & $174,98 \pm 95,32$ & $171,82 \pm 86,94$ & 0,936 & \\
\hline
\end{tabular}

M-W: Mann-Whitney

Gráfico 7 - Comparação das curvas de GLP1 VO pré-op e VO pós-op

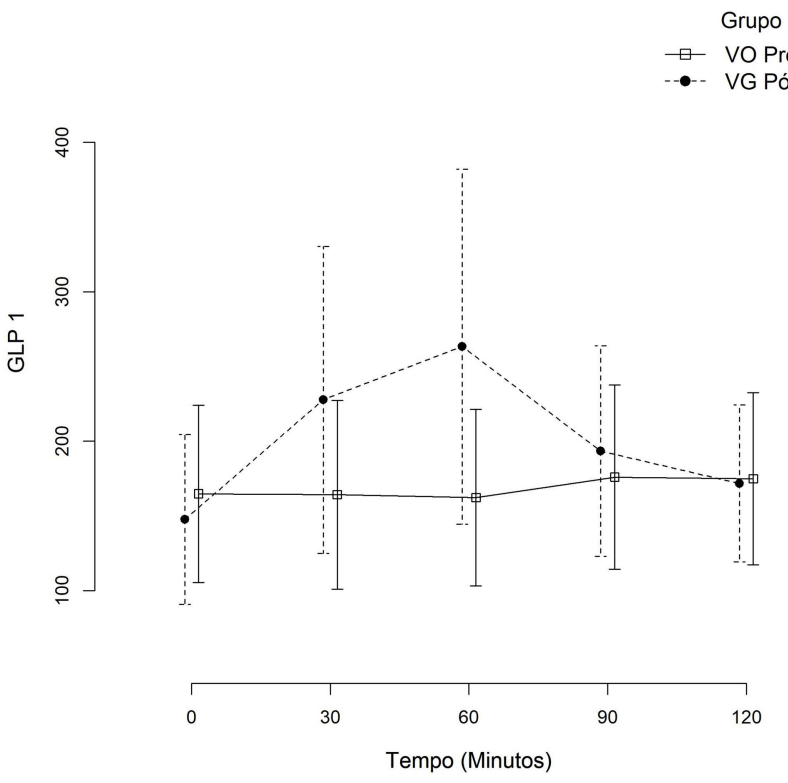


O GLP1 apresentou um comportamento com níveis mais elevados no pico ( $p<0,05$ no tempo 30 e 60), quando o alimento passou pela Via Oral pós-op (via jejunal). Também houve significância no cálculo grupo:tempo $p=0,002(p<0,05)$, mostrando que realmente existe uma diferença na curva. A comparação da AUC também mostrou um $p=0,001$ (Tabela 14, Gráfico 8).

Tabela 14 - Comparação do GLP1 na administração da solução Via Oral pré-operatória e Via Oral pós-operatória, por tempo de coleta

\begin{tabular}{cccccc}
\hline & Tempo & VO pré-op & VO pós-op & $\begin{array}{c}\text { p valor } \\
(\mathrm{M}-\mathrm{W})\end{array}$ & $\begin{array}{c}\text { p valor } \\
\text { (ANOVA) } \\
\text { grupo:tempo }\end{array}$ \\
\hline \multirow{4}{*}{ GLP1 } & 0 & $164,88 \pm 98,25$ & $158,47 \pm 85,42$ & 0,872 & \\
& 30 & $164,26 \pm 104,68$ & $375,61 \pm 276,8$ & 0,034 & \\
& 60 & $162,33 \pm 97,89$ & $38,41 \pm 234,06$ & 0,011 & 0,002 \\
& 90 & $175,99 \pm 102,16$ & $229,09 \pm 119,7$ & 0,276 & \\
\hline & 120 & $174,98 \pm 95,32$ & $219,46 \pm 99,21$ & 0,296 & \\
\hline
\end{tabular}

M-W: Mann-Whitney

Gráfico 8 - Comparação das curvas do GLP1 na administração da solução no pré-operatório e por via oral pós-operatória

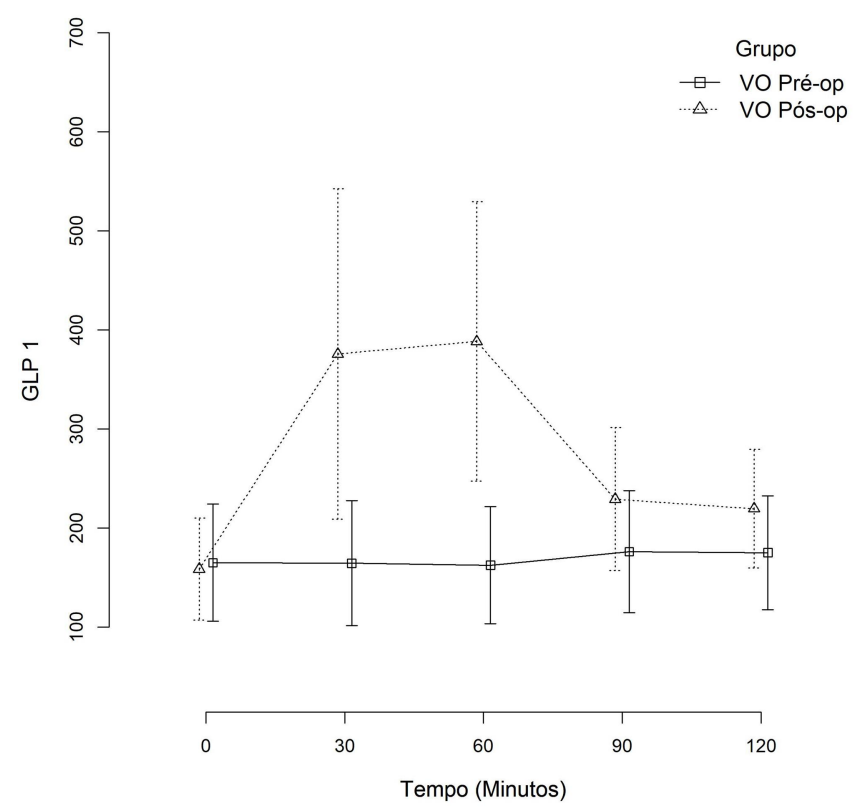


No que concerne à comparação das dosagens de GLP1 entre a VG pós-op e VO pós-op, não foram encontradas diferenças em nenhum dos tempos nem a AUC entre as duas vias de passagem do alimento. Mas, ao se avaliar a curva, observou-se uma curva maior do GLP1 quando o alimento passa pela via jejunal (Tabela 15, Gráfico 9).

Tabela 15 - Comparação do GLP1 na administração da solução por via oral e via gastrostomia no pós-operatório, por tempo de coleta

\begin{tabular}{cccccc}
\hline & Tempo & VG pós-op & VO pós-op & $\begin{array}{c}\text { p valor } \\
(\mathrm{M}-\mathrm{W})\end{array}$ & $\begin{array}{c}\text { p valor } \\
\text { (ANOVA) }\end{array}$ \\
\hline \multirow{4}{*}{ GLP1 } & 0 & $147,84 \pm 94,2$ & $158,47 \pm 85,42$ & 0,784 & \\
& 30 & $227,72 \pm 170,1$ & $375,61 \pm 276,8$ & 0,147 & \\
& 60 & $263,23 \pm 196,88$ & $38,41 \pm 234,06$ & 0,19 & 0,2352 \\
& 90 & $193,49 \pm 116,61$ & $229,09 \pm 119,7$ & 0,488 & \\
& 120 & $171,82 \pm 86,94$ & $219,46 \pm 99,21$ & 0,245 & \\
\hline
\end{tabular}

M-W: Mann-Whitney

Gráfico 9 - Comparação das curvas de GLP1 na administração da solução por via oral e via gastrostomia no pós-operatório

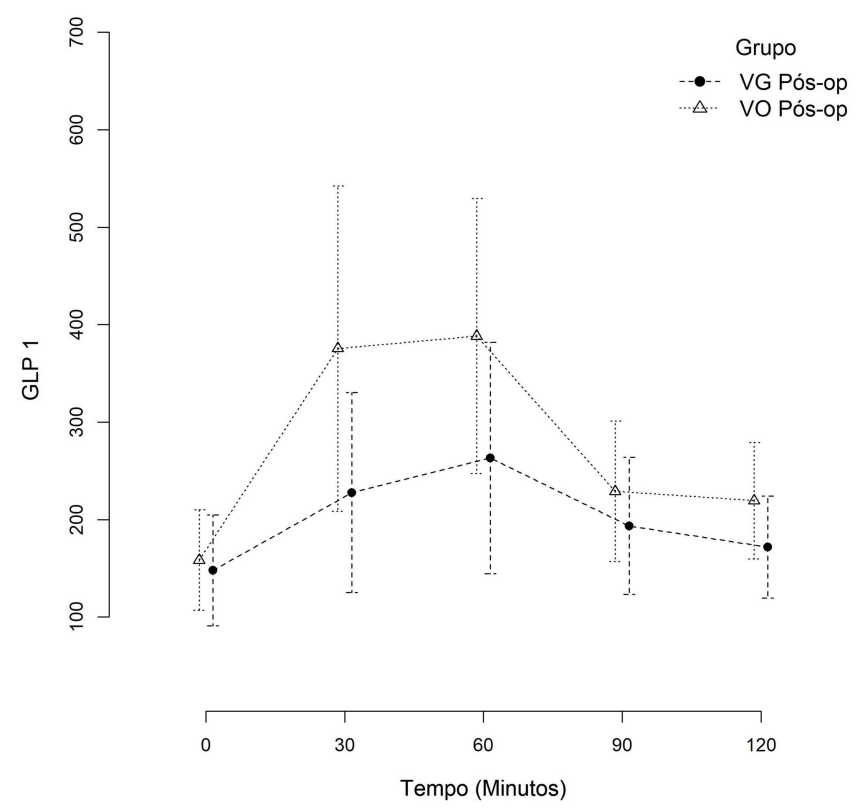


GIP

O GIP mostrou-se diferente no tempo 30 minutos com $p=0,028$, não apresentando pico na Via Gastrostomia pós-operatória. No entanto, no cálculo da $A \cup C$ observou-se significância com $p=0,009$. Com isso, notou-se uma queda do GIP com a solução, passando pela mesma via duodenal no pós-operatório da GDYR (Tabela 16, Gráfico 10).

Tabela 16 - Comparação do GIP na administração da solução Via Oral préoperatória e Via Gastrostomia pós-operatória, por tempo de coleta

\begin{tabular}{cccccc}
\hline & Tempo & VO pré-op & VG pós-op & $\begin{array}{c}\text { p valor } \\
\text { (M-W) }\end{array}$ & $\begin{array}{c}\text { p valor } \\
\text { (ANOVA) }\end{array}$ \\
\hline \multirow{4}{*}{ GIP } & 0 & $177,97 \pm 100,82$ & $115,85 \pm 61,42$ & 0,065 & \\
& 30 & $559,29 \pm 272,49$ & $305,65 \pm 206,1$ & 0,028 & \\
& 60 & $578,42 \pm 249,53$ & $472,59 \pm 206,69$ & 0,292 & 0,076 \\
& 90 & $509,7 \pm 260,36$ & $448,34 \pm 244,72$ & 0,575 & \\
& 120 & $474,99 \pm 285,98$ & $365,08 \pm 225,67$ & 0,243 & \\
\hline
\end{tabular}

M-W: Mann-Whitney

Gráfico 10 - Comparação das curvas de GIP VO pré-op e VG pós-op

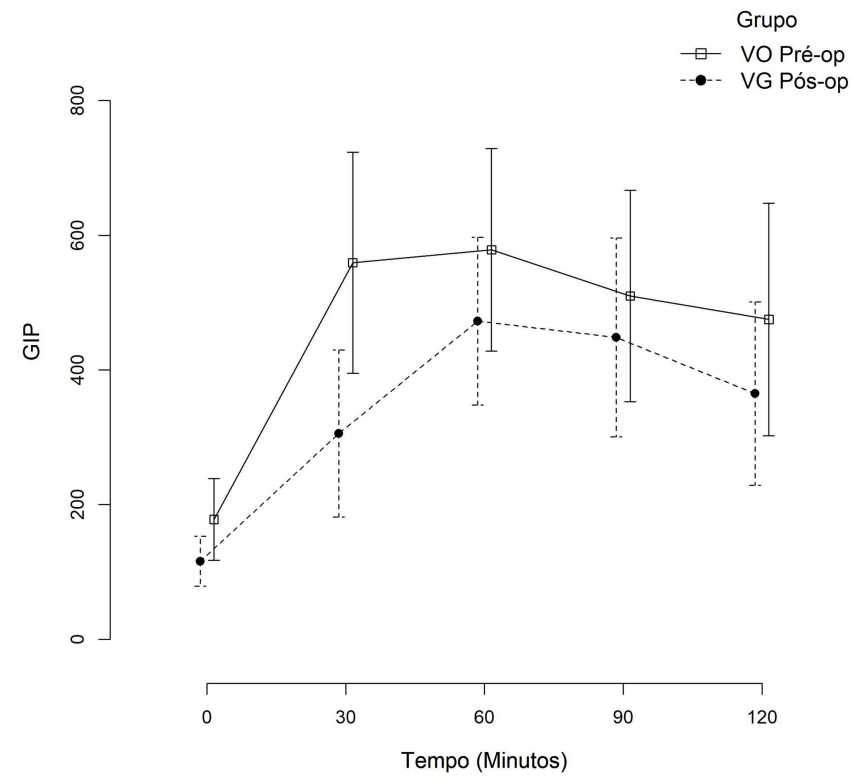


Comparando as dosagens de GIP no pré e pós operatório Via Oral, foi encontrada diferença como grupos e na AUC, com queda importante desse hormônio no pós-operatório (Tabela 17, Gráfico 11).

Tabela 17 - Comparação do GIP na administração da solução no pré e por via oral pós-operatória, por tempo de coleta

\begin{tabular}{cccccc}
\hline & Tempo & VO pré-op & VO pós-op & $\begin{array}{c}\text { p valor } \\
(\mathrm{M}-W)\end{array}$ & $\begin{array}{c}\text { p valor } \\
(\text { ANOVA) }\end{array}$ \\
\hline \multirow{4}{*}{ GIP } & 0 & $177,97 \pm 100,82$ & $135,86 \pm 93,05$ & 0,115 & \\
& 30 & $559,29 \pm 272,49$ & $482,21 \pm 317,62$ & 0,519 & \\
& 60 & $578,42 \pm 249,53$ & $432,98 \pm 171,02$ & 0,127 & 0,046 \\
& 90 & $509,7 \pm 260,36$ & $326,86 \pm 94,83$ & 0,048 & \\
& 120 & $474,99 \pm 285,98$ & $270,78 \pm 119,77$ & 0,01 & \\
\hline
\end{tabular}

M-W: Mann-Whitney

Gráfico 11 - Comparação das curvas do GIP VO pré-op e VO pós-op

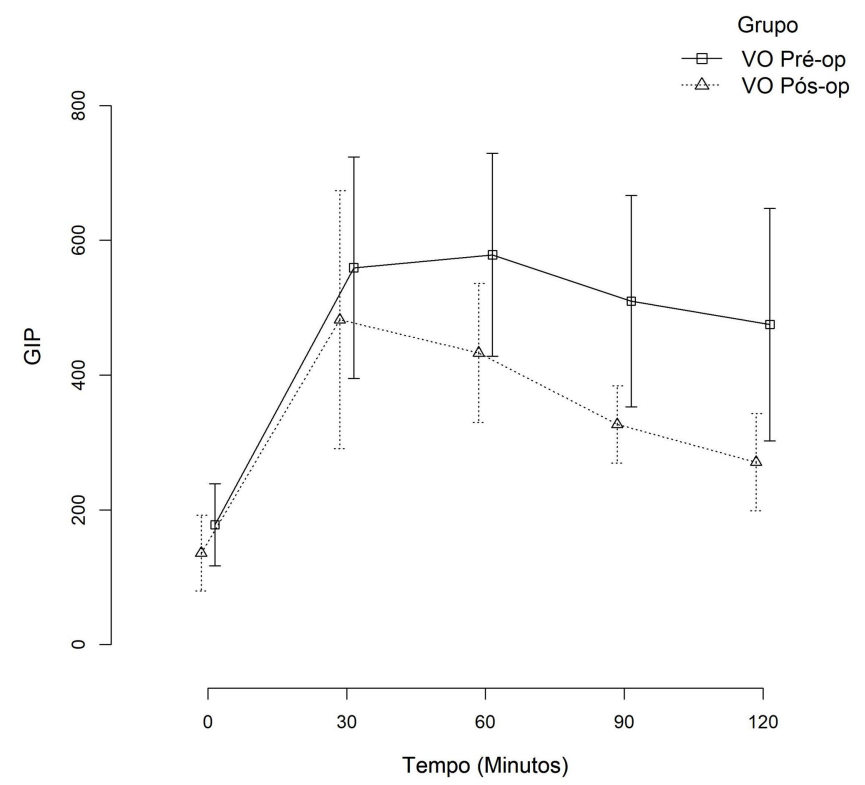


Na análise dos dados da administração da solução VG pós-op e VO pós-op não foi observada diferença entre os tempos estudados. Nesta etapa pós-operatória, não ficou evidente o estímulo à secreção do GIP pela passagem do alimento na via duodenal (Tabela 18, Gráfico 12).

Tabela 18 - Comparação do GIP na administração da solução Via Oral e Via Gastrostomia no pós-operatório, por tempo de coleta

\begin{tabular}{cccccc}
\hline & Tempo & VG pós-op & VO pós-op & $\begin{array}{c}\text { p valor } \\
(\mathrm{M}-\mathrm{W})\end{array}$ & $\begin{array}{c}\text { p valor } \\
\text { (ANOVA) }\end{array}$ \\
\hline \multirow{4}{*}{ GIP } & 0 & $115,85 \pm 61,42$ & $135,86 \pm 93,05$ & 0,365 & \\
& 30 & $305,65 \pm 206,1$ & $482,21 \pm 317,62$ & 0,101 & \\
& 60 & $472,59 \pm 206,69$ & $432,98 \pm 171,02$ & 0,63 & 0,969 \\
& 90 & $448,34 \pm 244,72$ & $326,86 \pm 94,83$ & 0,149 & \\
& 120 & $365,08 \pm 225,67$ & $270,78 \pm 119,77$ & 0,332 & \\
\hline
\end{tabular}

M-W: Mann-Whitney

Gráfico 12 - Comparação das curvas de GIP na administração da solução por via oral e via gastrostomia no pós-operatório

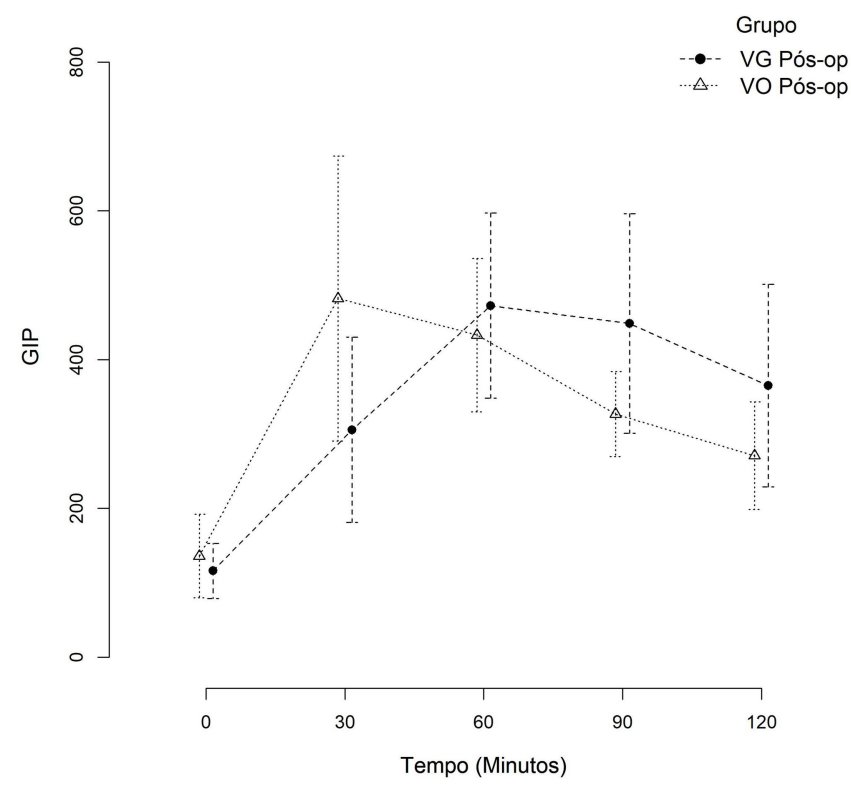




\section{Grelina}

Ao se comparar a dosagem sérica de grelina VO pré-op com o VG pós-op, não foi encontrada diferença estatística como grupo ou na AUC. A curva mostra uma média, aparentemente, mais baixa na VG pós-op ao se observar o gráfico (Tabela 19, Gráfico 13).

Tabela 19 - Comparação da Grelina na administração da solução Via Oral pré-operatória e Via Gastrostomia no pós-operatório, por tempo de coleta

\begin{tabular}{cccccc}
\hline & Tempo & VO pré-op & VG pós-op & $\begin{array}{c}\text { p valor } \\
(\mathrm{M}-W)\end{array}$ & $\begin{array}{c}\text { p valor } \\
(\text { ANOVA) }\end{array}$ \\
\hline \multirow{6}{*}{ Grelina } & 0 & $834 \pm 417,62$ & $734,31 \pm 289,95$ & 0,898 & \\
& 30 & $880,72 \pm 491,36$ & $738,59 \pm 289,75$ & 0,418 & \\
& 60 & $864,76 \pm 455,56$ & $733,8 \pm 275,35$ & 0,424 & 0,544 \\
& 90 & $852,62 \pm 487,73$ & $734,17 \pm 291,37$ & 0,53 & \\
& 120 & $892,35 \pm 397,64$ & $682,2 \pm 340,75$ & 0,198 & \\
\hline
\end{tabular}

M-W: Mann-Whitney

Gráfico 13 - Comparação das curvas de Grelina VO pré-op e VG pós-op

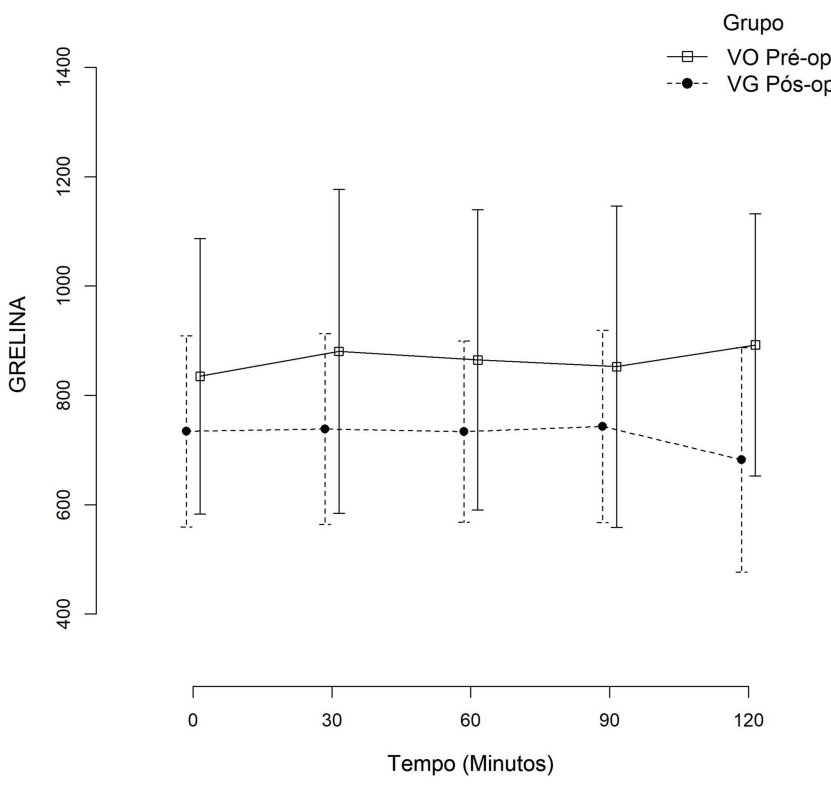


Comparando a VO pré-op com a VO pós-op (via jejunal), não foi encontrada diferença estatística como grupo nem AUC ( $p>0,05)$. Quando se olha o gráfico, observa-se uma tendência de queda da Grelina pela VO pósop (Tabela 20, Gráfico 14).

Tabela 20 - Comparação da Grelina na administração da solução Via Oral pré-operatória e Via Oral pós-operatória, por tempo de coleta

\begin{tabular}{cccccc}
\hline & Tempo & VO pré-op & VO pós-op & $\begin{array}{c}\text { p valor } \\
\text { (M-W) }\end{array}$ & $\begin{array}{c}\text { p valor } \\
\text { (ANOVA) }\end{array}$ \\
\hline \multirow{6}{*}{ Grelina } & 0 & $834 \pm 417,62$ & $745,53 \pm 251,47$ & 0,652 & \\
& 30 & $880,72 \pm 491,36$ & $796,49 \pm 285,95$ & 0,628 & \\
& 60 & $864,76 \pm 455,56$ & $778,94 \pm 309,39$ & 0,611 & 0,667 \\
& 90 & $852,62 \pm 487,73$ & $773,74 \pm 299,53$ & 0,653 & \\
& 120 & $892,35 \pm 397,64$ & $754,56 \pm 251,56$ & 0,343 & \\
\hline
\end{tabular}

M-W: Mann-Whitney

Gráfico 14 - Comparação das curvas de Grelina VO pré-op e VO pós-op

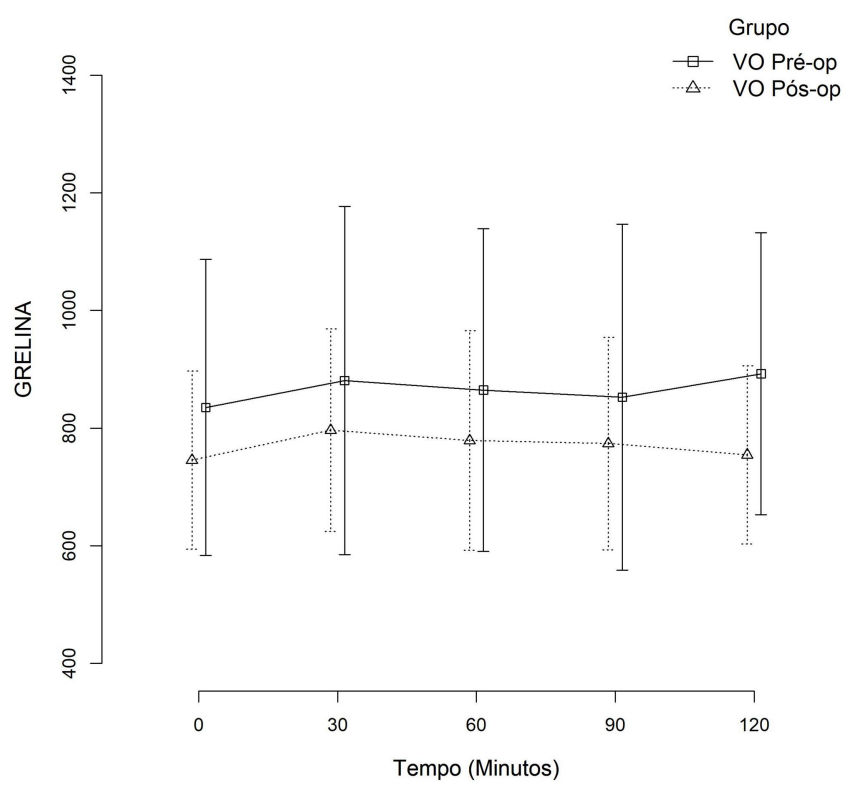


No pós-operatório, também não foi observada diferença estatística entre VG pós-op e a VO pós-op (duodenal $x$ jejunal) $(p>0,05)$ em nenhum tipo de análise estatística (Tabela 21, Gráfico 15).

Tabela 21 - Comparação da Grelina na administração da solução por via oral e via gastrostomia no pós-operatório, por tempo de coleta

\begin{tabular}{cccccc}
\hline & Tempo & VG pós-op & VO pós-op & $\begin{array}{c}\text { p valor } \\
\text { (M-W) }\end{array}$ & $\begin{array}{c}\text { p valor } \\
\text { (ANOVA) }\end{array}$ \\
\hline \multirow{6}{*}{ Grelina } & 0 & $734,31 \pm 289,95$ & $745,53 \pm 251,47$ & 0,924 & \\
& 30 & $738,59 \pm 289,75$ & $796,49 \pm 285,95$ & 0,642 & \\
& 60 & $733,8 \pm 275,35$ & $778,94 \pm 309,39$ & 0,722 & 0,753 \\
& 90 & $734,17 \pm 291,37$ & $773,74 \pm 299,53$ & 0,811 & \\
& 120 & $682,2 \pm 340,75$ & $754,56 \pm 251,56$ & 0,577 & \\
\hline
\end{tabular}

M-W: Mann-Whitney

Gráfico 15 - Comparação das curvas de Grelina VG pós-op e VO pós-op

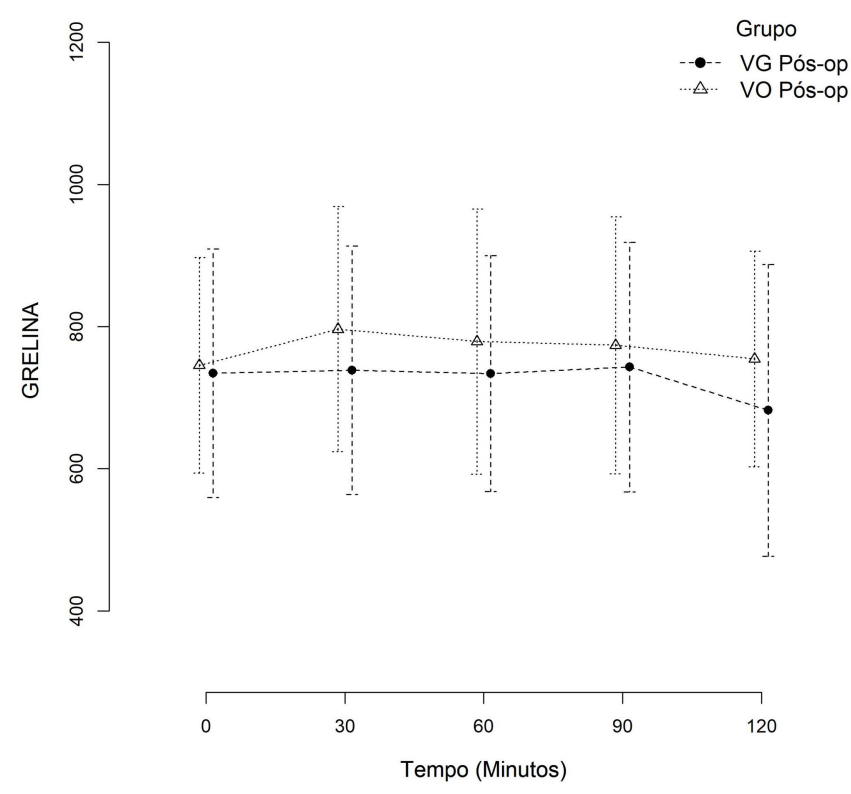




\subsubsection{Teste de tolerância oral à glicose - TTOG}

Para comparação de estímulo glicêmico, foi realizado TTOG no pré e pós-operatório por via oral. Observou-se diferença entre quase todos os tempos da curva com evidente melhora dos padrões de glicemia no pósoperatório (Tabela 22, Gráfico 16).

Tabela 22 - Comparação da glicemia por TTOG na administração da solução por Via Oral pré-operatória e Via Oral pós-operatória por tempo da coleta

\begin{tabular}{cccccc}
\hline & Tempo & VO pré-op & VO pós-op & $\begin{array}{c}\text { p valor } \\
(\mathrm{M}-\mathrm{W})\end{array}$ & $\begin{array}{c}\text { p valor } \\
\text { (ANOVA) }\end{array}$ \\
\hline \multirow{6}{*}{ GLICOSE } & 0 & $126,11 \pm 24,84$ & $89,22 \pm 19,56$ & 0,006 & \\
& 30 & $187,67 \pm 32,09$ & $141,44 \pm 20,43$ & 0,002 & \\
& 60 & $227 \pm 34,92$ & $194,22 \pm 53,54$ & 0,144 & \multirow{2}{*}{0,007} \\
& 90 & $240,89 \pm 42,19$ & $196,89 \pm 59,57$ & 0,089 & \\
& 120 & $242,33 \pm 67,84$ & $181,78 \pm 56,04$ & 0,056 & \\
\hline
\end{tabular}

M-W: Mann-Whitney

Gráfico 16 - Comparação entre curvas de glicemia do TTOG VO pré-op e VO pós-op

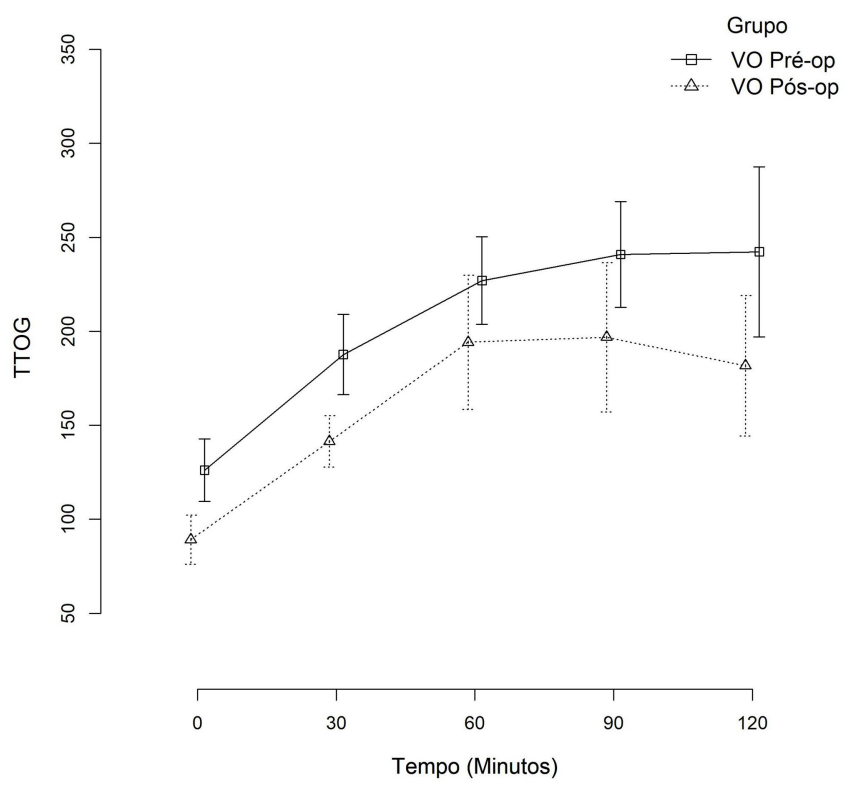




\subsubsection{HOMA-IR e HOMA-BETA}

O cálculo da resistência insulínica realizado pelo HOMA-IR mostrou uma diminuição significativa com $p<0,05$, comparando o pré-operatório com a Via Gastrostomia e a Via Oral pós-operatória, mas ao se comparar no pósoperatório a Via Gastrostomia e Via Oral não foi observada essa diferença. Observou-se também uma tendência de melhora do HOMA-BETA, sobretudo, na via oral, embora não tenha significância estatística (Tabela 23, Gráfico 17).

Tabela 23 - Comparação entre HOMA-IR e HOMA-BETA no pré-operatório, Via Gastrostomia pós-operatória e Via Oral pós-operatória

\begin{tabular}{lcccc}
\hline & VO pré-op & VG pós-op & VO pós-op & $\begin{array}{c}\text { p valor } \\
\text { (ANOVA) }\end{array}$ \\
\hline HOMA-IR & $8,29 \pm 3,38$ & $4,9 \pm 4,13$ & $4,82 \pm 4,85$ & $\begin{array}{c}p<0,05 \\
\text { (Vo pré-op XVG pós-op) } \\
\text { (Vo pré-op X vo pós-op) }\end{array}$ \\
\hline HOMA-BETA & $246,13 \pm 271,43$ & $687,29 \pm 1547,56$ & $839,85 \pm 1349,04$ & $p>0,05$ \\
\hline
\end{tabular}

Gráfico 17 - Comparação entre HOMA-IR e HOMA-BETA no VO pré-op, VG pós-op e VO pós-op
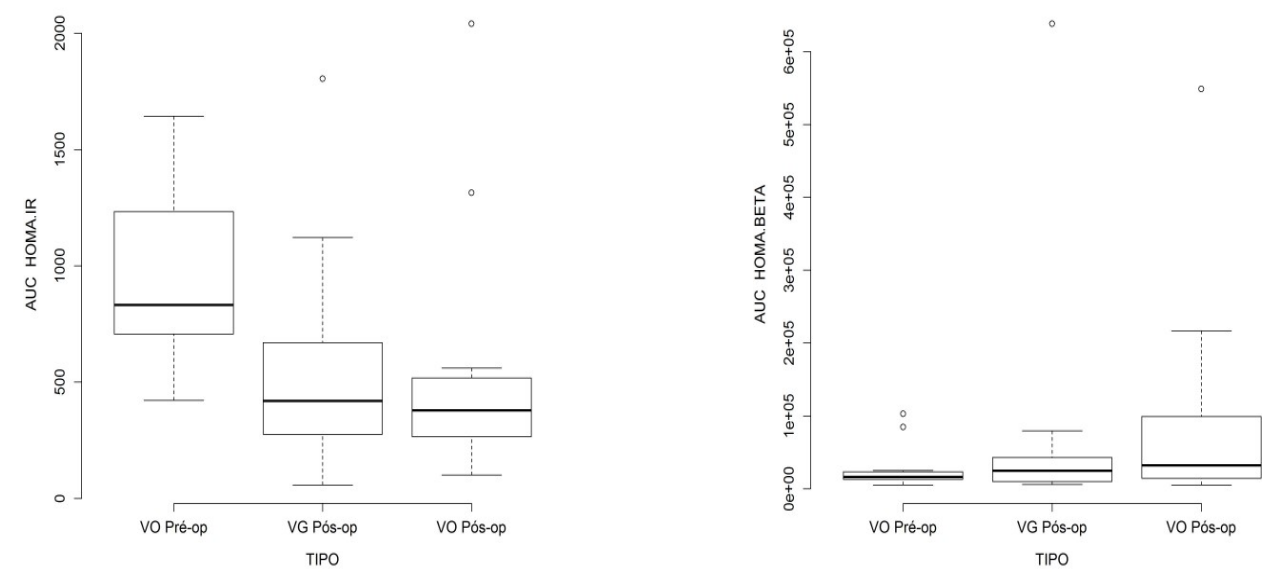
4.1.5 Comparações do perfil glicêmico e insulinêmico, secreção de entero-hormônios e TTOG entre os três tempos de avaliação

\section{Perfil glicêmico e insulinêmico e secreção de entero-hormônios entre via oral pré-operatória $x$ via gastrostomia pós-operatória}

$\mathrm{Na}$ análise das curvas de glicemia e insulinemia, observou-se que na mesma via de passagem do alimento no pós-operatório precoce (via duodenal) já acontece controle nos níveis glicêmicos, mesmo sem pico insulinêmico. Nota-se também que essa melhora glicêmica não tem relação com o aumento dos níveis de GLP1. Ocorre uma queda dos níveis de GIP mesmo com a passagem da solução pelo duodeno e a Grelina não tem alteração no pós-operatório (Gráfico 18).

Gráfico 18 - Curvas da Glicose, Insulina, GLP1, GIP e Grelina na comparação VO pré-op e VG pós-op
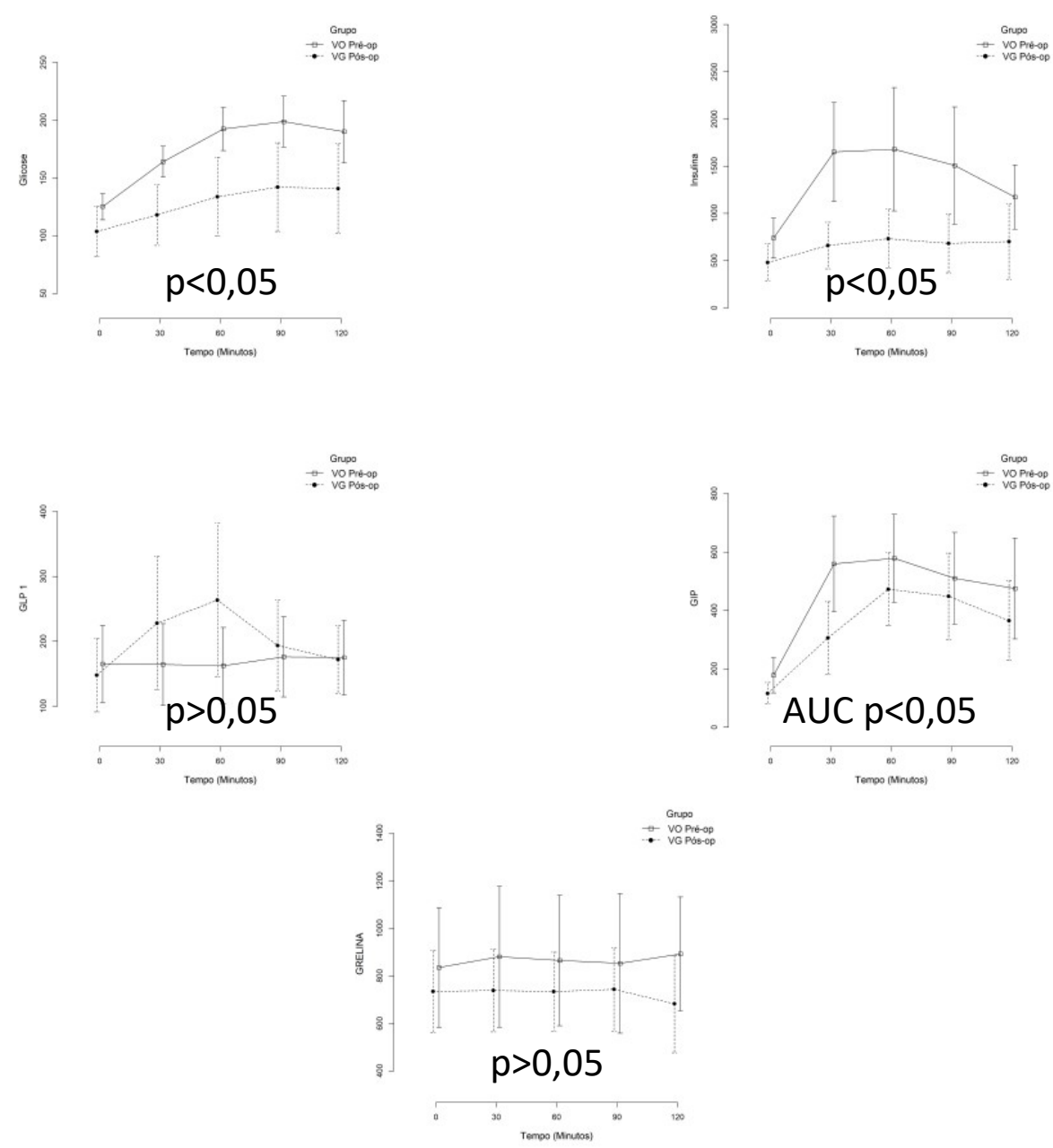
Perfil glicêmico e insulinêmico, secreção de entero-hormônios e TTOG entre Via Oral pré-operatória X Via Oral pós-operatória

Observou-se o mesmo efeito de melhora glicêmica e menor estímulo insulinêmico no pós operatório por diferentes vias de passagem do alimento (duodenal x jejunal) $(p<0,05)$. Quanto às incretinas, observou-se um decréscimo da curva de GIP com significância estatística $(p<0,05)$. A curva do GLP1 mostrou uma significância estatística nos tempos 30 e 60 minutos da curva e da AUC $(p<0,05)$, quando a solução foi administrada pela VO pós-op, evidenciando retorno do efeito incretínico. O TTOG apresentou normalização de sua curva na VO pós-op (Gráfico 19).

Gráfico 19 - Curvas da Glicose, Insulina, GLP1 , GIP, Grelina e TTOG na comparação VO pré-op e VO pós-op
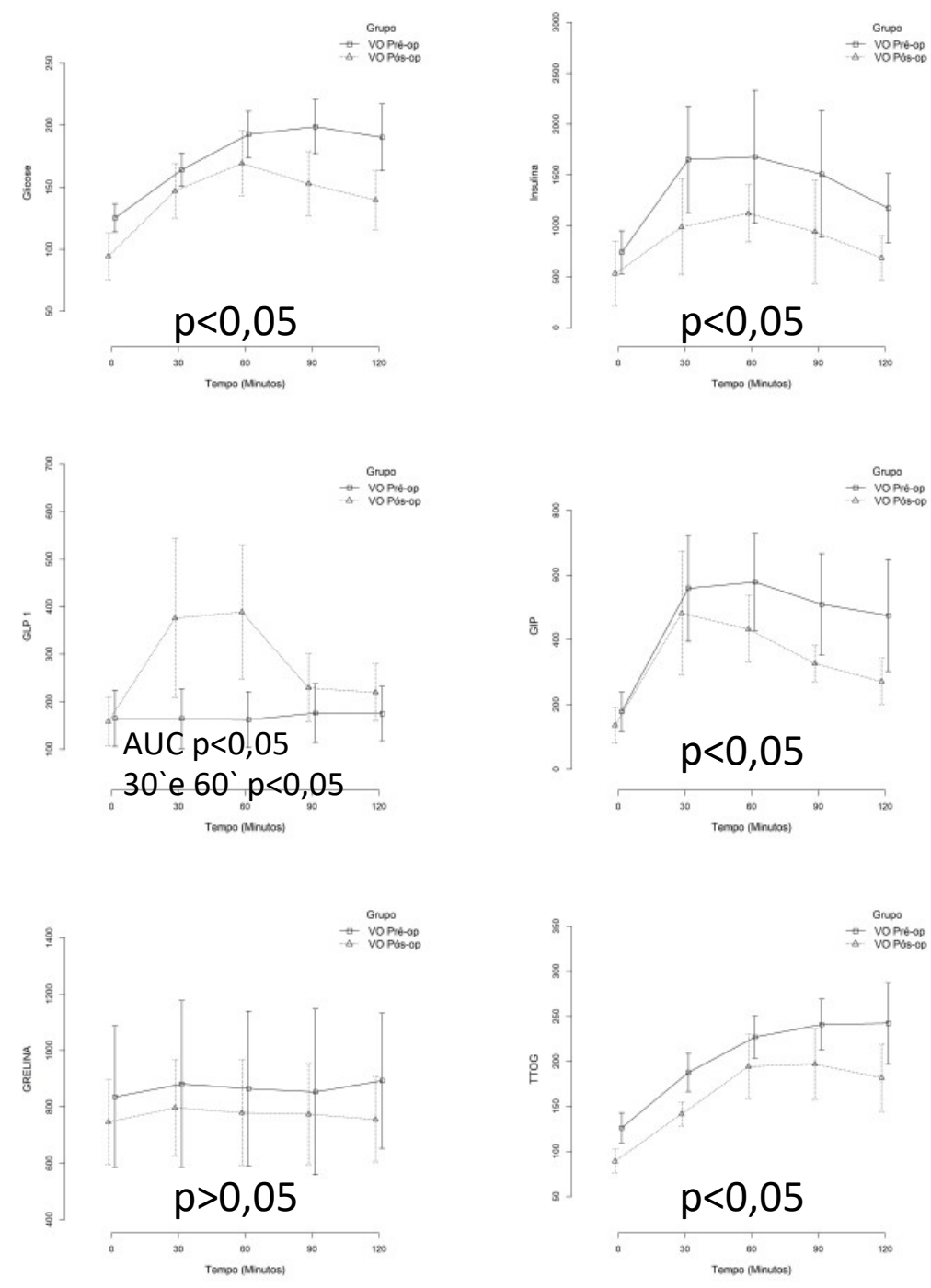
Perfil glicêmico e insulinêmico e secreção de entero-hormônios entre Via Gastrostomia pós-operatória X Via Oral pós operatória

No pós-operatório da GDYR, houve diferença na curva glicêmica entre as diferentes vias de passagem da solução-padrão (grupo:tempo $p=0,001)$ mostrando um menor pico na Via Gastrostomia (Gráfico 20). Não houve diferença nas secreções das incretinas $(p>0,05)$.

Gráfico 20 - Curvas da Glicose, Insulina, GLP1, GIP e Grelina na comparação VG pós-op e VO pós-op
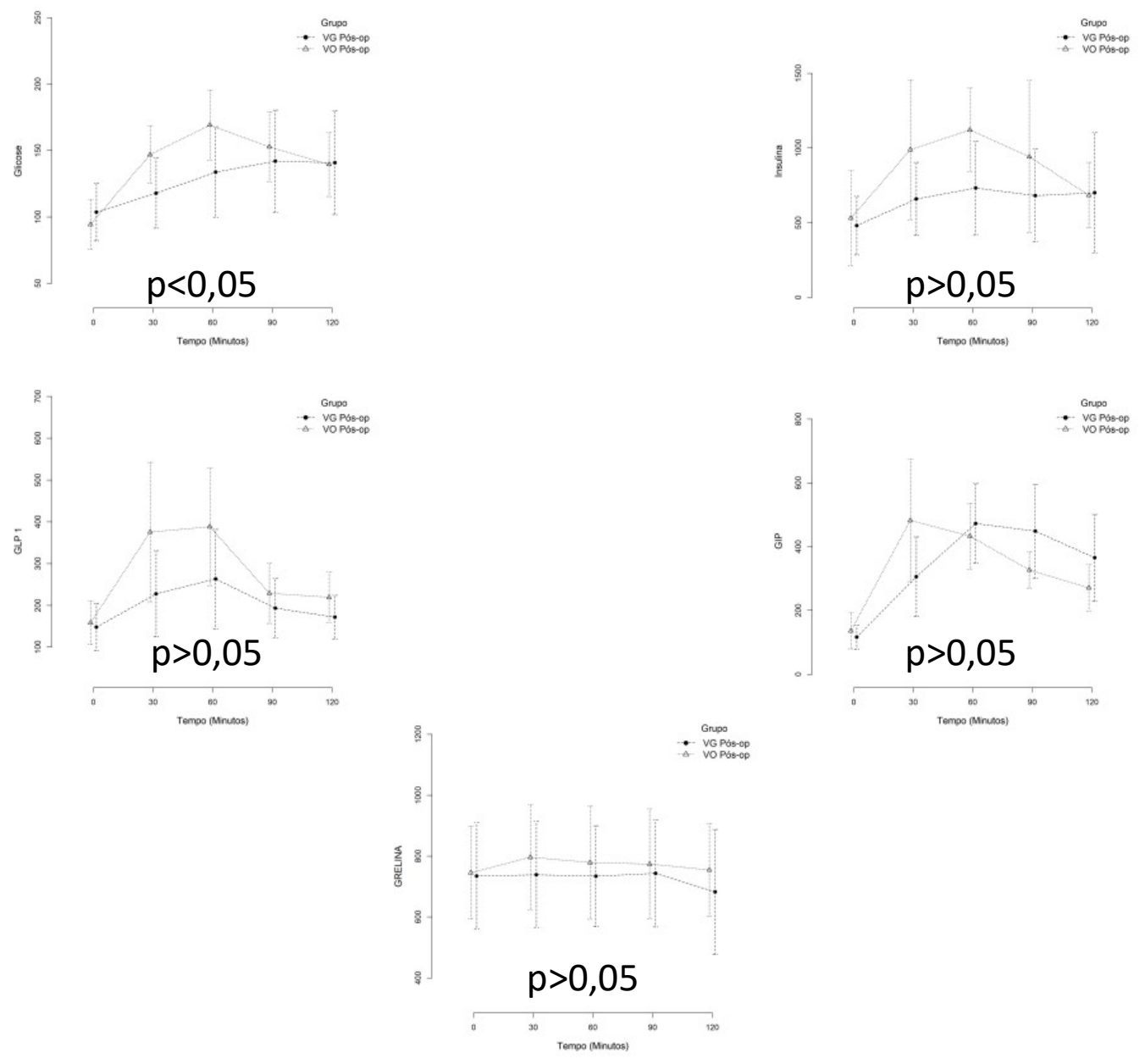
Perfil glicêmico e insulinêmico, secreção de enterohormônios e TTOG entre VO pré-op X VG pós-op X VO pós-op (Gráfico 21)

Ao se observar as três curvas, concomitantemente, pode-se perceber:

- melhora pós-operatória significativa da glicemia com queda da insulinemia, em ambas vias administradas (Via Oral pós-operatória e Via Gastrostomia pós-operatória). Na Via Gastrostomia, a redução foi maior quando comparada à Via Oral pós-operatória.

- quando comparada ao pré-operatório, houve elevação significante de GLP1 após a GDYR na Via Oral pós-operatória, embora não tenha sido observada diferença significante pela Via Gastrostomia. No pós-operatório entre a Via Oral e a Via Gastrostomia, não foi observada essa diferença.

- quando comparada ao pré-operatório, houve redução significante de GIP após a GDYR na Via Oral pós-operatória, embora não tenha sido observada diferença significante pela Via Gastrostomia. No pós-operatório entre a Via Oral e a Via Gastrostomia, não foi observada essa diferença.

- em relação à Grelina, embora tenha sido observada uma redução em números absolutos não houve diferença estatística na comparação entre os pré e pós-operatórios e também entre as vias oral e gastrostomia pós-operatória.

- ocorreu melhora significativa do TTOG após a cirurgia, onde os valores praticamente normalizaram na comparação da Via Oral pré- e Via Oral pós-operatórias. 
Gráfico 21 - Curvas da Glicose, Insulina, TTOG, GLP1, GIP e Grelina na comparação VO pré-op, VG pós-op e VO pós-op

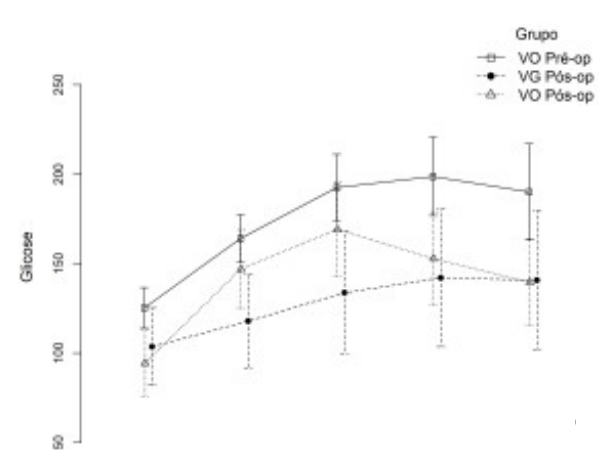

VG pós-op X VQ pós-op - p<0,05
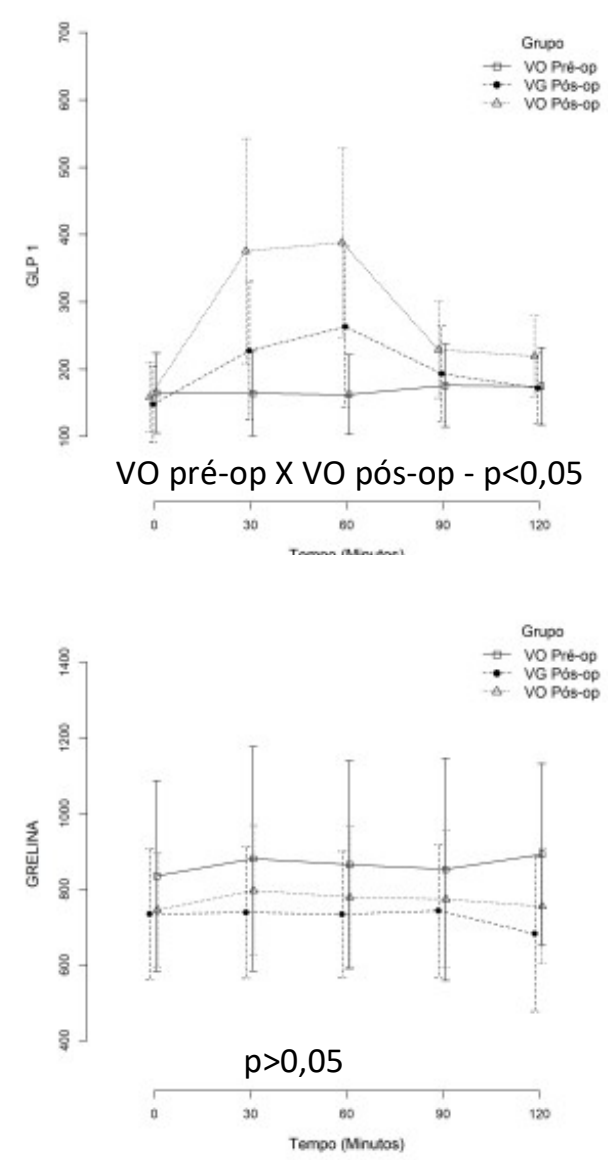

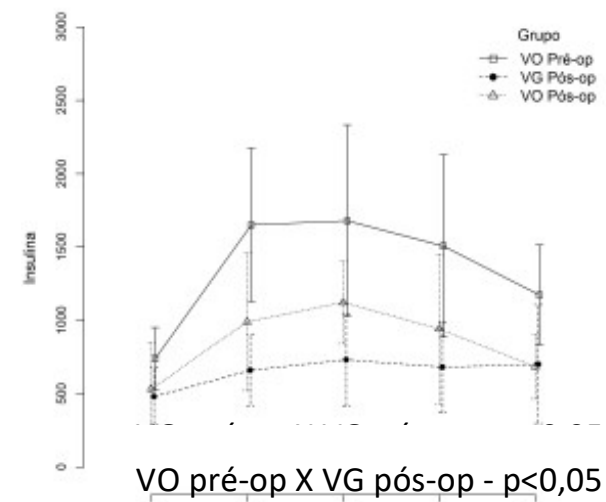

VO pré-op X VG pós-op - $p<0,05$
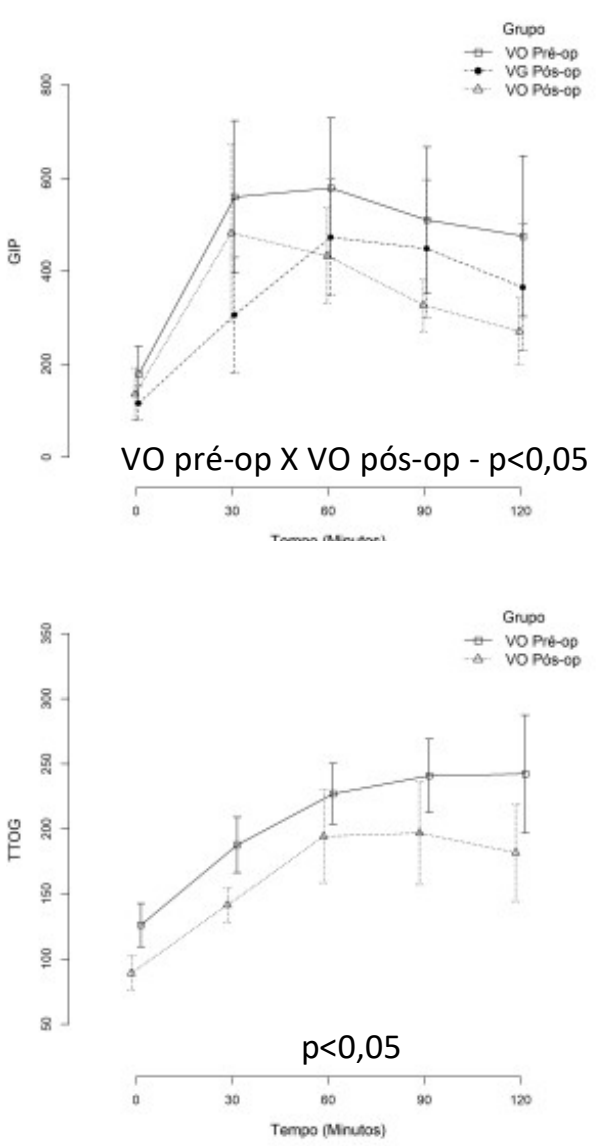
5 DISCUSSÃO 


\section{DISCUSSÃO}

\subsection{Aspectos Gerais}

O DM2 é um grupo heterogêneo e complexo de condições metabólicas caracterizado pelo aumento dos níveis séricos de glicose em razão de um prejuízo na secreção de insulina, aumento da resistência e seus efeitos e atenuação do efeito incretínico.

A obesidade associada ao DM2 está relacionada à resistência insulínica e às células beta serem incapazes de compensar a diminuição da sensibilidade insulínica ${ }^{(69)}$. A disfunção da célula beta existe em indivíduos com alto risco de desenvolver o DM2, mesmo quando seus níveis de glicose ainda permanecem normais, sugerindo que essa disfunção é crucial na fisiopatologia da doença ${ }^{(69)}$.

\subsection{Remissão do DM2 e melhora da resistência insulínica}

O presente estudo demonstrou uma melhora imediata nos controles glicêmicos no pós-operatório da GDYR associado a mudanças enterohormonais e de resistência insulínica de maneira drástica.

Precocemente, foi observada a queda significativa das curvas de glicemia e insulinemia ao se comparar os pré e o pós-operatórios em ambas as vias de administração da solução com consequente redução do HOMAIR, o que caracteriza uma melhora da resistência insulínica. A redução acentuada do HOMA-IR sem perda de peso no pós-operatório indica que outros fatores que não a perda de peso estejam envolvidos nessa melhora. Isbell et al. (2010) estudaram a restrição calórica intensa na resistência e produção insulínica e verificaram em um grupo de pacientes (por um período de 4 dias), com restrição calórica idêntica aos pacientes de pós-operatório de GDYR, que eles apresentaram melhora nos índices glicêmicos e de insulina, porém, sem alteração do GLP1, levando a crer que, nesses dias, a 
restrição calórica seria o principal fator desse controle glicêmico ${ }^{(51)}$. De fato, após a GDYR, o jejum pode ativar enzimas envolvidas na gliconeogênese e os mecanismos envolvidos nessa sinalização do sistema porta levam a uma diminuição da produção hepática de glicose e consequente queda da resistência insulínica independente de incretinas ${ }^{(57,70-72)}$.

Observou-se também uma melhora das médias do HOMA-BETA do pré-operatório de $246,13 \pm 271,43$ para $687,29 \pm 1547,56$ e $839,85 \pm 1349,04$ (via Gastrostomia e Via Oral, respectivamente) no pós-operatório. Esses dados não mostraram ter diferença estatística $(p<0,05)$; no entanto, levam a crer que já ocorre uma melhora da resposta da célula beta, imediamente, após a confecção da GDYR. Martinussen et al. (2015) estudaram pacientes com DM2, intolerância à glicose e pacientes não diabéticos no pré, pósoperatório com 1 semana e 3 meses pós-GDYR, utilizando o clamp hiperglicêmico, TTOG e uso de refeição-padrão para avaliar a resistência insulínica e a primeira fase da secreção insulínica. O grupo evidenciou que os pacientes já apresentam melhora importante da primeira fase de secreção da insulina pelas células beta, melhora do HOMA-BETA e também da sensibilidade à insulina dos tecidos periféricos, já na primeira semana do pós-operatório ${ }^{(73)}$. Os níveis mais baixos de glicema sérica levam a uma melhora da função das células beta em razão de uma melhora da glicotoxicidade, mesmo de maneira precoce, com subsequente aumento da secreção insulínica que contribui para o controle da glicemia no pósoperatório precoce. A glicotoxicidade é um efeito deletério, porém potencialmente reversível na célula beta pancreática, decorrente da hiperglicemia crônica ${ }^{(74,75)}$.

Dunn et al. (2012), em estudo com pacientes obesos diabéticos e não diabéticos com ressecção ou não de omento na GDYR, observaram que, após 1 mês de pós-operatório, ocorre diminuição da produção hepática da glicose, aumento da sensibilidade hepática à insulina e aumento da secreção insulínica, mas não há melhora da sensibilidade periférica da insulina ${ }^{(76)}$. Umeda et al. e Hansen et al. (2011) evidenciaram em estudos 
de pós-operatório de 1 semana que existe uma melhora importante da resistência e sensibilidade hepática à insulina nesse período ${ }^{(62,63)}$.

Uma queda importante da curva do TTOG foi observada ao se comparar a via oral pré-operatória com a via oral pós-operatória entre 3 a 7 dias após a cirurgia. Não existe padronização para esse teste após a GDYR nem por via oral ou por via da gastrostomia. Mesmo assim, com o aporte de glicose a $50 \%$ (75 g de glicose) chegando de maneira mais abrupta ao jejuno distal (o que levaria uma maior absorção da glicose), os pacientes apresentaram queda significativa da média de glicemia em todos os tempos, inclusive no pico de 90 minutos que teve média de 196,89 mg/dl. Na Via Gastrostomia, também foi evidenciada queda dessa glicemia ao ser administrada a solução-padrão com níveis médios de glicose muito inferiores em comparação ao pré-operatório, ou seja, a glicemia foi controlada com a GDYR mesmo com a passagem da dieta pelo duodeno no pós-operatório. Sete dos nove pacientes $(77,7 \%)$ tiveram normalização da curva de TTOG no pós-operatório, configurando remissão precoce da doença, um paciente atingiu a medida exata de $220 \mathrm{mg} / \mathrm{dl}$ no pico de 90 minutos e só um paciente manteve níveis mais altos no teste. Esta queda evidencia uma remissão do DM2 já com 1 semana após o procedimento, ou seja, o paciente deixa de ser diabético nesse período e já não haveria mais necessidade do uso de medicação. Esta melhora no pós-operatório da GDYR, provavelmente, ocorre em razão da quebra precoce do ciclo vicioso da hiperglicemia, estresse oxidativo e resistência à insulina, base fisiopatológica da doença.

Em suma, a melhora da glicemia no pós-operatório precoce está ligada ao fato de que o paciente tem restrição calórica importante, levando o fígado ao consumo da glicose. Com isso, há uma menor produção hepática de glicose e também aumento da sensibilidade hepática à insulina. A queda dos níveis de glicemia precocemente leva a uma menor glicotoxicidade. Esta queda da glicotoxicidade leva a uma melhor resposta da célula beta pancreática, o que melhora a secreção da insulina e melhora a sensibilidade hepática e periférica da mesma. Este efeito é visto no estudo, uma vez que os pacientes apresentam queda dos níveis de glicemia e, ao mesmo tempo, 
queda dos níveis de insulina em ambas as vias. Isso mostra que a insulina já apresenta uma melhor efetividade, ou seja, é necessária uma concentração sérica de insulina menor para manter o controle glicêmico dos indivíduos. Estudos com tratamento intensivo do DM2 por medicamentos e insulina mostram que, em curtos espaços de tempo (de 1 a 3 semanas) após o controle da hiperglicemia, os pacientes já apresentam melhora importante da secreção da insulina e função da célula beta ${ }^{(77,78)}$ corroborando que a melhora da glicotoxicidade é um efeito já visível também nos primeiros dias de pós-operatório.

Mas, essa melhora não é explicada somente pela restrição calórica. Kashyap et al., em estudo de 2010, compararam a resistência insulínica, a sensibilidade insulínica e a função da célula beta entre GDYR e Gastrectomia Vertical. A princípio, os pacientes tinham a mesma dieta restritiva pós-operatória, e os exames foram realizados pré-operatoriamente e com 1 e 4 semanas de pós operatório. Verificou-se melhora nos níveis glicêmicos com a GDYR associada a uma melhora da função da célula beta, da sensibilidade e da resistência à insulina, o que não aconteceu com a Gastrectomia Vertical, mostrando que há outros fatores associados à restrição calórica pura, provavelmente, ligada a alterações também das incretinas ${ }^{(79)}$.

\subsection{Papel das incretinas}

Historicamente, a GDYR é conhecida por seus mecanismos de emagrecimento pela restrição e disabsorção dos alimentos. A restrição ocorre pelo estômago de dimensões reduzidas e a disabsorção pelo desvio do duodeno e do jejuno proximal, levando o alimento de maneira mais rápida ao íleo. Mais recentemente, foi observado que a cirurgia poderia ter outro mecanismo de emagrecimento com a alteração de uma série de enterohormônios e incretinas (GLP1, GIP, PYY, Oxintomodulina, Insulina, Grelina e Glucagon) o que, provavelmente, levaria a uma alteração do "set point" do hipotálamo e da regulação do metabolismo e consumo energético do 
indivíduo associado a uma melhora da glicemia em pacientes diabéticos ${ }^{(80-82)}$.

Esse controle ocorre pelo importante aumento do GLP1 e GIP, sobretudo, levando ao estímulo das células beta do pâncreas e, consequentemente, à insulina ${ }^{(61,62)}$. Foi observado que os pacientes obesos diabéticos que possuem efeito incretínico suprimido apresentam melhora desse efeito no pós-operatório da GDYR ${ }^{(42)}$. No presente estudo, evidenciou-se que existe um pico em 30 e 60 minutos do GLP1, aumento da AUC e a comparação grupo:tempo com significância estatística $(p<0,05)$ ao se comparar a Via Oral pré com a Via Oral pós-operatória, mas não foi encontrada diferença no pós-operatório entre as vias de administração Oral e Gastrostomia ( $p>0,05)$. Também observou-se que o GIP apresenta queda no pós-operatório $(p<0,05)$ ao se comparar a Via Oral pré com a Via Oral pós-operatória. A Grelina também tem tendência à queda pelo gráfico (Gráfico 21), porém, sem significância estatística e independente da via de administração pós-operatória $(p>0,05)$. Com isso notou-se que o GIP e a Grelina não aparentam ter importância no controle glicêmico precoce da cirurgia. A Grelina é um hormônio orexígeno e já foi estudado por Cummings et al. (2002). Observou-se que, quando os pacientes são submetidos a uma dieta hipocalórica, os níveis de Grelina aumentam consideravelmente e que após a GDYR esse níveis caem de modo abrupto, exatamente como foi observado também em nosso estudo. Este também parece ser um mecanismo de controle da glicemia no pós-operatório, pois inibe o apetite e o desejo por alimentos com alta concentração calórica, consequentemente, diminuindo a ingesta de alimentos levando ao mecanismo básico da melhora da glicemia pela restrição calórica ${ }^{(48)}$.

Não obstante, a maioria dos estudos evidencia que o efeito incretínico costuma ter uma melhora mais proeminente a partir da quarta a sexta semana do pós operatório da GDYR ${ }^{(62,83,84)}$. Em nosso estudo, pôde-se observar que as mudanças nas incretinas, sobretudo o GLP-1, já se inicia nos primeiros dias do pós-operatório, como também foi observado por Hansen e Dirksen em estudos semelhantes ${ }^{(62,85)}$. 


\subsection{Correlação entre a melhora da glicemia e as teorias do intestino proximal e intestino distal}

No pós-operatório da GDYR, quando se administrou a solução-padrão por via da Gastrostomia (via duodenal), o paciente apresentou melhora significativa do controle da glicemia, queda da secreção e resistência insulínica, queda do GIP e da Grelina, com tendência de melhora da função das células beta. Foi observado também que, já nos primeiros dias, quando essa solução foi administrada por Via Oral, ou seja, por via jejunal, obtevese estímulo significativo da secreção do GLP-1, queda importante do GIP, queda da Grelina, melhora aparente da função da célula beta e melhora drástica da resistência insulínica com remissão do DM2. Com isso, independente da via de administração da solução no pós-operatório, o paciente tem melhora do efeito incretínico com base na melhora da secreção do GLP-1. Já a Grelina e o GIP não têm participação nessa melhora incretínica precoce.

Duas teorias tentam explicar essa resposta pós-operatória: a teoria do intestino proximal e a do intestino distal. Alguns autores advogam que a exclusão duodenal seria responsável pelo estímulo do GIP produzido pelas células $\mathrm{K}$ e a exclusão de algum fator anti-incretínico que pudesse ser produzido nessa região. Rubino et al., em estudo de 2006, mostraram por meio de um procedimento chamado Duodenal Jejunal Bypass (DJB), desenvolvido para estudar as teorias do intestino, o qual não realizava ressecção gástrica, mas, somente uma gastroentero-anastomose no jejuno distal, desviando o alimento do duodeno. Os autores observaram que, ao fazer isso, o rato geneticamente diabético apresentava melhora no padrão glicêmico e ao retornar o trânsito alimentar pelo duodeno o mesmo voltava a desenvolver diabetes, concluindo que a exclusão duodenal era o principal fator de melhora da GDYR ${ }^{(20)}$.

E a teoria do intestino distal defende o fato dos alimentos chegarem de maneira mais precoce ao íleo, o que estimularia a produção de GLP-1 pelas células $L$ presentes nessa topografia do intestino delgado. Além do 
aumento do GLP-1, essa teoria também estaria relacionada ao aporte precoce dos ácidos biliares que poderiam ter efeito nesse controle glicêmico $^{(46,81,82)}$.

Em resumo, o paciente volta a apresentar o efeito incretínico, melhora da função da célula beta e melhora da resistência insulínica independente da solução ter passagem ou não pelo duodeno. Obviamente, não se pode excluir a influência da teoria do intestino proximal, uma vez que o $Y$ de Roux já foi confeccionado, e a dieta infundida pela Via Gastrostomia chega mais rapidamente ao jejuno distal, podendo ocorrer um estímulo maior das células L. A ausência da fase cefálica da digestão inibida ao se administrar a solução diretamente pela Via Gastrostomia poderia mudar estímulos hormonais e neuronais, alterando o esvaziamento gástrico e a consequente alteração na absorção da glicose, podendo também comprometer essa avaliação.

\subsection{Outros mecanismos de controle glicêmico precoce}

Outros mecanismos de controle glicêmico têm seu papel no pósoperatório da GDYR, como a chegada mais precoce dos ácidos biliares ao jejuno distal / íleo proximal, queda dos triglicérides hepáticos e pancreáticos, alteração de microbiota, adaptação intestinal, alteração no eixo intestinocérebro-fígado e perda de peso per se. A chegada mais precoce da bile distalmente leva a uma alteração da sinalização da mesma por meio do receptor Farsenoid X (FXR), TGR5 e FGF-19. O trânsito transintestinal dos ácidos biliares ativa o FXR, induzindo a síntese e secreção da enterocina FGF-19. Esta enterocina leva a uma melhora da tolerância à glicose e diminui a produção hepática da glicose pelo sistema portal. Os ácidos biliares atuam também por meio do TGR5, estimulando as células $L$ e, consequentemente, a secreção de GLP-1 e PYY, como também regulam a microbiota do intestino ${ }^{(86,87)}$.

Pacientes com DM2 têm aumento de depósito de gordura no fígado e no pâncreas, quando comparados a pacientes normoglicêmicos com IMC 
semelhante ${ }^{(88)}$. Taylor et al. (2011) mostraram que pacientes com DM2 que foram submetidos à GDYR ou à dieta de muito baixa caloria (VLCD) apresentaram queda rápida dos depósitos hepáticos de gordura e, em paralelo, uma melhora da sensibilidade hepática à insulina com normalização da glicemia de jejum dentro de 7 dias ${ }^{(89)}$, indicando uma melhora do estresse oxidativo nesse período.

Outro possível mecanismo de controle glicêmico é o eixo intestinocérebro-fígado. O cérebro recebe sinalização do intestino proximal pela inervação aferente que se comunica com o núcleo do trato solitário, isso causa saciedade no indivíduo. No entanto, foi observado que a infusão de nutrientes de maneira direta no delgado leva a um bloqueio na produção hepática de glicose por meio de um sinal proveniente do Hipotálamo pela inervação eferente do ramo hepático do vago. Após a GDYR, o que é observado é justamente que o alimento chega ao jejuno terminal/íleo proximal de maneira mais rápida e, por isso, estimula a sinalização intestinal pela via aferente. Esta, por sua vez, estimula o núcleo do trato solitário que, por meio do hipotálamo e do vago, sinalizam o fígado a diminuir a produção hepática de glicose, realizando um controle precoce da homeostase glicêmica ${ }^{(90,91)}$.

Outro mecanismo de controle glicêmico pós-GDYR é a adaptação intestinal do enterócito. Esta é uma célula altamente especializada e realiza o transporte da glicose pela ação de um cotransportador de membrana chamado SGLT1. A expressão do SGLT1 aumenta gradativamente no trato gastrointestinal a partir do duodeno em sentido ao íleo, e é regulado pela concentração endoluminal da glicose, sugerindo sua função como sensor de glicose. Trabalhos evidenciam que, com o tempo, existe uma adaptação da alça alimentar com aumento da captação da glicose. Parker et al. (2010) propuseram que a captação de glicose pelo SGLT1 pode estimular a secreção de GLP-1 e GIP pelas células L e K do intestino ${ }^{(92)}$. 


\section{Sumário da discussão}

Observou-se remissão do DM2 no pós-operatório precoce (média de 5 dias) em $77,7 \%$ do indivíduos. No pós-operatório da GDYR, houve redução da glicemia sérica, insulinemia e HOMA-IR independente da via de administração (Oral ou Gastrostomia) de uma solução-padrão que mimetiza uma dieta balanceada. Isso é traduzido pela queda abrupta da resistência insulínica evidenciada pelo HOMA-IR. Associado a isso, evidenciou-se pico importante do GLP-1, sobretudo, na via oral pós-operatória, acompanhado da melhora da resistência insulínica. No entanto, essa curva do GLP-1 não tem correlação direta com o aumento da insulinemia, pelo contrário, a insulina decresce em ambas as vias. Evidenciou-se também que o GIP e a Grelina não têm, aparentemente, mecanismo de ação na remissão precoce do DM2. Com a melhora da glicemia e queda significativa das curvas de insulina no pós-operatório, tanto na via duodenal como na via jejunal observou-se que a melhora da glicemia independe da passagem ou não pelo duodeno do alimento. Associado a isso, tem-se o aumento do GLP-1 de maneira precoce, fortalecendo a teoria do intestino distal, pelo menos, nesse período de até 1 semana após a GDYR. 
6 CONCLUSÃO 


\section{CONCLUSÃO}

Os pacientes obesos graves e diabéticos submetidos à GDYR apresentaram:

a) Melhora significativa da glicemia, insulinemia e resistência insulínica, independente da oferta alimentar por Via Oral ou pela Gastrostomia, estudadas no pós-operatório precoce.

b) Melhora do efeito incretínico pelo incremento do GLP-1 e redução do GIP quando comparadas a Via Oral pré-operatória com a Via Oral pós-operatória. 
7 ANEXOS 


\section{ANEXO 1}

TERMO DE CONSENTIMENTO LIVRE E ESCLARECIDO

\section{DADOS DE IDENTIFICAÇÃO DO SUJEITO DA PESQUISA OU RESPONSÁVEL LEGAL}

1. NOME:

DOCUMENTO DE IDENTIDADE No : SEXO :.$M \square F \square$

DATA NASCIMENTO

ENDEREÇO

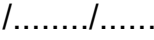

BAIRRO:

CEP:....

\section{CIDADE}

$N^{\circ}$

APTO:

2.RESPONSÁVEL LEGAL

NATUREZA (grau de parentesco, tutor, curador etc.)

DOCUMENTO DE IDENTIDADE :

SEXO: $M \square F \square$

DATA NASCIMENTO.: .....................

ENDEREÇO: $\mathrm{N}^{\mathrm{O}}$

APTO:

BAIRRO: CIDADE:

CEP: TELEFONE: DDD (

).

\section{DADOS SOBRE A PESQUISA}

1. TÍTULO DO PROTOCOLO DE PESQUISA: “Avaliação do metabolismo glicêmico e perfil entero-hormonal no pós-operatório precoce em pacientes obesos graves diabéticos submetidos a Gastroplastia em y de Roux. Comparação da oferta alimentar por via oral e por gastrostomia."

2. PESQUISADOR: Dr. Gustavo Fernandes CARGO/FUNÇÃO: Médico Cirurgião do Aparelho Digestivo e Dr. Marco Aurélio Santo CARGO/FUNÇÃO: Coordenador da Unidade de Cirurgia Bariátrica e Metabólica INSCRIÇÃO CONSELHO REGIONAL: No52911 UNIDADE DO HCFMUSP: Instituto Central do Hospital das Clínicas (ICHC)

3. AVALIAÇÃO DO RISCO DA PESQUISA:

$\begin{array}{lll}\text { RISCO MÍNIMO } & \square & \text { RISCO MÉDIO } \\ \text { RISCO BAIXO } & X & \text { RISCO MAIOR }\end{array}$

4.DURAÇÃO DA PESQUISA : 12 meses 
1 - Desenho do estudo e objetivo(s) Você está sendo convidado(a) a participar de um estudo clínico para verificar a evolução do diabetes e do peso (perda de peso) após a cirurgia de obesidade. Dentre as doenças associadas à obesidade, 0 diabetes é uma doença frequente e grave, onde, em muitos casos, ocorre controle após a cirurgia de obesidade. Portanto, é muito importante incluir uma avaliação de análise clínica e laboratorial para identificar alterações que possam prever melhor o controle do diabetes e da evolução do peso. Se você for diagnosticado no préoperatório com diabetes tipo 2, o médico irá realizar coleta de informações clínicas do diabetes (uso de medicamentos, tempo de história do diabetes, cálculo do índice de massa corpórea - IMC), doenças associadas a obesidade e coletas de sangue relacionadas ao diabetes e hormônios. Após a realização da cirurgia de obesidade, o médico continuará o acompanhamento clínico e laboratorial para verificar o controle do diabetes e da evolução de peso. O objetivo deste estudo é avaliar o comportamento dos hormônios relacionados à evolução clínica e laboratorial do diabetes e do peso depois de realizar a cirurgia da obesidade.

2 - Descrição dos procedimentos que serão realizados, com seus propósitos e identificação dos que forem experimentais e não rotineiros; Durante o estudo serão feitas coleta de informações clínicas e a realização de dosagens e curvas laboratoriais através da coleta de sangue por punção periférica da veia do antebraço após a cirurgia para verificar informações do sangue, com relação à diabetes e a secreção de hormônios. Serão feitas: dosagens séricas do peptídeo C; grelina e GLP-1, glicemia, insulina entre outros após a ingestão de um complemento nutricional (tipo suco de caixinha) após a cirurgia por 2 vezes, em dias consecutivos e a medida da glicemia (açúcar no sangue) através de monitorização contínua com sensor e dextro (punção do dedo junto com a fita dosadora).

3 - Relação dos procedimentos rotineiros e como são realizados - o tipo de cirurgia que já foi realizada neste estudo será o "Bypass" gástrico com reconstrução em $Y$ de Roux (cirurgia de redução do estômago com desvio do intestino) associado a uma gastrostomia de segurança e será feita a coleta de sangue por punção periférica da veia do antebraço após a cirurgia e a aceitação da dieta para verificar informações do sangue. $O$ tratamento destes pacientes não será alterado devido à pesquisa. Todos realizarão o tratamento de rotina de sua doença, assim como exames antes e após a cirurgia.

4 - Descrição dos desconfortos e riscos esperados nos procedimentos dos itens 2 e 3; Você irá colher exames de maneira semelhante aos colhidos antes da operação. Podem haver desconfortos e riscos, como a dor da picada quando houver coleta de exames de sangue, às vezes aparecimento de mancha roxa em torno da picada. Será feita a punção da veia periférica do antebraço para coleta de sangue antes e após a tomada do complemento nutricional (tipo suco de caixinha) por 2 vezes em dias consecutivos.

5 - Benefícios para o participante: acompanhamento e avaliação da evolução da diabetes e da perda de peso.

6 - Relação de procedimentos alternativos que possam ser vantajosos, pelos quais o paciente pode optar; não há procedimentos alternativos.

7 - Garantia de acesso: em qualquer etapa do estudo, você terá acesso aos profissionais responsáveis pela pesquisa para esclarecimento de eventuais dúvidas. O principal investigador é o Dr. Gustavo Fernandes e o Dr. Marco Aurélio Santo. que pode ser encontrado no endereço Av. Dr. Enéas de Carvalho Aguiar, 255 - $9^{\circ}$ andar Telefone(s) 30697561. Se você tiver alguma consideração ou dúvida 
sobre a ética da pesquisa, entre em contato com o Comitê de Ética em Pesquisa (CEP) - Rua Ovídio Pires de Campos, 225 - $5^{\circ}$ andar - tel: 3069-6442 ramais 16, 17, 18 ou 20 - e-mail: cappesq@hcnet.usp.br

8 - É garantida a liberdade da retirada de consentimento a qualquer momento e deixar de participar do estudo, sem qualquer prejuízo à continuidade de seu tratamento na Instituição;

09 - Direito de confidencialidade - As informações obtidas serão analisadas em conjunto com outros pacientes, não sendo divulgado a identificação de nenhum paciente;

10 - Direito de ser mantido atualizado sobre os resultados parciais das pesquisas, quando em estudos abertos, ou de resultados que sejam do conhecimento dos pesquisadores;

11 - Despesas e compensações: não há despesas pessoais para o participante em qualquer fase do estudo, incluindo exames e consultas. Também não há compensação financeira relacionada à sua participação.

\section{2 - Compromisso do pesquisador de utilizar os dados e o material coletado somente para esta pesquisa.}

Acredito ter sido suficientemente informado a respeito das informações que li ou que foram lidas para mim, descrevendo o estudo "Avaliação do metabolismo glicêmico e perfil enterohormonal no pós-operatório precoce em pacientes obesos graves diabéticos submetidos à Gastroplastia em Y de Roux. Comparação da oferta alimentar por via oral e por gastrostomia."

Eu discuti com o Dr. Gustavo Fernandes e/ou Dr. Marco Aurélio Santo sobre a minha decisão em participar nesse estudo. Ficaram claros para mim quais são os propósitos do estudo, os procedimentos a serem realizados, seus desconfortos e riscos, as garantias de confidencialidade e de esclarecimentos permanentes. Ficou claro também que minha participação é isenta de despesas e que tenho garantia do acesso a tratamento hospitalar quando necessário. Concordo voluntariamente em participar deste estudo e poderei retirar o meu consentimento a qualquer momento, antes ou durante o mesmo, sem penalidades ou prejuízo ou perda de qualquer benefício que eu possa ter adquirido, ou no meu atendimento neste Serviço.

Assinatura do paciente/representante legal

Data

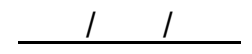

Assinatura da testemunha

Data 11

para casos de pacientes menores de 18 anos, analfabetos, semi-analfabetos ou portadores de deficiência auditiva ou visual.

(Somente para o responsável do projeto)

Declaro que obtive de forma apropriada e voluntária o Consentimento Livre e Esclarecido deste paciente ou representante legal para a participação neste estudo.

Assinatura do responsável pelo estudo

Data 11 


\section{ANEXO 2}

FOLHA DE COLETA DE DADOS DO PACIENTE

\section{FOLHA DE COLETA DE DADOS DO PACIENTE}

I- IDENTIFICAÇÃo

NOME: IDADE:

SEXO: REGISTRO:

TERMO DE CONSENTIMENTO: $\square$ SIM $\square$ NÃO

Data de Entrada no Estudo: ___ $/ \ldots$

II- PESO E ANTECEDENTES

PESO INICIAL: $\quad$ IMC INICIAL:

ALTURA:

COMORBIDADES:

III- MEDICAÇõES EM USO

INSULINA

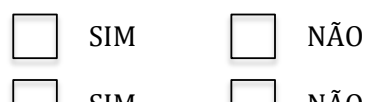

CORTICÓIDE

$\begin{array}{lll}\square & \text { SIM } & \\ \square & \text { NIM } & \square\end{array}$

ANÁLOGO GLP-1

$\square \operatorname{SIM} \quad \square$ NÃO

ANTI-RETROVIRAIS

$\mathrm{M}$ NÃO

IV- CHECAR EXAMES GERAIS

V- CRITÉRIOS DO ESTUDO

\begin{tabular}{|c|c|c|}
\hline PEPTÍDEO C: & $<2$ & $>2$ \\
\hline SOROLOGIA HEP.A: & Reagente & Não Reagente \\
\hline SOROLOGIA HEP.B: & Reagente & Não Reagente \\
\hline SOROLOGIA HEP.C: & Reagente & Não Reagente \\
\hline $\begin{array}{l}\text { TEMPO DE DIAG. DE } \\
\text { DIABETES MELLITUS: }\end{array}$ & $<10$ anos & $>10$ anos \\
\hline
\end{tabular}




\section{FOLHA DE ANOTAÇÃO DE CONTROLES DIÁRIOS DO PACIENTE}

\section{FOLHA DE SEGUIMENTO DIÁRIO}

\begin{tabular}{|c|c|}
\hline DATA & \\
\hline Peso & \\
\hline Circ. Abd & \\
\hline Circ. Pescoço & \\
\hline Dextro $_{1}$ & \\
\hline Dextro $_{2}$ & \\
\hline Dextro $_{3}$ & \\
\hline Dextro $_{4}$ & \\
\hline $\begin{array}{c}\text { Insulina? Dose? } \\
\text { Horário? }\end{array}$ & \\
\hline $\begin{array}{l}\text { Hipoglicemia? } \\
\text { Valor? }\end{array}$ & \\
\hline Uso de Glicose? & \\
\hline PA & \\
\hline $\mathrm{FC}$ & \\
\hline $\mathrm{T}^{\circ}$ & \\
\hline Débito Urinário & \\
\hline Dieta Adequada? & \\
\hline Intercorrências & \\
\hline
\end{tabular}

DATA

\begin{tabular}{|c|c|}
\hline Peso & \\
\hline Circ. Abd & \\
\hline Circ. Pescoço & \\
\hline Dextro $_{1}$ & \\
\hline Dextro $_{2}$ & \\
\hline Dextro $_{3}$ & \\
\hline Dextro $_{4}$ & \\
\hline $\begin{array}{c}\text { Insulina? Dose? } \\
\text { Horário? }\end{array}$ & \\
\hline $\begin{array}{l}\text { Hipoglicemia? } \\
\text { Valor? }\end{array}$ & \\
\hline Uso de Glicose? & \\
\hline PA & \\
\hline $\mathrm{FC}$ & \\
\hline $\mathrm{T}^{\mathrm{O}}$ & \\
\hline Débito Urinário & \\
\hline Dieta Adequada? & \\
\hline Intercorrências & \\
\hline
\end{tabular}

\section{DATA}

\begin{tabular}{|c|l|}
\hline Peso & \\
\hline Circ. Abd & \\
\hline Circ. Pescoço & \\
\hline Dextro $_{1}$ & \\
\hline Dextro $_{2}$ & \\
\hline Dextro $_{3}$ & \\
\hline Dextro $_{4}$ & \\
\hline $\begin{array}{c}\text { Insulina? Dose? } \\
\text { Horário? }\end{array}$ & \\
\hline Hipoglicemia? & \\
Valor? & \\
\hline Uso de Glicose? & \\
\hline PA & \\
\hline FC & \\
\hline$T^{\circ}$ & \\
\hline Débito Urinário & \\
\hline Dieta Adequada? & \\
\hline Intercorrências & \\
\hline
\end{tabular}

DATA

\begin{tabular}{|c|c|}
\hline Peso & \\
\hline Circ. Abd & \\
\hline Circ. Pescoço & \\
\hline Dextro $_{1}$ & \\
\hline Dextro $_{2}$ & \\
\hline Dextro $_{3}$ & \\
\hline Dextro $_{4}$ & \\
\hline $\begin{array}{c}\text { Insulina? Dose? } \\
\text { Horário? }\end{array}$ & \\
\hline $\begin{array}{c}\text { Hipoglicemia? } \\
\text { Valor? }\end{array}$ & \\
\hline Uso de Glicose? & \\
\hline PA & \\
\hline FC & \\
\hline$T^{\circ}$ & \\
\hline Débito Urinário & \\
\hline Dieta Adequada? & \\
\hline Intercorrências & \\
\hline
\end{tabular}


ANEXO 3

\section{DADOS COMPLETOS}

\begin{tabular}{|c|c|c|c|c|c|}
\hline & \multicolumn{5}{|c|}{ GLICOSE VIA ORAL PRÉ-OP } \\
\hline PACIENTE & 0 & 30 & 60 & 90 & 120 \\
\hline 1 & 121 & 174 & 205 & 195 & 172 \\
\hline 2 & 109 & 144 & 188 & 226 & 214 \\
\hline 3 & 145 & 181 & 187 & 183 & 160 \\
\hline 4 & 135 & 162 & 195 & 201 & 203 \\
\hline 5 & 133 & 187 & 224 & 206 & 215 \\
\hline 6 & 116 & 147 & 158 & 162 & 162 \\
\hline 7 & 143 & 204 & 245 & 250 & 245 \\
\hline 8 & 83 & 129 & 139 & 129 & 90 \\
\hline 9 & 121 & 149 & 197 & 226 & 240 \\
\hline 10 & 148 & 175 & 217 & 240 & 216 \\
\hline \multirow[t]{2}{*}{11} & 123 & 152 & 162 & 168 & 174 \\
\hline & \multicolumn{5}{|c|}{ GLICOSE VIA ORAL PÓS-OP } \\
\hline PACIENTE & 0 & 30 & 60 & 90 & 120 \\
\hline 1 & 63 & 140 & 123 & 96 & 90 \\
\hline 2 & 89 & 184 & 209 & 176 & 148 \\
\hline 3 & 85 & 127 & 129 & 116 & 107 \\
\hline 4 & 86 & 132 & 182 & 167 & 148 \\
\hline 5 & 72 & 84 & 118 & 134 & 131 \\
\hline 6 & 91 & 132 & 136 & 108 & 99 \\
\hline 7 & 79 & 156 & 192 & 178 & 159 \\
\hline 8 & 64 & 122 & 130 & 104 & 92 \\
\hline 9 & 152 & 215 & 240 & 226 & 215 \\
\hline 10 & 155 & 185 & 218 & 198 & 180 \\
\hline \multirow[t]{2}{*}{11} & 102 & 140 & 184 & 178 & 166 \\
\hline & \multicolumn{5}{|c|}{ GLICOSE VIA GASTROSTOMIA PÓS-OP } \\
\hline PACIENTE & 0 & 30 & 60 & 90 & 120 \\
\hline 1 & 94 & 80 & 81 & 88 & 87 \\
\hline 2 & 126 & 139 & 133 & 122 & 107 \\
\hline 3 & 78 & 130 & 115 & 107 & 106 \\
\hline 4 & 65 & 67 & 73 & 75 & 79 \\
\hline 5 & 73 & 79 & 85 & 96 & 97 \\
\hline 6 & 89 & 95 & 128 & 131 & 129 \\
\hline 7 & 83 & 127 & 175 & 200 & 186 \\
\hline 8 & 71 & 66 & 72 & 72 & 71 \\
\hline 9 & 153 & 161 & 206 & 229 & 234 \\
\hline 10 & 152 & 155 & 163 & 200 & 221 \\
\hline 11 & 156 & 198 & 240 & 242 & 232 \\
\hline
\end{tabular}




\begin{tabular}{|c|c|c|c|c|c|}
\hline \multirow[b]{2}{*}{ PACIENTE } & \multicolumn{5}{|c|}{ INSULINA VIA ORAL PRÉ-OP } \\
\hline & 0 & 30 & 60 & 90 & 120 \\
\hline 1 & 548,7 & 1940,4 & 921,68 & 1117,13 & 1250,72 \\
\hline 2 & 1337 & 1298 & 3227 & 3286 & 474,08 \\
\hline 3 & 258,15 & 400,75 & 423,99 & 511,32 & 554,63 \\
\hline 4 & 548,27 & 1470,35 & 1519,46 & 1637,34 & 1422,11 \\
\hline 5 & 868,26 & 1175,97 & 1161,2 & 705,69 & 1446,83 \\
\hline 6 & 816,79 & 1243,1 & 742,31 & 711,9 & 659,06 \\
\hline 7 & 1902 & 1525 & 2161 & 1956 & 2056 \\
\hline 8 & 998,9 & 2982 & 2226 & 3012 & 1364 \\
\hline 9 & 465,78 & 572,85 & 467,95 & 743,01 & 734,95 \\
\hline 10 & 514 & 2928 & 1989 & 2066 & 1578 \\
\hline \multirow[t]{2}{*}{11} & 602,81 & 1819 & 1522 & 1727 & 1590 \\
\hline & \multicolumn{5}{|c|}{ INSULINA VIA GASTROSTOMIA PÓS-OP } \\
\hline PACIENTE & 0 & 30 & 60 & 90 & 120 \\
\hline 1 & 341,5 & 290,39 & 80,91 & 101,66 & 93,15 \\
\hline 2 & 46,22 & 128,64 & 152,47 & 134,7 & 138,56 \\
\hline 3 & 65,96 & 211,02 & 214,98 & 150,29 & 105,23 \\
\hline 4 & 754,43 & 888,23 & 1620,63 & 1311,79 & 1205,35 \\
\hline 5 & 298,02 & 269,48 & 298,82 & 477,08 & 647,95 \\
\hline 6 & 394,62 & 394,62 & 1213,09 & 766,74 & 736,9 \\
\hline 7 & 450.47 & 644 & 880,06 & 835,89 & 467,95 \\
\hline 8 & 385,63 & 365,87 & 370,87 & 261,67 & 329,66 \\
\hline 9 & 432,57 & 370,87 & 365,87 & 404,8 & 461,44 \\
\hline 10 & 1301 & 749,42 & 1830 & 2191 & 2369 \\
\hline \multirow[t]{2}{*}{11} & 341,75 & 1203 & 728,67 & 862,11 & 352,74 \\
\hline & \multicolumn{5}{|c|}{ INSULINA VIA ORAL PÓS-OP } \\
\hline PACIENTE & 0 & 30 & 60 & 90 & 120 \\
\hline 1 & 42,33 & 71,3 & 55,02 & 62,51 & 59,02 \\
\hline 2 & 48,12 & 130,1 & 145,81 & 116,18 & 130,89 \\
\hline 3 & 78,73 & 290,27 & 184,01 & 129,58 & 96,42 \\
\hline 4 & 373,92 & 729,57 & 1074,8 & 676,54 & 580,77 \\
\hline 5 & 377,14 & 842,66 & 868,46 & 608,61 & 487,46 \\
\hline 6 & 548,77 & 421 & 1017,55 & 842,68 & 901,86 \\
\hline 7 & 428,02 & 561,4 & 1367 & 853,72 & 723,57 \\
\hline 8 & 395,29 & 2532 & 1594 & 715,38 & 606,36 \\
\hline 9 & 279,49 & 580,41 & 659,71 & 463,62 & 249,44 \\
\hline 10 & 631,61 & 1318 & 2414 & 1118 & 793,37 \\
\hline 11 & 368,84 & 750,1 & 1101 & 1129 & 1113 \\
\hline
\end{tabular}




\begin{tabular}{|c|c|c|c|c|c|}
\hline \multirow[b]{2}{*}{ PACIENTE } & \multicolumn{5}{|c|}{ TTOG VIA ORAL PRÉ-OP } \\
\hline & 0 & 30 & 60 & 90 & 120 \\
\hline \multicolumn{6}{|l|}{1} \\
\hline \multicolumn{6}{|l|}{2} \\
\hline 3 & 135 & 192 & 228 & 222 & 209 \\
\hline 4 & 142 & 195 & 224 & 258 & 284 \\
\hline 5 & 137 & 206 & 254 & 264 & 285 \\
\hline 6 & 146 & 178 & 218 & 221 & 195 \\
\hline 7 & 126 & 234 & 292 & 306 & 314 \\
\hline 8 & 80 & 132 & 180 & 199 & 149 \\
\hline 9 & 89 & 159 & 184 & 171 & 149 \\
\hline 10 & 150 & 224 & 249 & 283 & 322 \\
\hline \multirow[t]{2}{*}{11} & 130 & 169 & 214 & 244 & 274 \\
\hline & \multicolumn{5}{|c|}{ TTOG VIA ORAL PÓS-OP } \\
\hline PACIENTE & 0 & 30 & 60 & 90 & 120 \\
\hline \multicolumn{6}{|l|}{1} \\
\hline \multicolumn{6}{|l|}{2} \\
\hline 3 & 84 & 158 & 139 & 106 & 100 \\
\hline 4 & 99 & 156 & 208 & 204 & 174 \\
\hline 5 & 75 & 115 & 171 & 220 & 199 \\
\hline 6 & 79 & 109 & 132 & 128 & 106 \\
\hline 7 & 78 & 168 & 257 & 247 & 219 \\
\hline 8 & 81 & 146 & 176 & 181 & 177 \\
\hline 9 & 133 & 156 & 298 & 306 & 286 \\
\hline 10 & 103 & 134 & 181 & 194 & 187 \\
\hline 11 & 71 & 131 & 186 & 186 & 188 \\
\hline
\end{tabular}




\begin{tabular}{|c|c|c|c|c|c|}
\hline \multirow[b]{2}{*}{ PACIENTE } & \multicolumn{5}{|c|}{ GLP1 VIA ORAL PRÉ-OP } \\
\hline & 0 & 30 & 60 & 90 & 120 \\
\hline 1 & 89,39 & 45,54 & 101,65 & 203,02 & 113,76 \\
\hline 2 & 50,29 & 72,03 & 50,29 & 47,6 & 54,19 \\
\hline 3 & 45,19 & 43,42 & 51,61 & 54,51 & 61,63 \\
\hline 4 & 94,15 & 112,36 & 105,57 & 122,43 & 146,37 \\
\hline 5 & 72,13 & 68,16 & 109,61 & 74,16 & 89,39 \\
\hline 6 & 256,91 & 149,82 & 109,61 & 94,15 & 134,79 \\
\hline 7 & 306,02 & 288,87 & 297,57 & 312,21 & 310,16 \\
\hline 8 & 210,3 & 240,92 & 219,03 & 256,2 & 240,92 \\
\hline 9 & 188,59 & 207,32 & 168,17 & 230,21 & 230,21 \\
\hline 10 & 207,32 & 235,62 & 230,21 & 213,24 & 219,03 \\
\hline \multirow[t]{2}{*}{11} & 294,36 & 342,85 & 324,32 & 328,11 & 324,32 \\
\hline & \multicolumn{5}{|c|}{ GLP1 GASTROSTOMIA PÓS-OP } \\
\hline PACIENTE & 0 & 30 & 60 & 90 & 120 \\
\hline 1 & 70,35 & 95,13 & 71,19 & 56,1 & 58,89 \\
\hline 2 & 52,13 & 398,77 & 208,55 & 200,39 & 102,47 \\
\hline 3 & 57,04 & 182,52 & 161,48 & 120,15 & 79,11 \\
\hline 4 & 96,6 & 89,39 & 120,95 & 99,1 & 91,74 \\
\hline 5 & 84,82 & 80,42 & 68,16 & 38,45 & 84,82 \\
\hline 6 & 112,36 & 118,04 & 329,09 & 196,46 & 160,55 \\
\hline 7 & 265,93 & 566,76 & 707,86 & 431,81 & 293,25 \\
\hline 8 & 181,99 & 181,99 & 175,19 & 188,59 & 195 \\
\hline 9 & 219,03 & 213,24 & 370,1 & 240,92 & 246,11 \\
\hline 10 & 201,24 & 175,19 & 230,21 & 251,2 & 288,87 \\
\hline \multirow[t]{2}{*}{11} & 316,61 & 454,54 & 478,41 & 312,68 & 256,41 \\
\hline & \multicolumn{5}{|c|}{ GLP1 VIA ORAL PÓS-OP } \\
\hline PACIENTE & 0 & 30 & 60 & 90 & 120 \\
\hline 1 & 52,26 & 124,89 & 74,79 & 62,82 & 60,42 \\
\hline 2 & 46,23 & 327,93 & 214,93 & 126,59 & 115,32 \\
\hline 3 & 53,55 & 155,39 & 118,62 & 101,83 & 92,92 \\
\hline 4 & 118,04 & 130,19 & 367,8 & 221,41 & 169,95 \\
\hline 5 & 84,82 & 228,65 & 251,56 & 149,82 & 166,14 \\
\hline 6 & 139,66 & 125,44 & 379,06 & 200,81 & 169,95 \\
\hline 7 & 240,92 & 555,57 & 853,83 & 441,94 & 322,26 \\
\hline 8 & 213,24 & 745,28 & 505,82 & 312,21 & 246,11 \\
\hline 9 & 201,24 & 948,92 & 677,84 & 275,33 & 201,24 \\
\hline 10 & 261,11 & 348,85 & 441,94 & 279,92 & 275,33 \\
\hline 11 & 288,03 & 399,5 & 402,59 & 367,24 & 328,11 \\
\hline
\end{tabular}




\begin{tabular}{|c|c|c|c|c|c|}
\hline \multirow[b]{2}{*}{ PACIENTE } & \multicolumn{5}{|c|}{ GIP VIA ORAL PRÉ-OP } \\
\hline & 0 & 30 & 60 & 90 & 120 \\
\hline 1 & 403,26 & 332,34 & 969,47 & 1096 & 1267 \\
\hline 2 & 93,1 & 286,46 & 161,85 & 197,18 & 258,41 \\
\hline 3 & 81,71 & 154,27 & 168,56 & 172,27 & 190,81 \\
\hline 4 & 146 & 479,6 & 571,75 & 550,54 & 543,66 \\
\hline 5 & 119,54 & 445,09 & 445,09 & 241,18 & 467,78 \\
\hline 6 & 316,96 & 601,35 & 601,35 & 393,51 & 504,2 \\
\hline 7 & 3494 & 782,93 & 1971 & 3044 & 1780 \\
\hline 8 & 307,07 & 1412 & 1605 & 1797 & 1136 \\
\hline 9 & 362,65 & 1698 & 1828 & 1865 & 1154 \\
\hline 10 & 325,28 & 2900 & 2830 & 1890 & 1164 \\
\hline \multirow[t]{2}{*}{11} & 189,77 & 1004 & 683,4 & 582,74 & 508,36 \\
\hline & \multicolumn{5}{|c|}{ GIP VIA GASTROSTOMIA PÓS-OP } \\
\hline PACIENTE & 0 & 30 & 60 & 90 & 120 \\
\hline 1 & 374,08 & 240,97 & 40,64 & 181,8 & 43,2 \\
\hline 2 & 66,08 & 179,34 & 200,97 & 138,64 & 185,33 \\
\hline 3 & 56,63 & 126,73 & 154,27 & 139,09 & 106,93 \\
\hline 4 & 139,21 & 434,2 & 616,73 & 445,09 & 328,41 \\
\hline 5 & 88,76 & 221,26 & 320,73 & 393,51 & 393,51 \\
\hline 6 & 78,05 & 161,73 & 717,67 & 517,01 & 571,75 \\
\hline 7 & 663,19 & 2953 & 2619 & 1959 & 1222 \\
\hline 8 & 212,78 & 257,5 & 499,02 & 314,58 & 322,07 \\
\hline 9 & 278,8 & 830,41 & 1855 & 1588 & 1547 \\
\hline 10 & 180,71 & 248,82 & 2460 & 4414 & 3205 \\
\hline \multirow[t]{2}{*}{11} & 77,98 & 643,77 & 516,94 & 364,32 & 199,66 \\
\hline & \multicolumn{5}{|c|}{ GIP VIA ORAL PÓS-OP } \\
\hline PACIENTE & 0 & 30 & 60 & 90 & 120 \\
\hline 1 & 49,57 & 165,91 & 92,39 & 105,16 & 81,54 \\
\hline 2 & 64,55 & 163,62 & 192,23 & 140,5 & 157,44 \\
\hline 3 & 51,56 & 176,68 & 142,97 & 104,27 & 104,8 \\
\hline 4 & 103 & 203,76 & 517,01 & 348,6 & 295,49 \\
\hline 5 & 93,11 & 348,6 & 379,37 & 340,35 & 309,6 \\
\hline 6 & 110,8 & 203,58 & 504,2 & 517,01 & 601,35 \\
\hline 7 & 441,44 & 1585 & 1755 & 1085 & 691,73 \\
\hline 8 & 390,34 & 4085 & 2142 & 1311 & 1090 \\
\hline 9 & 191,82 & 1259 & 1420 & 782,93 & 489,41 \\
\hline 10 & 102,36 & 350,92 & 626,09 & 360,52 & 244,48 \\
\hline 11 & 125,02 & 325,94 & 436,75 & 385,62 & 274,52 \\
\hline
\end{tabular}




\begin{tabular}{|c|c|c|c|c|c|}
\hline \multirow[b]{2}{*}{ PACIENTE } & \multicolumn{5}{|c|}{ GRELINA VIA ORAL PRÉ-OP } \\
\hline & 0 & 30 & 60 & 90 & 120 \\
\hline 1 & 577,47 & 669,64 & 798,06 & 574,75 & 769,18 \\
\hline 2 & 479 & 530,56 & 437,31 & 351,86 & 412,75 \\
\hline 3 & 507,9 & 418,94 & 406,52 & 484,83 & 449,38 \\
\hline 4 & 499,55 & 520,45 & 494,44 & 531,18 & 718,31 \\
\hline 5 & 380,52 & 286,06 & 494,44 & 364,53 & 409,91 \\
\hline 6 & 520,45 & 618,25 & 637,15 & 536,62 & 718,31 \\
\hline 7 & 1156 & 1247 & 1172 & 1156 & 1233 \\
\hline 8 & 1108 & 1007 & 952,45 & 1140 & 1140 \\
\hline 9 & 1402 & 1368 & 1156 & 1277 & 1202 \\
\hline 10 & 1016 & 1124 & 1033 & 1075 & 1164 \\
\hline \multirow[t]{2}{*}{11} & 1538 & 1898 & 1931 & 1887 & 1599 \\
\hline & \multicolumn{5}{|c|}{ GRELINA VIA ORAL PRÉ-OP } \\
\hline PACIENTE & 0 & 30 & 60 & 90 & 120 \\
\hline 1 & 617,63 & 412,75 & 725,05 & 569,3 & 449,38 \\
\hline 2 & 558,36 & 487,66 & 298,66 & 299,87 & 486,74 \\
\hline 3 & 561,09 & 630,79 & 710,11 & 774,02 & 669,63 \\
\hline 4 & 423,07 & 669,85 & 520,45 & 499,55 & 364,53 \\
\hline 5 & 323,27 & 292,57 & 334,2 & 286,06 & 51,82 \\
\hline 6 & 605,05 & 576,13 & 732,76 & 777,8 & 718,31 \\
\hline 7 & 1075 & 1172 & 1132 & 1092 & 1156 \\
\hline 8 & 768,65 & 875,21 & 834,12 & 834,12 & 875,21 \\
\hline 9 & 1247 & 1075 & 1092 & 1016 & 1124 \\
\hline 10 & 1024 & 914,58 & 988,99 & 1042 & 1007 \\
\hline \multirow[t]{2}{*}{11} & 874,24 & 1018 & 703,51 & 984,18 & 601,54 \\
\hline & \multicolumn{5}{|c|}{ GRELINA VIA ORAL PRÉ-OP } \\
\hline PACIENTE & 0 & 30 & 60 & 90 & 120 \\
\hline 1 & 412,75 & 443,36 & 566,57 & 452,37 & 400,25 \\
\hline 2 & 449,38 & 406,52 & 282,71 & 381,2 & 522,11 \\
\hline 3 & 628,17 & 730,01 & 490,64 & 617,63 & 524,93 \\
\hline 4 & 612,06 & 1288 & 732,76 & 777,8 & 762,5 \\
\hline 5 & 409,91 & 423,07 & 450,48 & 305,96 & 459,95 \\
\hline 6 & 809,33 & 725,5 & 690,23 & 809,33 & 676,58 \\
\hline 7 & 1059 & 970,88 & 1187 & 1124 & 1092 \\
\hline 8 & 895,1 & 914,58 & 979,97 & 979,97 & 952,45 \\
\hline 9 & 1042 & 1100 & 1164 & 1156 & 1050 \\
\hline 10 & 952,45 & 885,21 & 988,99 & 854,89 & 875,21 \\
\hline 11 & 930,7 & 874,24 & 1035 & 1052 & 984,18 \\
\hline
\end{tabular}




\section{REFERÊNCIAS}




\section{REFERÊNCIAS}

1. Sociedade Brasileira de Cirurgia Bariátrica, Colégio Brasileiro de Cirurgiões, Colégio Brasileiro de Cirurgia Digestiva, Sociedade Brasileira de Cirurgia Laparoscópica, Associação Brasileira para o Estudo da Obesidade, Sociedade Brasileira de Endocrinologia e Mertabologia. Consenso Brasileiro Multissocietário em Cirurgia da Obesidade. 2006.

2. Kanavos P, van den Aardweg S, Schurer W. Diabetes expenditure, burden of disease and management in 5 EU countries. LSE Health. 2012. p. 1-113.

3. WHO. Obesity: preventing and managing the global epidemic. Report of a WHO consultation. World Health Organ Tech Rep Ser. 2000;894:i $-x i i, 1-253$.

4. Yang W, Dall TM, Halder P, Gallo P, Kowal SL, Hogan PF, et al. Economic costs of diabetes in the U.S. in 2012. Diabetes Care. 2013;36(4):1033-46.

5. Sociedade Brasileira de Diabetes. Diretrizes SBD-2015. Rio de Janeiro: GEN Grupo Editorial Nacional; 2015.

6. American Diabetes Association. Standards of medical care in diabetes2016. Diabetes Care. 2014;37(Suppl.1):14-80.

7. Mitre NCD, Dias RC, Dias JMD, Faria APS, Costa DC, Carvalho GM, Ribeiro ACP. Adaptação para o português e confiabilidade de uma versão modificada do Physical Performance Test. Geriatr Gerontol. 2008;2(3):104-19.

8. Motala AA, Omar MA. Evaluation of WHO and NDDG criteria for impaired glucose tolerance. Diabetes Res Clin Pract. 1994;23(2):1039.

9. Sociedade Brasileira de Cardiologia. I Diretriz Brasileira de diagnóstico e tratamento da síndrome metabólica. Arq Bras Cardiol. 2005;84(suplemento I):4-28.

10. Nambi V, Hoogwerf BJ, Sprecher DL. A truly deadly quartet: obesity, hypertension, hypertriglyceridemia, and hyperinsulinemia. Cleve Clin J Med. 2002;69(12):985-9. 
11. Rehman K, Akash MSH. Mechanisms of inflammatory responses and development of insulin resistance: how are they interlinked? J Biomed Sci. 2016;23(1):87.

12. Everhart JE, Pettitt DJ, Bennett PH, Knowler WC. Duration of obesity increases the incidence of NIDDM. Diabetes. 1992;41(2):235-40.

13. National Diabetes Education Initiative. 2016 American Diabetes Association (ADA) diabetes guidelines summary recommendation from NDEI. 2016;1-46.

14. Dixon JB, Zimmet $P$, Alberti KG, Rubino F. Bariatric surgery: An IDF statement for obese Type 2 diabetes. Surg Obes Relat Dis. 2011;7(4):433-47.

15. Schauer PR, Kashyap SR, Wolski K, Brethauer SA, Kirwan JP, Pothier $\mathrm{CE}$, et al. Bariatric surgery versus intensive medical therapy in obese patients with diabetes. N Engl J Med. 2012;366(17):1567-76.

16. Buchwald H, Estok R, Fahrbach K, Banel D, Jensen MD, Pories WJ, et al. Weight and type 2 diabetes after bariatric surgery: systematic review and meta-analysis. Am J Med. 2009;122(3):248-56.e5.

17. Pories WJ, MacDonald KG, Morgan EJ, Sinha MK, Dohm GL, Swanson MS, et al. Surgical treatment of obesity and its effect on diabetes: 10-y follow-up. Am J Clin Nutr. 1992;55(Suppl. 2):582S585 S.

18. Sjöström L, Lindroos A-K, Peltonen M, Torgerson J, Bouchard C, Carlsson B, et al. Lifestyle, diabetes, and cardiovascular risk factors 10 years after bariatric surgery. N Engl J Med. 2004;351(26):2683-93.

19. Schauer PR, Bhatt DL, Kirwan JP, Wolski K, Aminian A, Brethauer SA, Navaneethan SD, Singh RP, Pothier CE, Nissen SE, Kashyap SR; STAMPEDE Investigators. Bariatric surgery versus intensive medical therapy for diabetes - 5-year outcomes. N Engl J Med. 2017; 376(7): $641-51$.

20. Rubino F, Forgione A, Cummings DE, Vix M, Gnuli D, Mingrone G, et al. The mechanism of diabetes control after gastrointestinal bypass surgery reveals a role of the proximal small intestine in the pathophysiology of type 2 diabetes. Ann Surg. 2006;244(5):741-9. 
21. Lee Y-C, Lee W-J, Liew P-L. Predictors of remission of type 2 diabetes mellitus in obese patients after gastrointestinal surgery. Obes Res Clin Pract. 2013;7(6):e494-500.

22. Nauck MA, Homberger E, Siegel EG, Allen RC, Eaton RP, Ebert R, et al. Incretin effects of increasing glucose loads in man calculated from venous insulin and C-peptide responses. J Clin Endocrinol Metab. 1986;63(2)492-8.

23. Usdin TB, Mezey E, Button DC, Brownstein MJ, Bonner TI. Gastric inhibitory polypeptide receptor, a member of the secretin-vasoactive intestinal peptide receptor family, is widely distributed in peripheral organs and the brain. Endocrinology. 1993;133(6):2861-70.

24. Yip RGC, Boylan MO, Kieffer TJ, Wolfe MM. Functional GIP receptors are present on adipocytes. Endocrinology. 1998;139(9):4004-7.

25. Miyawaki K, Yamada Y, Yano H, Niwa H, Ban N, Ihara Y KA. Glucose intolerance caused by a defect in the entero-insular axis: a study in gastric inhibitory polypeptide receptor knockout mice. Proc Natl Acad Sci U S A. 1999;96(Suppl. 2):14843-7.

26. Baggio LL, Drucker DJ. Biology of Incretins: GLP-1 and GIP. Gastroenterology. 2007;132(6):2131-57.

27. Miyawaki K, Yamada Y, Ban N, Ihara Y, Tsukiyama K, Zhou H, et al. Inhibition of gastric inhibitory polypeptide signaling prevents obesity. Nat Med. 2002;8(7):738-42.

28. Tappenden KA, McBurney MI. Systemic short-chain fatty acids rapidly alter gastrointestinal structure, function, and expression of early response genes. Dig Dis Sci. 1998;43(7):1526-36.

29. Orskov C, Wettergren A, Holst JJ. Biological effects and metabolic rates of glucagon-like peptide-1 7-36 amide and glucagon-like peptide$17-37$ in healthy-subjects are indistinguishable. Diabetes. 1993;42(5): 658-61.

30. Mojsov S, Weir GC, Habener JF. Insulinotropin: Glucagon-like peptide I (7-37) co-encoded in the glucagon gene is a potent stimulator of insulin release in the perfused rat pancreas. J Clin Invest. 1987;79(2): 616-9.

31. Drucker DJ. Review series The role of gut hormones in glucose homeostasis. Pancreas. 2007;117(1):24-32. 
32. Jiang G, Zhang BB. Glucagon and regulation of glucose metabolism. Am J Physiol Endocrinol Metab. 2003;284(4):E671-8.

33. Nauck M, Stöckmann F, Ebert R, Creutzfeldt W. Reduced incretin effect in type 2 (non-insulin-dependent) diabetes. Diabetologia. 1986; 29:46-52.

34. Knop FK, Aaboe K, Vilsboll T, Madsbad S, Holst JJ KT. Reduced Incretin effect in obese subjects with normal glucose tolerance as compared to lean control subjects. Diabetes. 2008;57(Suppl1):A410.

35. Toft-Nielsen MB, Damholt MB, Madsbad S, Hilsted LM, Hughes TE, Michelsen BK, Holst JJ. Determinants of the impaired secretion of glucagon- like peptide-1 in type 2 diabetic patients. J Clin Endocrinol Metab. 2001;86(8):3717-23.

36. Muscelli E, Mari A, Casolaro A, Camastra S, Seghieri G, Gastaldelli A, et al. Separate impact of obesity and glucose tolerance on the incretin effect in normal subjects and type 2 diabetic patients. Diabetes. 2008; 57(5):1340-8.

37. Vilsbøll T, Agersø H, Krarup T, Holst JJ. Similar elimination rates of glucagon-like peptide-1 in obese type 2 diabetic patients and healthy subjects. J Clin Endocrinol Metab. 2003;88(1):220-4.

38. Vilsbøll T, Agersø H, Lauritsen T, Deacon CF, Aaboe K, Madsbad S, et al. The elimination rates of intact GIP as well as its primary metabolite, GIP 3-42, are similar in type 2 diabetic patients and healthy subjects. Regul Pept. 2006;137(3):168-72.

39. Hojberg PV, Vilsboll T, Rabol R, Knop FK, Bache M, Krarup T, et al. Four weeks of near-normalisation of blood glucose improves the insulin response to glucagon-like peptide-1 and glucose-dependent insulinotropic polypeptide in patients with type 2 diabetes. Diabetologia. 2009;52(2):199-207.

40. Vaag AA, Holst JJ, Vølund A, Beck-Nielsen H. Gut incretin hormones in identical twins discordant for non-insulin-dependent diabetes mellitus (NIDDM) - Evidence for decreased glucagon-like peptide 1 secretion during oral glucose ingestion in NIDDM twins. Eur J Endocrinol. 1996; 135(4):425-32. 
41. Vilsbøll T, Knop FK, Krarup T, Johansen A, Madsbad S, Larsen S, et al. The Pathophysiology of diabetes involves a defective amplification of the late-phase insulin response to glucose by glucose-dependent insulinotropic polypeptide - regardless of etiology and phenotype. J Clin Endocrinol Metab. 2003;88(10):4897-903.

42. Laferrère $B$. Effect of gastric bypass surgery on the incretins. Diabetes Metab. 2009;35(6 Pt 2):513-7.

43. Näslund E, Kral JG. Impact of gastric bypass surgery on gut hormones and glucose homeostasis in type 2 diabetes. Diabetes. 2006;55(Suppl. 2):55-60.

44. Dirksen C, Jørgensen NB, Bojsen-Møller KN, Jacobsen SH, Hansen DL, Worm D, et al. Mechanisms of improved glycaemic control after Roux-en-Y gastric bypass. Diabetologia. 2012;55(7):1890-901.

45. De Moura EGH, Orso IRB, Martins BDC, Lopes GS, De Oliveira SL, Galvão-Neto MDP, et al. Improvement of insulin resistance and reduction of cardiovascular risk among obese patients with type 2 diabetes with the duodenojejunal bypass liner. Obes Surg. 2011;21(7): 941-7.

46. Thaler JP, Cummings DE. Minireview: Hormonal and metabolic mechanisms of diabetes remission after gastrointestinal surgery. Endocrinology. 2009;150(6):2518-25.

47. Kamvissi V, Salerno A, Bornstein SR, Mingrone G, Rubino F. Incretins or anti-incretins ? a new model for the "entero-pancreatic axis". Hormon Metab Res. 2015;47(1):84-7.

48. Cummings DE, Weigle DS, Frayo RS, Breen PA, Ma MK, Dellinger EP, Purnell JQ. Plasma ghrelin levels after diet-induced weight loss or gastric bypass surgery. N Engl J Med. 2002;346(21):1623-30.

49. Nguyen KT, Korner J. The sum of many parts: Potential mechanisms for improvement in glucose homeostasis after bariatric surgery. Curr Diab Rep. 2014;14(5):481,

50. Kashyap SR, Bhatt DL, Wolski K, Watanabe RM, Abdul-Ghani M, Abood B, et al. Metabolic effects of bariatric surgery in patients with moderate obesity and type 2 diabetes: Analysis of a randomized control trial comparing surgery with intensive medical treatment. Diabetes Care. 2013;36(8):2175-82. 
51. Isbell JM, Tamboli RA, Hansen EN, Saliba J, Dunn JP, Phillips SE, et al. The importance of caloric restriction in the early improvements in insulin sensitivity after Roux-en-Y gastric bypass surgery. Diabetes Care. 2010;33(7):1438-42.

52. Dutia R, Brakoniecki K, Bunker P, Paultre F, Homel P, Carpentier AC, et al. Limited recovery of $\beta$-cell function after gastric bypass despite clinical diabetes remission. Diabetes. 2014;63(4):1214-23.

53. Wang PYT, Caspi L, Lam CKL, Chari M, Li X, Light PE, et al. Upper intestinal lipids trigger a gut-brain-liver axis to regulate glucose production. Nature. 2008;452(7190):1012-6.

54. Ganguly S, Tan HC, Lee PC, Tham KW. Metabolic bariatric surgery and type 2 diabetes mellitus: An endocrinologist's perspective. J Biomed Res. 2015;29(2):105-11.

55. Patti ME, Houten SM, Bianco AC, Bernier R, Larsen PR, Holst JJ, et al. Serum bile acids are higher in humans with prior gastric bypass: potential contribution to improved glucose and lipid metabolism. Obesity (Silver Spring). 2009;17(9):1671-7.

56. Pournaras DJ, Glicksman C, Vincent RP, Kuganolipava S, AlaghbandZadeh J, Mahon D, et al. The role of bile after Roux-en-Y gastric bypass in promoting weight loss and improving glycaemic control. Endocrinology. 2012;153(8):3613-9.

57. Mithieux G, Bady I, Gautier A, Croset M, Rajas F, Zitoun C. Induction of control genes in intestinal gluconeogenesis is sequential during fasting and maximal in diabetes. Am $\mathrm{J}$ Physiol Endocrinol Metab. 2004;286(3):E370-5.

58. Troy S, Soty M, Ribeiro L, Laval L, Migrenne S, Fioramonti X, et al. Intestinal gluconeogenesis is a key factor for early metabolic changes after gastric bypass but not after gastric lap-band in mice. Cell Metab. 2008;8(3):201-11.

59. Mithieux G, Misery P, Magnan C, Pillot B, Gautier-Stein A, Bernard C, et al. Portal sensing of intestinal gluconeogenesis is a mechanistic link in the diminution of food intake induced by diet protein. Cell Metab. 2005;2(5):321-9.

60. Geloneze B, Pareja JC. Does bariatric surgery cure the metabolic syndrome? Arq Bras Endocrinol Metabol. 2006;50(2):400-7. 
61. Dirksen C, Hansen DL, Madsbad S, Hvolris LE, Naver LS, Holst JJ, et al. Postprandial diabetic glucose tolerance is normalized by gastric bypass feeding as opposed to gastric feeding and is associated with exaggerated GLP-1 secretion: A case report. Diabetes Care. 2010; 33(2):375-7.

62. Hansen EN, Tamboli RA, Isbell JM, Saliba J, Dunn JP, Marks-Shulman $\mathrm{PA}$, et al. Role of the foregut in the early improvement in glucose tolerance and insulin sensitivity following RouX-en-Y gastric bypass surgery. Am J Physiol Gastrointest Liver Physiol. 2011;300(5):G795802.

63. Umeda LM, Silva EA, Carneiro G, Arasaki CH, Geloneze B, Zanella MT. Early improvement in glycemic control after bariatric surgery and its relationships with insulin, GLP-1, and glucagon secretion in type 2 diabetic patients. Obes Surg. 2011;21(7):896-901.

64. Wajchenberg BL, Santomauro ATMG, Nery M, Santos RF, Silva MELR, Ursich MJM, et al. Resistência à insulina: métodos diagnósticos e fatores que influenciam a ação da insulina. Arq Bras Endocrinol Metabol. 1999;43(2):76-85.

65. Geloneze B, Vasques ACJ, Stabe CFC, Pareja JC, Rosado LEFPL, Queiroz EC, et al. HOMA1-IR and HOMA2-IR indexes in identifying insulin resistance and metabolic syndrome: Brazilian Metabolic Syndrome Study (BRAMS). Arq Bras Endocrinol Metabol. 2009;53(2): 281-7.

66. Hill J, Hicks D, James J, Vanterpool G, Brown P, Diggle J, Hardman H. Blood glucose monitoring Guidelines Consensus Document. Trend UK Train Res Educ Nurses Diabetes. 2014;(May):1-16.

67. Puñales MKC, Geremia C, Mondadori $P$, Pickler $M$, Fornari A, Tschiedel B. Como a monitorização contínua de glicose subcutânea pode colaborar na interpretação dos valores da HbA1c no diabetes melito tipo 1? Arq Bras Endocrinol Metabol. 2008;52(2).

68. Berger K, Coral S, Souza DAL, Khawali C, Hauache OM, Vieira JGH. Monitorização Contínua de Glicose: Análise Crítica Baseada em Experiência ao Longo de Um Ano. 2004;(Dm):983-90.

69. Kahn SE, Hull RL, Utzschneider KM. Mechanisms linking obesity to insulin resistance and type 2 diabetes. Nature. 2006;444(7121):840-6. 
70. Mithieux G, Andreelli F, Magnan C. Intestinal gluconeogenesis: key signal of central control of energy and glucose homeostasis. Curr Opin Clin Nutr Metab Care. 2009;12(4):419-23.

71. Troy S, Soty M, Ribeiro L, Laval L, Migrenne S, Fioramonti X, et al. Intestinal gluconeogenesis is a key factor for early metabolic changes after gastric bypass but not after gastric lap-band in mice. Cell Metab. 2008;8(3):201-11.

72. Mithieux G, Misery P, Magnan C, Pillot B, Gautier-Stein A, Bernard C, et al. Portal sensing of intestinal gluconeogenesis is a mechanistic link in the diminution of food intake induced by diet protein. Cell Metab. 2005;2(5):321-9.

73. Martinussen C, Bojsen-Møller KN, Dirksen C, Jacobsen SH, Jørgensen NB, Kristiansen VB, et al. Immediate enhancement of firstphase insulin secretion and unchanged glucose effectiveness in patients with type 2 diabetes after Roux-en-Y gastric bypass. Am J Physiol - Endocrinol Metab. 2015;308(6):E535-44.

74. Bojsen-Møller KN, Dirksen C, Jørgensen NB, Jacobsen SH, Serup AK, Albers $\mathrm{PH}$, et al. Early enhancements of hepatic and later of peripheral insulin sensitivity combined with increased postprandial insulin secretion contribute to improved glycemic control after Roux-en-Y gastric bypass. Diabetes. 2014;63(5):1725-37.

75. Gleason CE, Gonzalez M, Harmon JS, Robertson RP. Determinants of glucose toxicity and its reversibility in the pancreatic islet beta-cell line, HIT-T15. Am J Physiol Endocrinol Metab. 2000;279(5):E997-1002.

76. Dunn JP, Abumrad NN, Breitman I, Marks-Shulman PA, Flynn CR, Jabbour K, et al. Hepatic and peripheral insulin sensitivity and diabetes remission at 1 month after Roux-en-Y gastric bypass surgery in patients randomized to omentectomy. Diabetes Care. 2012;35(1):13742.

77. Chen HS, Hsiao L-C, Wu T-E, Lee S-H, Jap TS, Lin HD. Beneficial effects of insulin on glycemic control and B-cell function in newly diagnosed type 2 diabetes with severe hyperglycemia after short-term intensive insulin therapy. Diabetes Care. 2008;31(10):1927-32.

78. Ryan EA, Imes S, Wallace C. Short-term intensive insulin therapy in newly diagnosed type 2 diabetes. Diabetes Care. 2004;27(5):1028-32. 
79. Kashyap SR, Daud S, Kelly KR, Gastaldelli A, Win H, Brethauer S, et al. Acute effects of gastric bypass versus gastric restrictive surgery on beta-cell function and insulinotropic hormones in severely obese patients with type 2 diabetes. Int J Obes (Lond). 2010;34(3):462-71.

80. Pories WJ, Swanson MS, MacDonald KG, Long SB, Morris PG, Brown $\mathrm{BM}$, et al. Who would have thought it? an operation proves to be the most effective therapy for adult-onset diabetes mellitus. Ann Surg. $1995 ; 222(3): 339-52$.

81. Batterham RL, Cummings DE. Mechanisms of diabetes improvement following bariatric/metabolic surgery. Diabetes Care. 2016;39(6):893901.

82. Kamvissi-Lorenz V, Raffaelli M, Bornstein S, Mingrone G. Role of the gut on glucose homeostasis: lesson learned from metabolic surgery. Curr Atheroscler Rep. 2017;19(2):9.

83. Pournaras DJ, Aasheim ET, Bueter M, Ahmed AR, Welbourn R, Olbers $\mathrm{T}$, et al. Effect of bypassing the proximal gut on gut hormones involved with glycemic control and weight loss. Surg Obes Relat Dis. 2012;8(4): 371-4.

84. Lindqvist A, Peter Spégel, Ekelund M, Mulder H, Groop L, Hedenbro J, et al. Effects of ingestion routes on hormonal and metabolic profiles in gastric-bypassed humans. J Clin Endocrinol Metab. 2013;98(5):85661.

85. Dirksen C, Hansen DL, Madsbad S, Hvolris LE, Naver LS, Holst JJ, Worm D. Postprandial diabetic glucose tolerance is normalized by gastric bypass feeding as opposed to gastric feeding and is associated with exaggerated GLP-1 secretion: a case report. Diabetes Care. 2010; 33(2):375-7.

86. Penney NC, Kinross J, Newton RC, Purkayastha S. The role of bile acids in reducing the metabolic complications of obesity after bariatric surgery: a systematic review. Int J Obes. 2015;39(11):1565-74.

87. Fang S, Suh JM, Reilly SM, Yu E, Osborn O, Lackey D, et al. Intestinal FXR agonism promotes adipose tissue browning and reduces obesity and insulin resistance. Nat Med. 2015;21(2):159-65.

88. Taylor R. Banting Memorial Lecture 2012: reversing the twin cycles of type 2 diabetes. Diabet Med. 2013;30(3):267-75. 
89. Lim EL, Hollingsworth KG, Aribisala BS, Chen MJ, Mathers JC, Taylor R. Reversal of type 2 diabetes: Normalisation of beta cell function in association with decreased pancreas and liver triacylglycerol. Diabetologia. 2011;54(10):2506-14.

90. Breen DM, Rasmussen BA, Kokorovic A, Wang R, Cheung GWC, Lam TKT. Jejunal nutrient sensing is required for duodenal-jejunal bypass surgery to rapidly lower glucose concentrations in uncontrolled diabetes. Nat Med. 2012;18(6):950-5.

91. Wang PYT, Caspi L, Lam CKL, Chari M, Li X, Light PE, et al. Upper intestinal lipids trigger a gut-brain-liver axis to regulate glucose production. Nature. 2008;452(7190):1012-6.

92. Parker HE, Reimann F, Gribble FM. Molecular mechanisms underlying nutrient-stimulated incretin secretion. Expert Rev Mol Med. 2010;12:e1. 